Florida International University

FIU Digital Commons

8-24-2018

\title{
Contextual Affordances of Social Media, Clinical Prosess Changes and Health Service Outcomes
}

Haoran Zheng

hzhen003@fiu.edu

Follow this and additional works at: https://digitalcommons.fiu.edu/etd

Part of the Business Analytics Commons, and the Management Information Systems Commons

\section{Recommended Citation}

Zheng, Haoran, "Contextual Affordances of Social Media, Clinical Prosess Changes and Health Service Outcomes" (2018). FIU Electronic Theses and Dissertations. 3852.

https://digitalcommons.fiu.edu/etd/3852

This work is brought to you for free and open access by the University Graduate School at FIU Digital Commons. It has been accepted for inclusion in FIU Electronic Theses and Dissertations by an authorized administrator of FIU Digital Commons. For more information, please contact dcc@fiu.edu. 


\section{FLORIDA INTERNATIONAL UNIVERSITY}

Miami, Florida

CONTEXTUAL AFFORDANCES OF SOCIAL MEDIA, CLINICAL PROCESS

CHANGES AND HEALTH SERVICE OUTCOMES

A dissertation submitted in partial fulfillment of

the requirements for the degree of

DOCTOR OF PHILOSOPHY

in

BUSINESS ADMINISTRATION

by

Haoran Zheng

2018 
To: Dean Joanne Li

College of Business

This dissertation, written by Haoran Zheng, and entitled Contextual Affordances of Social Media, Clinical Process Changes and Health Service Outcomes, having been approved in respect to style and intellectual content, is referred to you for judgment. We have read this dissertation and recommend that it be approved.

Monica Chiarini Tremblay

Manjul Gupta

George Marakas

William Newburry

Major Professor, Weidong Xia

Date of Defense: August 24, 2018

The dissertation of Haoran Zheng is approved.

Dean Joanne Li
College of Business

College of Business

Andrés G. Gil

Vice President for Research and Economic Development and Dean of the University Graduate School

Florida International University, 2018 


\section{ACKNOWLEDGMENTS}

I wish to thank various people for their help to this dissertation. I would like to express my most profound appreciation to my major advisor Dr. Weidong Xia for his consistent support throughout this dissertation and my Ph.D. career. I would not be able to complete this project without his valuable and constructive guidance from the planning and development phase, to the countless hours and patience he generously gave during the data collection phase. Dr. Xia was my mentor since the first day of this program and who recruited me into the program. I can still recall the first time we met for a program interview in his office. A constant theme during the interview was the word commitment, my commitment to the program, the department and the university's commitment as well as the advisor's commitment to the student. It indeed is one of the most critical elements in my experience. I've had doubts and setbacks throughout the program, but I've always worked them out as I gradually realized it's also a commitment to myself. I would like to extend my appreciation to my committee member Dr. Manjul Gupta who worked with me for over a year during which I learned a lot about methodology and then applied the things I learned in my dissertation. My other committee members Dr. Monica Chiarini

Tremblay, Dr. George Marakas and Dr. William Newburry for their valuable feedbacks in committee meetings, and the time they spent. It has always been a pleasure working with you, and it's my privilege to have all of you on my committee.

I would like to acknowledge the dedicated help provided by the University Faculty and Staff, especially in my department: Information Systems and Business Analytics. Special thanks to Program Coordinator Janey Sardinas and Coordinator of 
Administrative Services Yasemin Shirazi for their help in coordination of events. I would like to give thanks to my peer Ph.D. students who have been great companions, friends throughout the program.

I would like to offer my special thanks to Dr.Wang Lin, and Dr. Liao Lina for their incredible assistance with the collection of my data and for enabling me to visit their hospitals and offices to observe their daily operations. My special thanks are extended to the staff of their hospitals who provided help in the process and the doctors who took time from their impossible busy schedule and filled out the survey.

Last but not the least, I would like to express my most sincere gratitude to my parents: Liu Li, and Zheng Xianshu who's always been there for me and provided an enormous amount of support in the ways they could to help me complete this dissertation. Thank you! 
ABSTRACT OF THE DESSERTATION

CONTEXTUAL AFFORDANCES OF SOCIAL MEDIA, CLINICAL PROCESS

CHANGES AND HEALTH SERVICE OUTCOMES

by

Haoran Zheng

Florida International University, 2018

Miami, Florida

Professor Weidong Xia, Major Professor

Never had consumers been empowered by information technologies such as social media-enabled portals that permit them to access and conduct all aspects of life and work activities through a mobile phone at any time from anywhere. WeChat, with over 963 million active monthly users, represents such a revolutionary platform. In healthcare, patients can use WeChat to make doctor appointments, access health and lab results, consult with doctors, and check on the queuing status and parking conditions in the health clinics and hospitals. Such social-media-enabled systems have transformed the relationships between consumers and businesses into a new paradigm in which the supply-side is driven by the demand-side. As a result, the new technology is fundamentally changing; not only the context in which business is conducted but also the business itself.

The extant literature on technology acceptance, however, has mostly focused on technical functionalities and user characteristics without adequately considering the 
specific context in which the technology is used. Although these affordance concepts have advanced our knowledge about the interactions between technology and users, the specific contexts in which such interactions occur have been largely ignored. There is a critical literature gap that hinders our ability to understand and provide guidelines to help organizations deal with the complex challenges they face in managing social mediaenabled technologies in today's changing environment.

Our research attempts to bridge this critical literature gap by conceptualizing the concept of contextual affordance, and by examining its determinants and consequences in healthcare services. We use a combination of qualitative method and quantitative method. Research sites are in China across multiple healthcare facilities. The anticipated findings include validated dimensions of contextual affordance and relationships between contextual affordance and its determinants and impacts on clinical process changes and health service outcomes. Theoretically, this study extends the current understanding of affordance by considering contextual dimensions of affordance, and by examining the relationships between contextual affordance and its determinants and consequences. Practically, this study sheds new lights on how organizations should go beyond the outof-context interactions between technologies and users by considering users' perceived affordance of technology within the specific contexts of use. 


\section{TABLE OF CONTENTS}

CHAPTER

PAGE

CHAPTER 1. INTRODUCTION ................................................................................... 1

1.1 Practical Challenges/dilemmas (Mobile Social Media Enabled Platforms) ............. 1

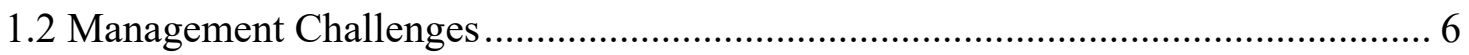

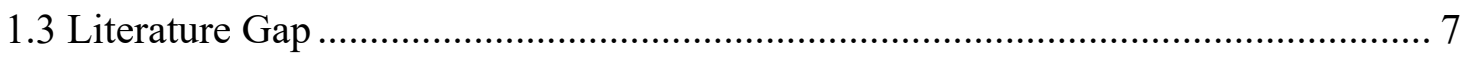

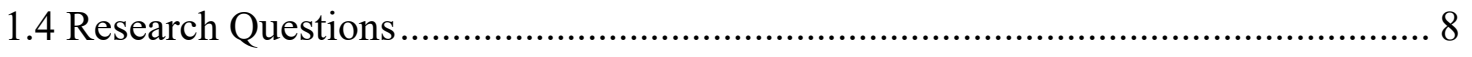

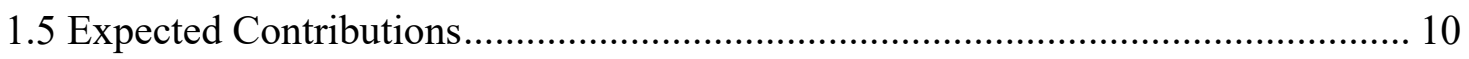

CHAPTER 2. LITERATURE REVIEW ............................................................ 12

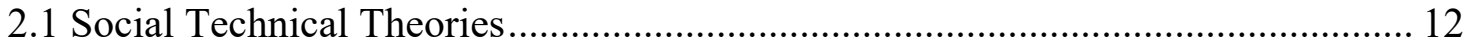

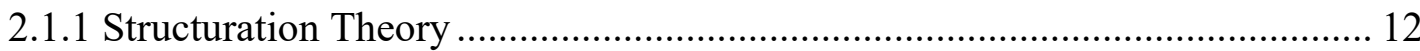

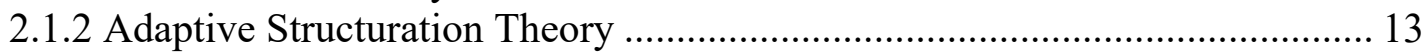

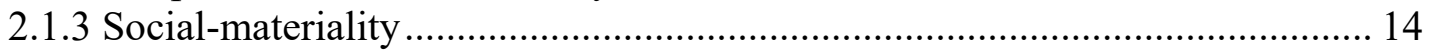

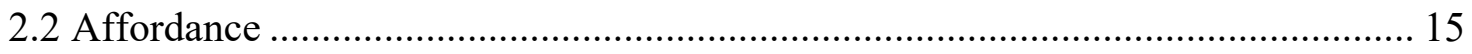

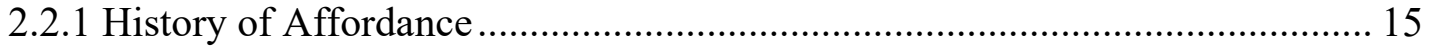

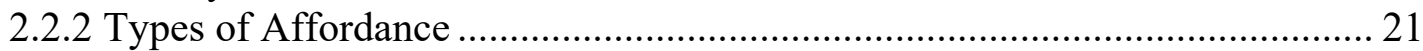

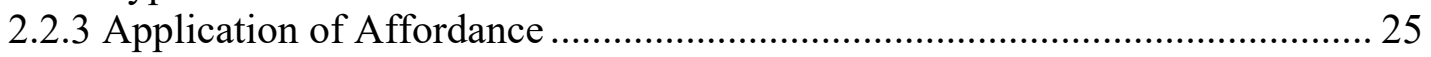

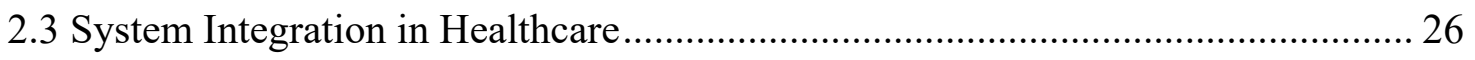

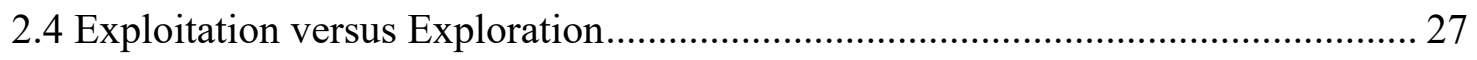

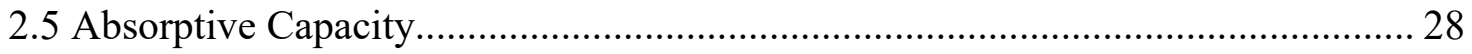

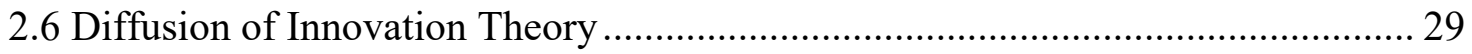

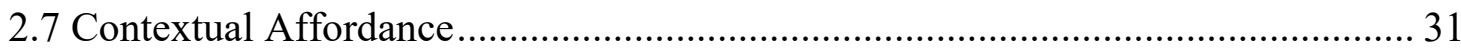

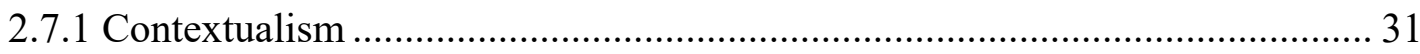

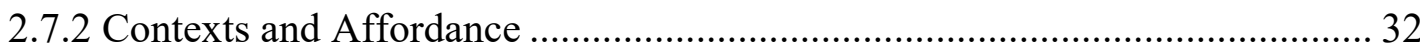

2.7.3 General versus Specific Contextual Affordance............................................... 35

CHAPTER 3. RESEARCH MODEL AND HYPOTHESES DEVELOPMENT .... 37

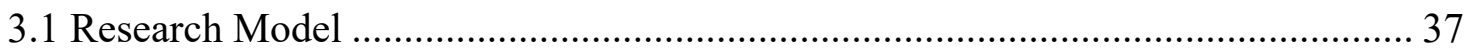

3.1.1 Specific Context and Specific Contextual Affordance .................................... 38

3.1.2 Absorptive Capacity and General Contextual Affordance ............................... 38

3.1.3 Technology Characteristics and General Contextual Affordance .................... 39

3.1.4 Specific Contextual Affordance, General Contextual Affordance ................... 40

3.1.5 Specific Contextual Affordance and Behavioral Affordance ……................... 40

3.1.6 General Contextual Affordance and Behavior Affordance ………………....... 41

3.1.7 Behavioral Affordances and Clinical Process Changes.................................... 41 
CHAPTER 4. RESEARCH METHODOLOGY .................................................... 44

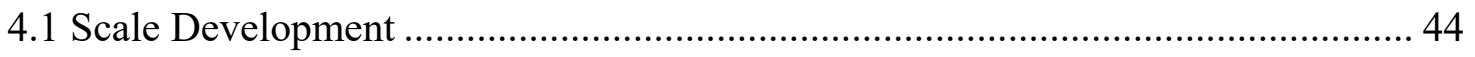

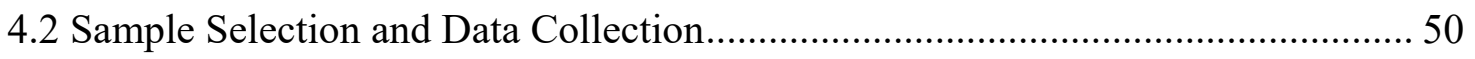

4.3 Testing for Common Method Bias ....................................................................... 57

CHAPTER 5. DATA ANALYSIS ....................................................................... 59

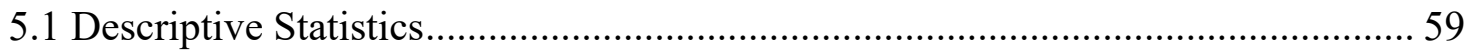

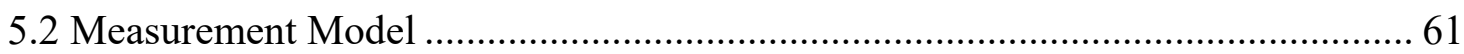

5.2.1 Determination of formative and reflective constructs ................................ 61

5.2.2 Reflective Measurement Model Assessment - Reliability .............................. 62

5.2.3 Reflective Measurement Model Assessment - Convergent validity ................ 64

5.2.4 Reflective Measurement Model Assessment - Discriminate validity ............. 65

5.2.5 Formative Measurement Model Assessment - Content Validity ........................6 68

5.2.6 Formative Measurement Model Assessment - Collinearity ............................. 69

5.2.7 Formative Measurement Model Assessment - Confirmatory Tetrad Analysis 72

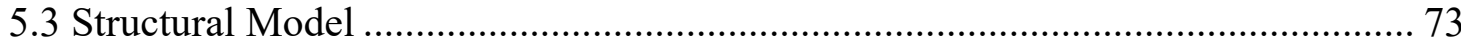

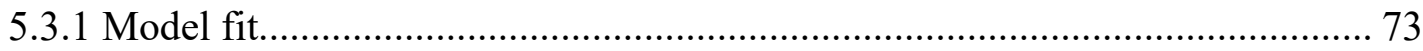

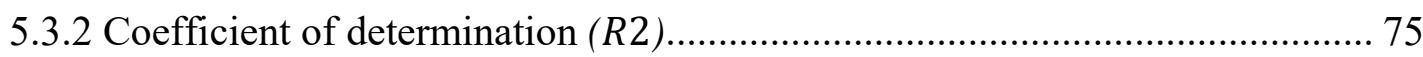

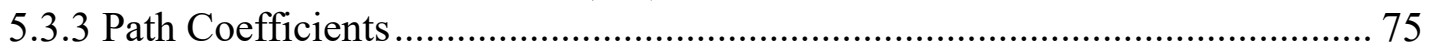

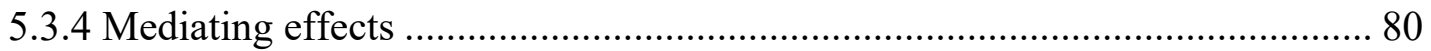

CHAPTER 6. DISCUSSION.................................................................................. 84

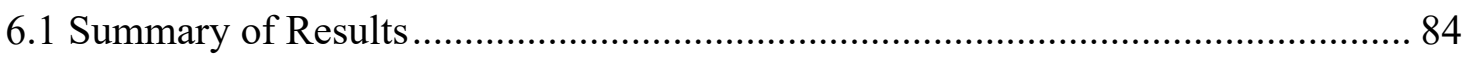

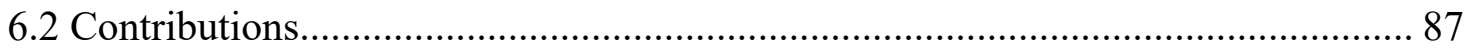

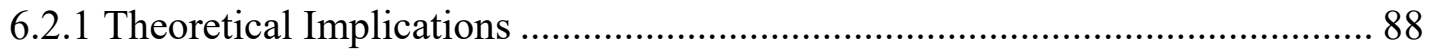

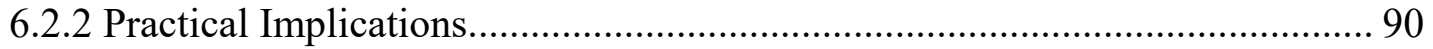

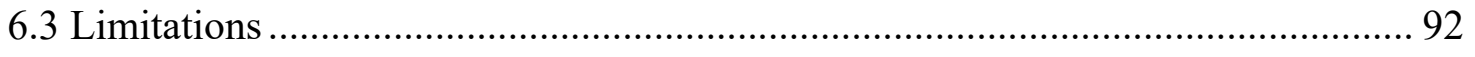

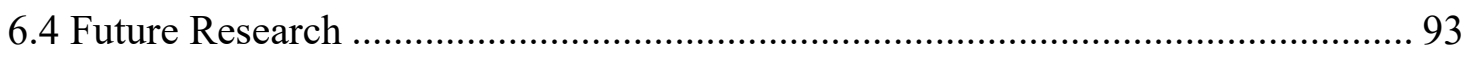

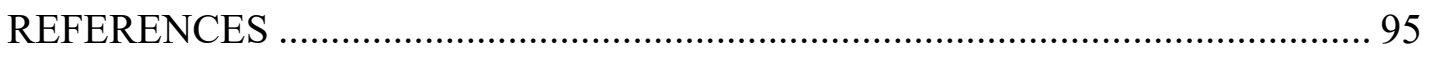

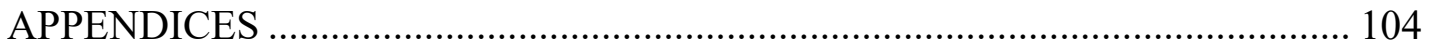

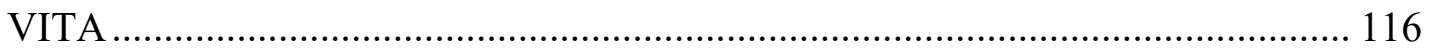




\section{LIST OF TABLES}

$\begin{array}{ll}\text { TABLE } & \text { PAGE }\end{array}$

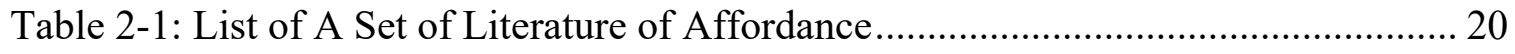

Table 2-2: Types of Affordance and Unit of Analysis .............................................. 24

Table 2-3: Frequency for Different Types of Affordance ........................................ 25

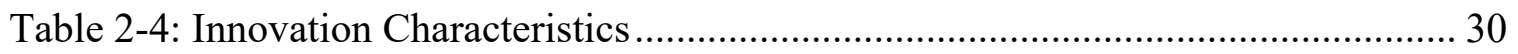

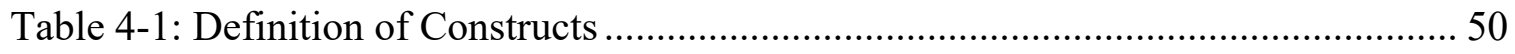

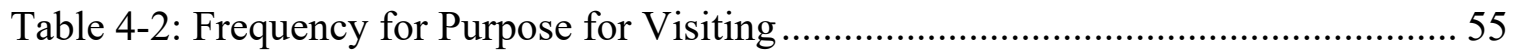

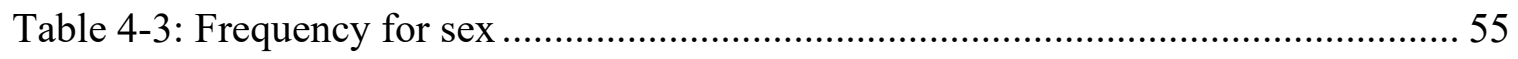

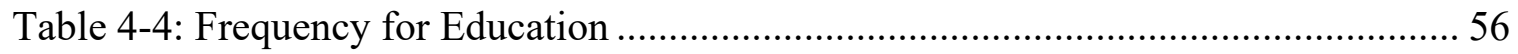

Table 4-5: Frequency for Purpose for Year Started Using WeChat .............................. 56

Table 4-6: Frequency for Average Time Spent on WeChat ........................................ 57

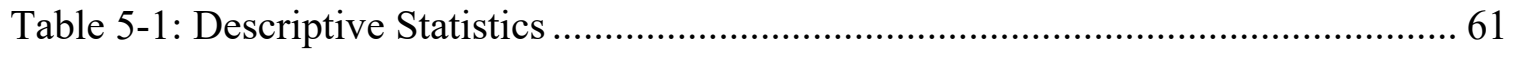

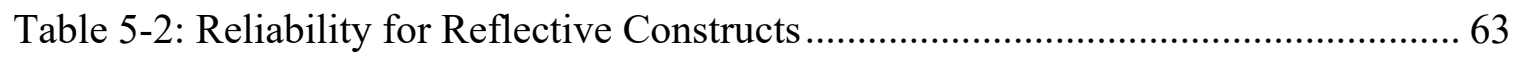

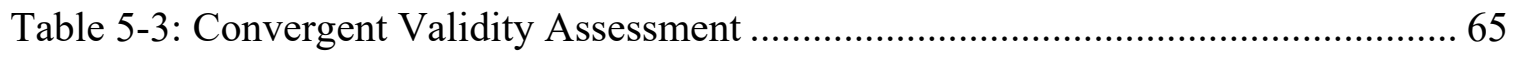

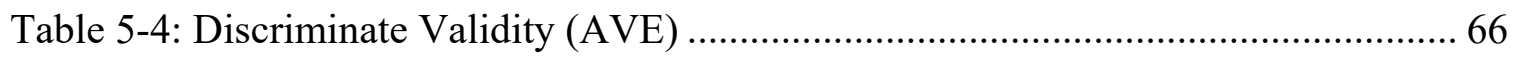

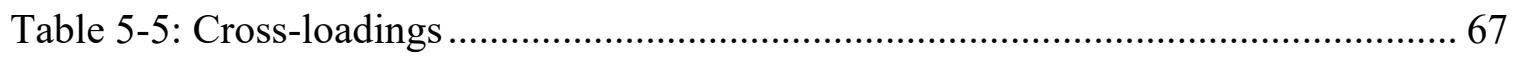

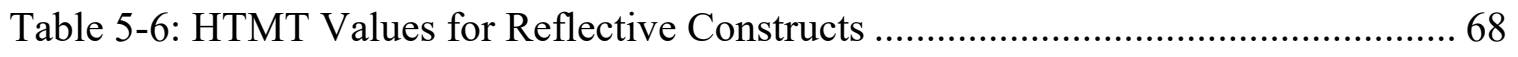

Table 5-7: VIF Values for Formative Constructs ................................................ 70

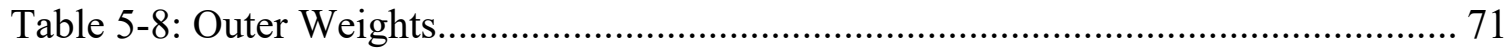

Table 5-9: Outer Weights from Bootstrapping .................................................. 71

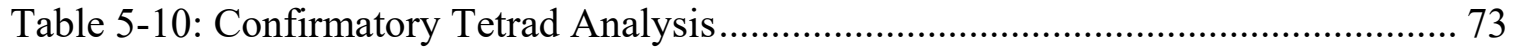


Table 5-11: $R 2$ Values of the Endogenous Constructs ................................................. 75

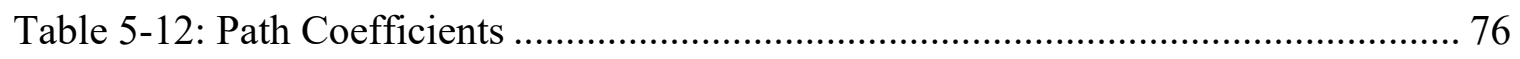

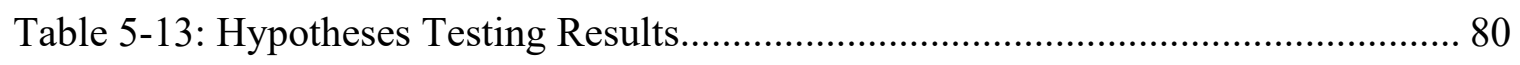

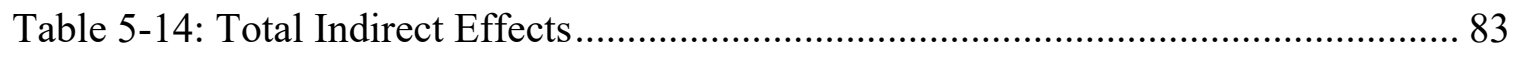

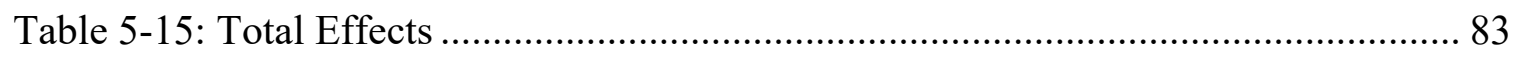




\section{LIST OF FIGURES}

\section{FIGURE}

\section{PAGE}

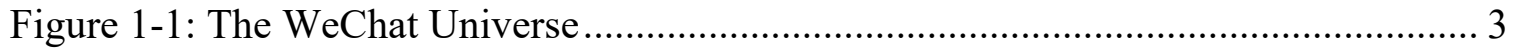

Figure 1-2 : Before WeChat Implementation ....................................................... 5

Figure 1-3 After WeChat Implementation ........................................................... 5

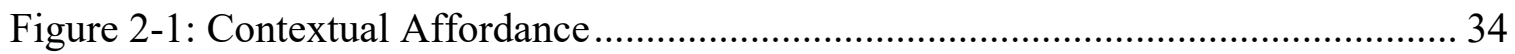

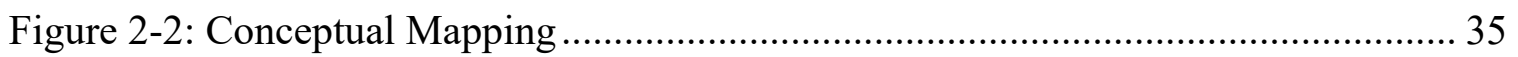

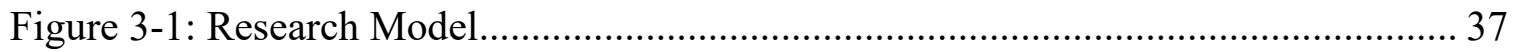

Figure 4-1: Scale Development procedure (Churchill Jr, 1979) .................................. 48

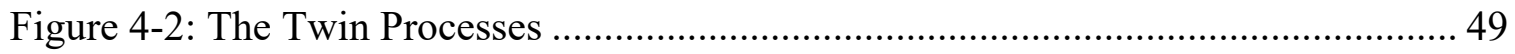

Figure 5-1: Path Coefficients of the Structural Model................................................. 79 


\section{CHAPTER 1 . INTRODUCTION}

\subsection{Practical Challenges/dilemmas (Mobile Social Media Enabled Platforms)}

The use of social media by organizations has evolved over the years and, as a result, has drastically changed organizational processes (Treem \& Leonardi, 2013). Social media in isolation, however, can no longer fulfill the increasing demands from the informed customers. The integration of social media and other functional systems in organizations mitigate the challenges brought forward by ever-changing customer demands. An organization's singular approach without considering contextual factors for databases, ERP systems, and other functional systems has proven to be unproductive (Markus, Tanis, \& Van Fenema, 2000; Stonebraker \& Cetintemel, 2005). For instance, high customization entails a high cost, loose control but higher satisfaction (Haines, 2009). High standardization, on the other hand, may be effective but hardly satisfying informed customers. Such dynamics shape an organization's IT capabilities. Consequently, the effects of these technology investments are mixed for most organizations (Bharadwaj, 2000; Melville, Kraemer, \& Gurbaxani, 2004). In practice, this puts organizations in a real dilemma. To gain a competitive advantage, organizations see the necessity to stay current with the new technology; however, the influences of the contexts on the process of adopting, implementing and dissimilating these technologies are largely ignored (Orlikowski \& Scott, 2008), which may lead to unsatisfactory results. Context-specific theories play an important role in discovering hidden relationships and interactions towards outcome measures compared to using general theories that ignore context. For instance, Hong, Chan, Thong, Chasalow, and Dhillon (2013) examine and 
compare context-specific technology acceptance model (TAM) versus general TAM. The former reveals relationships that general TAM cannot capture. Similarly, Venkatesh, Thong, Chan, Hu, and Brown (2011) articulate expanded IS continuance model in context and provide a richer understanding of changes and emergent constructs that occur in the longitudinal study. Context is defined as "situational opportunities and constrains that affect the occurrence and meaning of organizational behaviors as well as functional relationships between variables" (Johns, 2006).

An article featured in Economist (http://www.economist.com/) illustrates the transformations in life that the social media platform WeChat has carried out to average consumers from personal life to business. WeChat is a mobile instant text and voice messaging communication service developed by Tencent Holdings, Ltd. in China in January 2011(C. H. Lien \& Cao, 2014). Aside from basic communication functions, WeChat replaces business card exchange by scanning QR codes and minimizes the need to carry cash or credit cards for day to day expenses to become a universal hub for everything from offline to online. One can book and pay for a taxi, theater tickets, train tickets, vacation plans, settle utility bills and split dinner tabs with friends without leaving the WeChat universe. It is estimated that WeChat has over 960 million active users. According to Tencent Quarter and Interim Results, the monthly active users are defined as the total number of WeChat users sending out at least one message during the last calendar month before the relevant date. WeChat has similar features to those like WhatsApp and Line. The embedded features such as push-to-talk, video chatting, group chats, WeChat wallet, and options for dynamic interaction service such as mini-programs 
make WeChat more functional than any single Western app (C.-H. Lien, Cao, \& Zhou, 2017).

WeChat as mobile technology is deeply ingrained in the daily life of the Chinese. Individual consumers are supplied with access and an abundant amount of information, and as a result, they become increasingly able to directly access online to offline services' backend systems functionalities and data. As such, contextual factors surrounding the specific circumstances of use become more influential in determining consumers' perceptions and behaviors. Figure 1 illustrates the WeChat Universe.

\section{Monthly Active User: 963M*}

Daily Active User: 768M

\section{Daily Average Time spent: $\mathbf{4 0}$ Minutes}
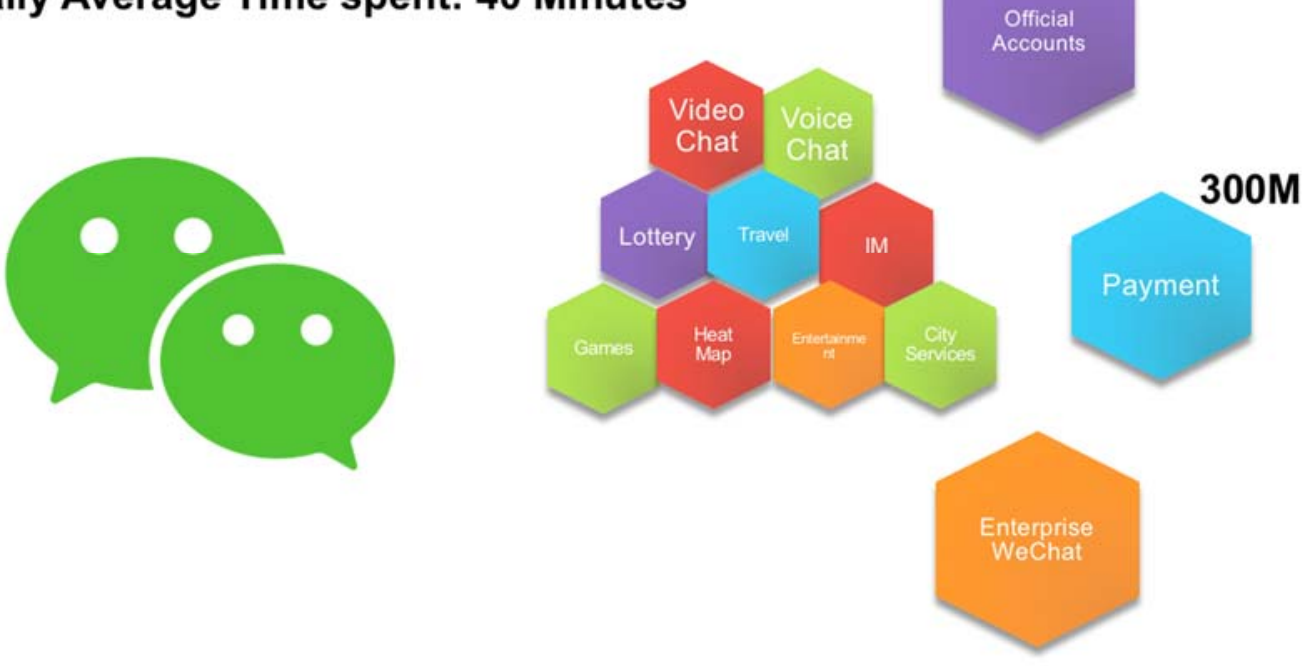

Figure 1-1: The WeChat Universe

* "WeChat User \& Business Ecosystem Report 2017". TechNode. 2017-04-24. Retrieved 2017-05-06

In the healthcare context, large hospitals started investing in the integrated WeChat patient portal through a WeChat public account. A generic hospital WeChat public account enables the hospital to have push notifications, marketing campaigns, hospital news, etc. sent directly to subscribed patient's mobile phone. On the other hand, patients can register, make appointments, access their lab results, pay bills, consult with 
doctors, and look up hospital information including a hospital directory, physician directory, and navigation. There are also value-added functions for the patient's family and friends. They will be able to order meals, send flowers to designated in-patient bed, and order certain physical examinations.

In some cases, the portal is also capable of AI diagnostic functions that can diagnose and make some suggestions for some uncomplicated diseases basic on a patient's input. The portal also sends highly customized medicine protocol adherence alert that is tailored to the individual patient. As an immediate result, a patient will be able to manage their time more efficiently and effectively with access to the back end of the system, and they will know where they are each step of the way in their care-seeking processes. The following figure illustrates before and after WeChat implementation for a patient going through the conventional care-seeking process as oppose to using WeChat patient portal in China.

Before WeChat implementation, the patient flow is a linear process from scheduling an appointment, to registering on site, receiving treatment, getting lab results, picking up medicine, and making payments. For each step in the process, the patient must physically be there making the wait time long. However, after WeChat implementation the patient flow is transformed from the linear process to a more patient-centric approach where multiple links can be accessed directly through the patient portal, providing add-on functions such as general information, physician information, and hospital directory. This patient-centric approach not only shortens patient waiting time in between each link, but also changes the focal point from hospital processes to the patient. 
Before

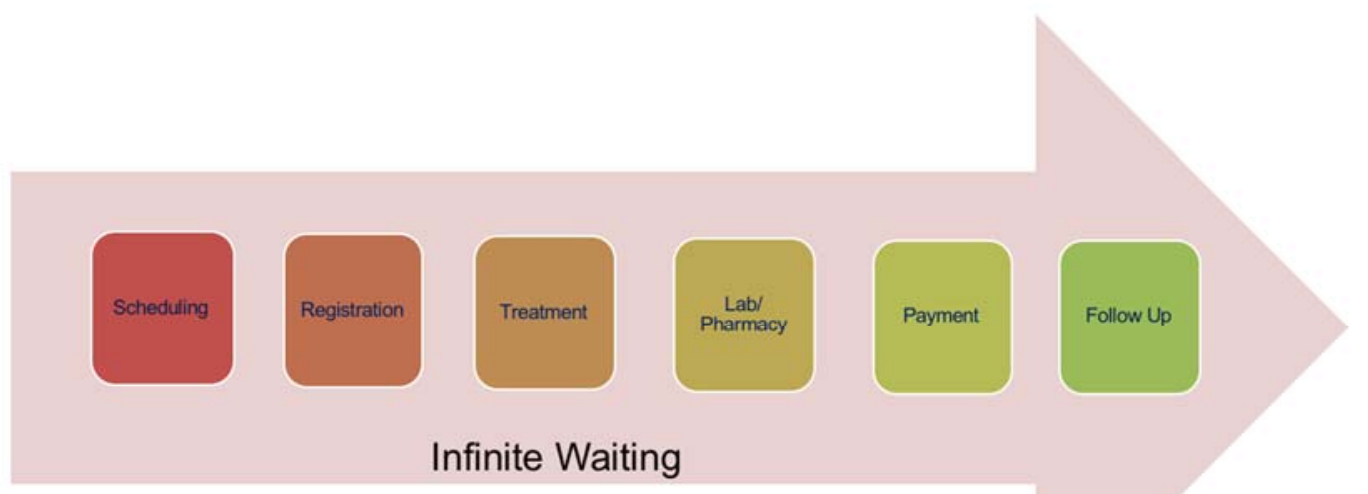

Figure 1-2 : Before WeChat Implementation

After

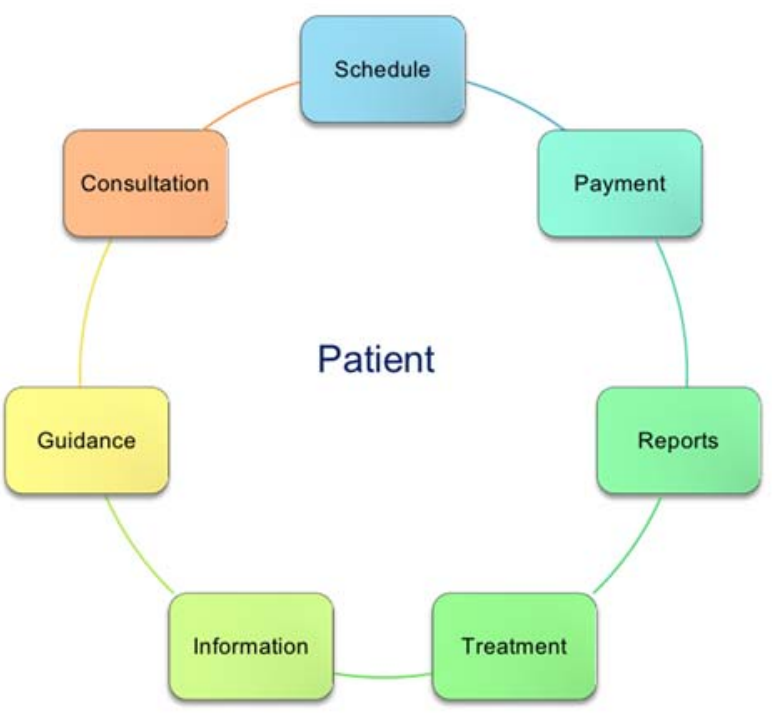

Figure 1-3 After WeChat Implementation 
The hospitals can use these new measures to optimize patients' care-seeking processes, enhance patient satisfaction and patient-physician relationship when moving from a conventional linear process towards a promising patient-centric care process.

\subsection{Management Challenges}

In this ever-connected environment, management of an organization is challenged by them are to make "smart" investments in social media-enabled technologies. The successes of such investment essentially hinder doing the right thing at the right time to the right person. In the healthcare context, hospital and health service providers spend millions of dollars already on different information systems with the hope to stay ahead of their competitors, minimize occurrences of medical errors, improve care quality and patient satisfaction. However, the results of the investments are mixed. As the president of a tier three hospitals in Chongqing said,

"We spent much time in developing and implementing information systems (WeChat) across the hospital, but it is like no one knows what's going on. 'We need some money here, we need some money there' are all I hear. I have no option but to say yes. I think the overall architecture and design is a complete disaster. We do not see any positive results from those investments."

This is not an isolated and a stand-alone case. Finding a balance among the available resources, subsequent planning, control and assessment that considers specific contexts becomes one of the central issues for these hospitals and other companies across the industry. To manage these complex processes among the interactions of stakeholders, the management question becomes one as to how an organization should take into 
consideration the interaction between technology and context in its planning and assessment of technological investment and usage.

\subsection{Literature Gap}

Researchers have used social-technical perspectives to study the interactions between technology, user and organizations, such as structuration theory by Giddens' (1979), adaptive structuration theory (AST) by DeSanctis and Poole (1994), social materiality by Orlikowski and Scott (2008), and more recently affordance. Affordance is defined as the possibilities and limits for action that a material object offers to a person (Giddens, 1979). There are different types of affordance: functional affordance, real affordance concerning the rational aspect of the material artifact and subjective affordance about the perceptual aspect of the social actor. Affordance advances our understanding across sociology, psychology, and information systems research.

Scholars have studied individual characteristics, technology characteristics, interactions between the individual and technology in technology adoption and implementation. However, the contextual aspect has been largely ignored. There is a critical gap in the extant literature. The conceptualization of affordance has suffered from the limitations of focusing on the interaction of the individual and technology without considering the unique context in which those interactions happen.

An individual may interact with the same technology differently when such interactions occur in different contexts. The different ways of interaction in both scenarios can be largely traced back to the disparities in individual and cultural-historical contexts. For instance, Skype is an instant messaging app that features text messages and video chat services. Either sending a text, voice chatting, video chatting, file exchanging 
or screen sharing, one may use one or several Skype's functions dependent on what needs exist. Contextual factors of the individual user shape what functions Skype affords the user in a particular context. The differences occur within a user and the specific context of use. The same argument can be made to multiple users. One may use Skype for business meetings, while another may use Skype to video chat with families. Text chat with emojis may not be appropriate in a business setting, while they can be used in a family setting to express emotions and intimacy. The differences occur between the users and their contexts. The Skype example demonstrates how affordance is contextualized to users in different scenarios. To predict to use or not to use a particular system is not just a question of the user, technology, the user, and technology, but a question of aforementioned specified to a context. The conceptualization of affordance, as it is currently defined, cannot explain these differences emerging from context. As a result, there is a need to expand the concept of affordance beyond what we know today to include the contextual aspects.

\subsection{Research Questions}

In this research, we used affordance as the lens to examine the role of social media enactment in clinical process changes and outcomes. The concept of affordance is not new. It has been a concept for IS scholars for years in graphic design (Hartson, 2003; Norman, 1999), organizational changes (Leonardi, 2011; Strong, Volkoff, Johnson, \& Pelletier, 2014; Volkoff \& Strong, 2013; Zammuto, Griffith, Majchrzak, Dougherty, \& Faraj, 2007) and more recently in social media-enabled applications (Argyris \& Monu, 2015; Chen, Xu, Cao, \& Zhang, 2016; Wang, Li, \& Suomi, 2016). However, the affordance literature has so far not considered the contextual aspects of the concept. Our 
study responds to calls for research examining the effects of contexts. This research attempts to bridge the literature gap by conceptualizing and operationalizing the concept of contextual affordance by examining its determinants and consequences in healthcare services. We set the scope of affordances in the research contexts. Based on extensive literature reviews and field studies, we combined the affordances with contexts and investigated the dimensions of these affordances. We aimed to develop measurements for these affordances and tested the validity and reliability of the measurements.

\section{RQ1. How is contextual affordance conceptualized and operationalized?}

Following the conceptualization and operationalization of contextual affordances, we were interested in finding the most crucial determinants that influenced such affordances in the healthcare contexts in China based on literature reviews and interviews from subject experts.

\section{RQ2. What are the factors that determine contextual affordance?}

The purpose of this research was to empirically test the effects of contextual affordances in several healthcare facilities in southern China. In light of the patient portal implementations across these healthcare facilities, the processes in which patients seeking treatments changed before and after the implementations. The results of healthcare facilities' technology investments are unclear. One of the key indicators was a patient's overall experience and satisfaction towards the hospital.

RQ3. What are the effects of contextual affordance on such outcomes as organization processes and healthcare outcomes?

We proposed that patient satisfaction and their relationships with physicians depended on whether or not the perceived positive process changes in a healthcare 
facility were seen as positive. The nature of the perceived process was dependent on the successful adoption of a social media, enabled-patient portal. The effects were observed by introducing the concept of contextual affordance in a general or specific sense.

Finally, these contextual affordances were determined by a patient's specific context, absorptive capacity, and perception of technology characteristics.

\subsection{Expected Contributions}

This study extends the current body of literature of affordance by considering contextual factors. It further conceptualizes and operationalizes contextual affordance into different components with carefully developed measures. Not only does it advance the concept of affordance, but it also taps into the relationships between affordance and other relevant variables extracted from the literature by addressing the importance of context to explain additional variances that have not yet been explained. This study places affordance in emerging organizations and adds to the understanding of affordance and its role in organizational settings.

Context, like a missing piece, uniquely contributes to organizational outcomes. Its influence has not yet been fully recognized. This study provided an alternative to the onesize-fits-all approach that has historically proven to be insufficient. This study provided an understanding of contextual affordance and its effects. By doing so, it offers guidelines and insights to help organizations better plan, control and assess organizational activities.

Our study responded to calls for research examining different contexts when studying the relationship between a technology-the artifact and an actor-the social (Orlikowski \& Scott, 2008). We conceptualized and measured contextual affordances at 
the individual level. But our theory focuses on how the perceived affordance in emerging healthcare facilities in China affected patient satisfaction through clinical process changes. We proposed that the level of patient satisfaction depended on whether process changes strategically complemented one another, producing a positive interaction through the duo concept of exploration and exploitation processes.

We tested our hypotheses using 352 samples collected from four large hospitals in southwest China during a six-month period. We used structural equation modeling and empirically examined the effects of proposed constructs on patient satisfaction. The results provided support for the proposed contingency effects. Patients in large hospitals yielded higher levels of satisfaction when the general and specific contextual affordance levels were high through perceived clinical processes demonstrating changes either being explorative or exploitative. Furthermore, the specific contextual affordance was positively influenced by patients' personal preferences, cultural norms, and beliefs. The general contextual affordance was positively influenced by absorptive capacity as well as perceived as innovative characteristics of the patient portal.

This dissertation is organized as follows: Chapter two presents a detailed literature review of affordance and other main constructs, provides a comprehensive summary of studies incorporating affordance, both theoretically and empirically, taxonomies based on our review, and relevant findings. Chapter three illustrates the conceptualization of contextual affordance, the research model, and hypothesis. Chapter four and five present research methods and the analysis of the results. Chapter 6 provides a summary, discusses contributions, limitations and future research. 


\section{CHAPTER 2 . LITERATURE REVIEW}

\subsection{Social Technical Theories}

\subsubsection{Structuration Theory}

Sociologist Anthony Giddens and his contributions to structuration theory is widely used in sociology and has been broadly cited in the realm of information systems as well (DeSanctis \& Poole, 1994; M. Jones, Orlikowski, \& Munir, 2004; Karsten, 2003; Orlikowski, 2008). Structuration theory concerns the relationship between individuals and society, departing from the traditional dualistic views that see social phenomena as determined by either objective social structures or autonomous human agents. Structuration theory sees a social phenomenon as a mutually constitutive duality. The theory of structuration centers in the creation and reproduction of social systems that are weighted on both structures and agents without giving preference to either.

Structures refer to the "rules and resources" embedded in agents' memory traces. Agents call upon their memory traces and perform social actions based on their knowledgeability. Knowledgeability refers to "what agents know about what they do, and why they do it' (Giddons, 1984). Structuration theory concerns how agents (a person or a group) and structure are interrelated to form a new social structure through domination (power), signification (meaning), and legitimization (norm). When an agent uses these structures for social actions, he/she presents himself/herself in the forms of domination, interpretive scheme, and communication in the forms of signification, norms, and sanctions in the form of legitimation.

Structuration theory has received attention, expansion, and critiques from researchers since it is origination(Archer \& Archer, 1995; Thompson, 1984). Archer and 
Archer (1995) opposed to the idea of the inseparability of structure and agency in structuration theory. Thompson (1984) puts forth that the use of the terms in Giddens' concept is too broad. The phrase "rules and resources" as the definition of structure is problematic as it is too general and inconsistent both internally and with conventional social structure theory.

The structuration theory has been used in IS research to examine how people in practice interact with technology (Orlikowski, 2000) and the dynamics of intertwined processes of technology appropriation and use. The notion of duality of structure in structuration theory is in line with the notion of affordance in human-technology interactions. It provides explanations and a theoretical basis for using affordance in information systems. Jones and Karsten (2008) summarize the key implications for information systems research related to the key features of structuration theory. In rejection of both positivism and strong interpretivism, IS researchers should not consider that structure determines action, nor is action independent of structure. In the presence of duality of structure, researchers should consider structure and agency as mutually constitutive. In relation to agents, there is the possibility to do otherwise. Researchers should consider that structural constraint simply places limits upon the options open to action in each circumstance.

\subsubsection{Adaptive Structuration Theory}

Adaptive structuration theory (AST) extends the original structuration theory by taking process changes into account. It examines structures from technology in use. Structures emerge from interactions of human and technology (DeSanctis \& Poole, 1994). AST addresses some existing issues in technology and organizational changes 
from three perspectives: decision-making, social technology, and institutional. Decisionmaking focuses on rigid determinism and is in line with positivist approaches. Social technology focuses on soft determinism and is in line with a mixture of positivist and interpretive approaches. Institutional focuses on social structure, non-deterministic models with interpretive approaches. One of the key considerations from all approaches is that technology properties and contextual contingencies can play critical roles in the outcomes of advanced information technology use. There are no clear-cut patterns indicating one feature or one property leads to positive or negative outcomes (DeSanctis \& Poole, 1994). AST is widely adopted in studying group decision support systems (Gopal, Bostrom, \& Chin, 1992; Miranda \& Bostrom, 1993) and ERP systems (Furumo \& Melcher, 2006; LeRouge \& Webb, 2004; Niederman, Briggs, de Vreede, \& Kolfschoten, 2008).

The notion of taking process changes into considerations from AST advances the Giddons (1984) original structuration theory and strengthens the tie with affordance. Affordance as a mid-range theory provides a powerful tool to examine the humantechnology phenomenon in emerging organizations.

\subsubsection{Social-materiality}

Orlikowski (2008) concludes that most studies do not consider the role of technology in the organization of life. They provide an alternative view, socialmateriality. Social-materiality challenges the assumption that technology, work, and organizations should be conceptualized separately, putting forward the inherent inseparability between the technical and the social (Orlikowski \& Scott, 2008). From the social-material perspective, people and things exist only concerning each other. Scholars 
subsequently use the relational property of social-materiality to articulate the figural, asymmetric, and dynamic interactions among artifacts, actors, and structures (Mazmanian, Cohn, \& Dourish, 2014; Parmiggiani \& Mikalsen, 2013).

One argument lies in Giddens's (1984) structuration theory and Gibson's (1977) affordance. He cites the interpretations of affordance by Zammuto et al. (2007) for organizing as a way to conceptualize the process by which information technology and organizations are woven together. "Although IT and organization features may exist independently of each other, their value for explaining organizational form and function comes from how they are enacted together" (Zammuto et al., 2007).

\subsection{Affordance}

\subsubsection{History of Affordance}

The concept of affordance originated from Gibson, is defined as the possibilities and limits for action that a material object offers to an actor. It describes the relationship between an animal and the environment, as Gibson notes, "the affordances of the environment are what it offers the animal, what it provides or furnishes, either for good or ill” (p. 127). This notion derails from the traditional dichotomy of technological determinism versus social determinism, provides apparent attractions for studying the coevolution of human and technology (Bloomfield, Latham, \& Vurdubakis, 2010).

Affordance, as one of the intermediate approaches of viewing technology, unites, and yet distinguishes itself from, structuration theory by Giddens' (1979), adaptive structuration theory (AST) by (DeSanctis \& Poole, 1994), and social materiality by (Orlikowski \& Scott, 2008). Even though all these approaches seek ways to understand the interplays among a technology, an actor, and an organization, they emphasize different aspects. 
While the sensitivity of affordance in examining issues in the social-technological phenomenon has been disputed, its burgeoning union with critical theories refines its perspective for the study of social-technical interactions. Affordance, rooted in a relational ontology, gives equal weights to both the social and the material (Faraj \& Azad, 2012).

\begin{tabular}{|c|c|c|c|}
\hline Author & Context & Methodology & Relevant Findings \\
\hline $\begin{array}{c}\text { (Norman } \\
1999)\end{array}$ & $\begin{array}{l}\text { Graphical } \\
\text { Design }\end{array}$ & Conceptual & $\begin{array}{l}\text { Proposed a set of concepts: real } \\
\text { affordances, perceived affordances, } \\
\text { constraints, conventions }\end{array}$ \\
\hline $\begin{array}{l}\text { (Fayard and } \\
\text { Weeks 2007) }\end{array}$ & Organization & Empirical & $\begin{array}{l}\text { Develop a theory of the } \\
\text { environmental affordances of } \\
\text { informal interaction: proximity, } \\
\text { privacy, and legitimacy }\end{array}$ \\
\hline $\begin{array}{l}\text { (Grgic, Still } \\
\text { et al. 2016) }\end{array}$ & $\begin{array}{l}\text { Interface } \\
\text { Design }\end{array}$ & Empirical & $\begin{array}{l}\text { 1. When a user is under high central } \\
\text { executive load, fewer resources are } \\
\text { available to complete affordance- } \\
\text { based interactions, and those } \\
\text { interactions are negatively impacted. } \\
\text { 2. Affordances do not always } \\
\text { interact with working memory load. }\end{array}$ \\
\hline $\begin{array}{l}\text { (Lu and } \\
\text { Cheng 2013) }\end{array}$ & $\begin{array}{l}\text { Human- } \\
\text { affordance } \\
\text { interactions }\end{array}$ & Conceptual & $\begin{array}{l}\text { Proposed affordance-meaning-- } \\
\text { generation model to integrate } \\
\text { affordance, product semantic and } \\
\text { signifier and factors that involve in } \\
\text { human-affordance interactions to } \\
\text { clarify the different roles of these } \\
\text { concepts from the perspective of } \\
\text { human artifact and its proper } \\
\text { function }\end{array}$ \\
\hline $\begin{array}{l}\text { (Hutchby } \\
\text { 2001) }\end{array}$ & Sociology & Conceptual & $\begin{array}{l}\text { 1. Affordances are not just } \\
\text { functional but also relational aspects } \\
\text { of an object's material presence in } \\
\text { the world. } 2 \text {. Affordances can be } \\
\text { laminated or compounded. } 3 \text {. } \\
\text { Affordances of artifacts (i.e., } \\
\text { manufactured objects) do not } \\
\text { necessarily derive from natural } \\
\text { features of the artifacts materiality. }\end{array}$ \\
\hline
\end{tabular}




\begin{tabular}{|c|c|c|c|}
\hline $\begin{array}{l}\text { (Zammuto, } \\
\text { Griffith, et } \\
\text { al. 2007) }\end{array}$ & $\begin{array}{l}\text { Information } \\
\text { Technology and } \\
\text { Organization }\end{array}$ & Conceptual & $\begin{array}{l}\text { Proposed five organization } \\
\text { affordances: visualizing entire work } \\
\text { processes, real-time/flexible } \\
\text { products and service innovation, } \\
\text { virtual collaboration, mass } \\
\text { collaboration, and } \\
\text { simulation/synthetic reality that } \\
\text { emerged from the interaction of } \\
\text { technology and organization }\end{array}$ \\
\hline $\begin{array}{l}\text { (Markus and } \\
\text { Silver 2008) }\end{array}$ & $\begin{array}{l}\text { Information } \\
\text { System Design, } \\
\text { Information } \\
\text { technology } \\
\text { effects }\end{array}$ & Conceptual & $\begin{array}{l}\text { Proposed technical objects, } \\
\text { functional affordances, and symbolic } \\
\text { expressions. The technical objects } \\
\text { concept pertains to the IT artifacts } \\
\text { themselves. The functional } \\
\text { affordances and symbolic } \\
\text { expressions concepts refer to } \\
\text { relations between technical objects } \\
\text { and users. }\end{array}$ \\
\hline $\begin{array}{l}\text { (Bloomfield, } \\
\text { Latham, et } \\
\text { al. 2010) }\end{array}$ & $\begin{array}{c}\text { Sociology } \\
\text { Sociomateriality }\end{array}$ & Conceptual & $\begin{array}{l}\text { Proposed that the affordances of } \\
\text { technological objects are not } \\
\text { reducible to their material } \\
\text { constitution but are inextricably tied } \\
\text { to specific, historically situated } \\
\text { modes of engagement and ways of } \\
\text { life. }\end{array}$ \\
\hline $\begin{array}{l}\text { (Leonardi } \\
\text { 2011) }\end{array}$ & $\begin{array}{l}\text { Organization } \\
\text { Change }\end{array}$ & Empirical & $\begin{array}{l}\text { A change in technology at any given } \\
\text { time is linked to the routines that } \\
\text { came before it and will be linked to } \\
\text { the routines that come after just as a } \\
\text { change in routines is linked to the } \\
\text { technologies that preceded and will } \\
\text { follow it }\end{array}$ \\
\hline $\begin{array}{l}\text { (Jung, } \\
\text { Schneider, et } \\
\text { al. 2010) }\end{array}$ & $\begin{array}{l}\text { Technology- } \\
\text { mediated group } \\
\text { collaboration }\end{array}$ & Empirical & $\begin{array}{l}\text { By embedding the theoretically } \\
\text { derived mechanisms "providing } \\
\text { feedback" and "designing for } \\
\text { optimal challenge" into the } \\
\text { collaboration environment, } \\
\text { significant performance gains were } \\
\text { realized. }\end{array}$ \\
\hline $\begin{array}{l}\text { (Turner and } \\
\text { Turner 2002) }\end{array}$ & $\begin{array}{l}\text { Collaborative } \\
\text { Virtual } \\
\text { Environment } \\
\end{array}$ & Empirical & $\begin{array}{l}\text { Proposed three levels of affordances: } \\
\text { basic usability, supporting user } \\
\text { tasks, and cultural affordance }\end{array}$ \\
\hline $\begin{array}{l}\text { (Tansley, } \\
\text { Sacks, et al. } \\
\text { 2003) }\end{array}$ & $\begin{array}{l}\text { Knowledge } \\
\text { construction }\end{array}$ & Empirical & $\begin{array}{l}\text { The benefits of eLearning } \\
\text { technologies emerge from } \\
\text { participants engaging in 'knowing in }\end{array}$ \\
\hline
\end{tabular}




\begin{tabular}{|c|c|c|c|}
\hline & $\begin{array}{l}\text { through } \\
\text { eLearning }\end{array}$ & & $\begin{array}{l}\text { practice' in planning, undertaking } \\
\text { their teaching duties and engaging in } \\
\text { social reflective processes }\end{array}$ \\
\hline $\begin{array}{l}\text { (Turner } \\
2005)\end{array}$ & Phenomenology & Conceptual & $\begin{array}{l}\text { Proposed simple affordance and } \\
\text { complex affordance }\end{array}$ \\
\hline $\begin{array}{l}\text { (Kaptelinin } \\
\text { and Nardi } \\
\text { 2012) }\end{array}$ & $\begin{array}{l}\text { Information } \\
\text { Interface and } \\
\text { Presentation }\end{array}$ & Conceptual & $\begin{array}{l}\text { Proposed understanding technology } \\
\text { affordances as possibilities for } \\
\text { mediated human action, and argued } \\
\text { that adopting a mediated action } \\
\text { perspective on affordances has direct } \\
\text { implications for understanding } \\
\text { specifically human uses of } \\
\text { technology presented an initial } \\
\text { outline of the mediated action } \\
\text { perspective on affordances which } \\
\text { deliberately focuses on individual } \\
\text { human actions }\end{array}$ \\
\hline $\begin{array}{l}\text { (Goel, } \\
\text { Johnson, et } \\
\text { al. 2013) }\end{array}$ & $\begin{array}{l}\text { Virtual world } \\
\text { influence } \\
\text { learning }\end{array}$ & Empirical & $\begin{array}{l}\text { Offer the conceptualization and } \\
\text { measurement of context and social } \\
\text { facilitation as unique affordances of } \\
\text { virtual worlds }\end{array}$ \\
\hline $\begin{array}{l}\text { (Wagner, } \\
\text { Vollmar, et } \\
\text { al. 2014) }\end{array}$ & $\begin{array}{l}\text { Social media } \\
\text { affordance in } \\
\text { knowledge } \\
\text { creation }\end{array}$ & Conceptual & $\begin{array}{l}\text { 1. Social media affords a variety of } \\
\text { new behaviors that were not } \\
\text { previously possible, e.g., authoring, } \\
\text { reviewability, editability, re- } \\
\text { combinability, association, and } \\
\text { experimentation. } 2 \text {. The behaviors } \\
\text { afforded by social media have } \\
\text { implications for the knowledge } \\
\text { creation process. }\end{array}$ \\
\hline $\begin{array}{l}\text { (Volkoff and } \\
\text { Strong 2013) }\end{array}$ & $\begin{array}{l}\text { Organization } \\
\text { change }\end{array}$ & Empirical & $\begin{array}{l}\text { Linked the concept of affordances } \\
\text { more firmly and thoroughly to its } \\
\text { critical realist roots by explaining } \\
\text { how affordances are a special case } \\
\text { of generative mechanisms. }\end{array}$ \\
\hline $\begin{array}{l}\text { (Strong, } \\
\text { Volkoff, et } \\
\text { al. 2014) }\end{array}$ & $\begin{array}{c}\text { electronic } \\
\text { health record } \\
(\mathrm{EHR}) \text { system } \\
\text { implementation } \\
\text { and } \\
\text { organization } \\
\text { change }\end{array}$ & Empirical & $\begin{array}{l}\text { 1. Identified eight affordances } \\
\text { arising from the relation between the } \\
\text { EHR and the healthcare } \\
\text { organization. 2. Differentiated } \\
\text { potential affordances and actualized } \\
\text { affordances. 3. Distinguished } \\
\text { individual affordances versus } \\
\text { organizational affordances versus } \\
\text { the bundle of interacting affordances }\end{array}$ \\
\hline
\end{tabular}




\begin{tabular}{|c|c|c|c|}
\hline & & & $\begin{array}{l}\text { 4. Specified long-term versus short- } \\
\text { term outcomes. }\end{array}$ \\
\hline $\begin{array}{c}\text { (Hartson } \\
\text { 2003) }\end{array}$ & $\begin{array}{l}\text { Interaction } \\
\text { Design and } \\
\text { Evaluation }\end{array}$ & Conceptual & $\begin{array}{l}\text { Proposed and explored the use of the } \\
\text { complementary terms, cognitive } \\
\text { affordance, physical affordance, } \\
\text { sensory affordance, and functional } \\
\text { affordance to refer to the } \\
\text { corresponding concepts in } \\
\text { interaction analysis and design. }\end{array}$ \\
\hline $\begin{array}{l}\text { (Chen, Qian } \\
\text { et al. 2016) }\end{array}$ & $\begin{array}{l}\text { Cybersecurity } \\
\text { Design }\end{array}$ & Empirical & $\begin{array}{l}\text { Synthesized a four-layer affordance- } \\
\text { based framework. }\end{array}$ \\
\hline $\begin{array}{l}\text { (Groshek and } \\
\text { Tandoc } \\
\text { 2017) }\end{array}$ & $\begin{array}{l}\text { Journalism, } \\
\text { Social Media }\end{array}$ & Empirical & $\begin{array}{l}\text { 1. While legacy journalists were } \\
\text { among the most popular users } \\
\text { regarding some followers, they were } \\
\text { no longer the most influential in } \\
\text { generating discussions and } \\
\text { gatekeeping information } 2 \text {. The } \\
\text { affordance effect whereby } \\
\text { individuals may have been } \\
\text { marginalized due to a lack of pre- } \\
\text { existing influence and legitimation. }\end{array}$ \\
\hline $\begin{array}{l}\text { (Chen, Xu et } \\
\text { al. 2016) }\end{array}$ & $\begin{array}{l}\text { The } \\
\text { government, } \\
\text { Social Media }\end{array}$ & Empirical & $\begin{array}{l}\text { Identified fifteen aspects of social } \\
\text { media policies and four affordances } \\
\text { of social media for government } \\
\text { practices; visibility, editability, } \\
\text { persistence, and interactivity }\end{array}$ \\
\hline $\begin{array}{l}\text { (Oshlyansky, } \\
\text { Thimbleby, } \\
\text { et al. 2004) }\end{array}$ & $\begin{array}{l}\text { Information } \\
\text { interfaces and } \\
\text { presentation }\end{array}$ & Empirical & $\begin{array}{l}\text { The affordance of an object has been } \\
\text { learned in a cultural context. The } \\
\text { design of the object provides no } \\
\text { actual affordance for its correct use. }\end{array}$ \\
\hline $\begin{array}{l}\text { (Wang, Li et } \\
\text { al. 2016) }\end{array}$ & $\begin{array}{c}\text { The } \\
\text { organization, } \\
\text { Social Media }\end{array}$ & Empirical & $\begin{array}{l}\text { Four affordances of social media } \\
\text { within an organization were } \\
\text { identified as helping the formation } \\
\text { of value-co-creation, namely: } \\
\text { dialogue affordances, affordance of } \\
\text { accessibility, monitorability } \\
\text { affordances and transparency } \\
\text { affordances. }\end{array}$ \\
\hline $\begin{array}{l}\text { (Bang, Lee, } \\
\text { et al. 2014) }\end{array}$ & $\begin{array}{l}\text { Mobile } \\
\text { technology, e- } \\
\text { commerce }\end{array}$ & Empirical & $\begin{array}{l}\text { Empirically tested, the affordance of } \\
\text { mobile technologies in the context of } \\
\text { e-commerce and verified } \\
\text { heterogenous and time-varying } \\
\text { impacts on technology use. }\end{array}$ \\
\hline
\end{tabular}




\begin{tabular}{|c|c|c|c|}
\hline $\begin{array}{l}\text { (Argyris and } \\
\text { Monu 2015) }\end{array}$ & $\begin{array}{l}\text { Social Media in } \\
\text { Organization } \\
\text { communication }\end{array}$ & Empirical & $\begin{array}{l}\text { Demonstrated that social media } \\
\text { provides unique capacities to aid } \\
\text { external communication in } \\
\text { comparison to the traditional media } \\
\text { and that these affordances expand } \\
\text { the previously known affordances } \\
\text { for internal communication. }\end{array}$ \\
\hline $\begin{array}{l}\text { (Olapiriyakul } \\
\text { and } \\
\text { Widmeyer } \\
\text { 2009) }\end{array}$ & Virtual World & Empirical & $\begin{array}{l}\text { Presented the development of a } \\
\text { measurement instrument for these } \\
\text { three types and reported the initial } \\
\text { validation of the scales. }\end{array}$ \\
\hline $\begin{array}{l}\text { (Seet and } \\
\text { Goh 2012) }\end{array}$ & $\begin{array}{l}\text { E-reader } \\
\text { devices in } \\
\text { collaborative } \\
\text { learning }\end{array}$ & Empirical & $\begin{array}{l}\text { Identified five affordances that } \\
\text { influence users' acceptance of a } \\
\text { system. These affordance factors are } \\
\text { mobility affordance, support } \\
\text { affordance, connectivity affordance, } \\
\text { immediacy affordance, and } \\
\text { collaborative affordance. }\end{array}$ \\
\hline $\begin{array}{l}\text { (Brown, } \\
\text { Neel, et al. } \\
\text { 2015) }\end{array}$ & Psychology & Empirical & $\begin{array}{l}\text { Provided an instrument for assessing } \\
\text { situational characteristics that may } \\
\text { elicit seven fundamentally important } \\
\text { human motives. }\end{array}$ \\
\hline $\begin{array}{l}\text { (Grgecic, } \\
\text { Holten, et al. } \\
\text { 2015) }\end{array}$ & $\begin{array}{l}\text { Information } \\
\text { System } \\
\text { Adoption }\end{array}$ & Empirical & $\begin{array}{l}\text { Developed measures for functional } \\
\text { affordance and empirically tested the } \\
\text { effects of functional affordances on } \\
\text { information quality and system } \\
\text { quality }\end{array}$ \\
\hline $\begin{array}{l}\text { (Abhari, } \\
\text { Davidson, et } \\
\text { al. 2016) }\end{array}$ & $\begin{array}{l}\text { Co-innovation } \\
\text { platforms }\end{array}$ & Empirical & $\begin{array}{l}\text { Conceptualized co-innovation } \\
\text { platform affordances and developed } \\
\text { a valid and reliable measurement } \\
\text { instrument capturing critical facets } \\
\text { of co-innovation, namely ideation, } \\
\text { collaboration, and communication. }\end{array}$ \\
\hline $\begin{array}{l}\text { (Rice, Evans, } \\
\text { et al. 2017) }\end{array}$ & $\begin{array}{l}\text { Information and } \\
\text { communication } \\
\text { technology in } \\
\text { organizations }\end{array}$ & Empirical & $\begin{array}{l}\text { Provided a large set of items for } \\
\text { assessing organizational media } \\
\text { affordances possible actions with } \\
\text { media can be distinct, reliable, and } \\
\text { valid when associated with a } \\
\text { primary set of affordance types } \\
\text { within an organizational context }\end{array}$ \\
\hline
\end{tabular}

Table 2-1: List of A Set of Literature of Affordance 
Table 2-1 illustrates a selection of papers that have evaluated the concept of affordance, shows the methodologies that each paper has utilized and its relevant findings.

\subsubsection{Types of Affordance}

Different types of affordance were observed in our review. One should address the material aspects of affordance which is inherently embedded in the artifacts. On a function level, these features can be manufactured. One should also address the social aspects derived from the interactions between an actor and an artifact. One should acknowledge that affordance changes when multiple actors interact through an artifact.

Furthermore, depending on the types and stages of affordance, affordance can be either stable (Grgic, Still, \& Still, 2016; Zammuto et al., 2007) or emergent (Fayard \& Weeks, 2007; Norman, 1999). Affordance is inherently embedded in the contexts in which interactions between actors and artifacts occur. Context refers to the intention, culture, knowledge and other characteristics of an actor, creates distinctive interpretations of what, when, where, and how artifacts afford.

Although the use of affordance in information systems discipline has gained popularity in recent years, there is ambiguity in the literature regarding the classification of affordance. Most authors have studied affordance in a particular context without considering the specifics of context in the conceptualization and operationalization of affordance. We posit, however, that aside from general affordance, specific affordance emerges from that particular context in which interactions are embodied. Below we begin by introducing different classifications and conceptualizations of affordance in the literature. 
Gibson's original affordance concept offers action possibilities in an environment with an actor. It is independent of the actor's experience, knowledge, and culture. One could claim an affordance either exists or does not exist, Norman (1999) distinguishes real affordance from perceived affordance in interface design and claims that perceived affordance articulates an actor's perception of action possibilities rather than what is true. In Norman's view, affordance is contingent upon the experience, knowledge, or culture of the actor. In our research, we used the term objective affordance to describe affordances offered by the artifacts, and the term subjective affordance to describe affordances associated with the actor.

In addition to Norman's view of affordance, numerous scholars address the relational property of affordance. Gaver (1991) puts forward the notion of sequential affordances (We will use the term behavioral affordance to describe affordance in actions.) and nested affordances (We will use the term interactive affordance to describe affordances in bundles.) that describe affordances revealed over time and grouped in space. One of the critical aspects drawn from the relational property of affordance is that affordances of an object differ from one individual to another Hutchby (2001).

We also note that scholars see affordance differently from its state: either static or emergent. Upon recognizing the importance of interactions between affordances and technology, scholars tend to study specific types of affordance in specific situations (Fayard and Weeks 2007; Grgic et al. 2016). These studies consider the emergent properties of affordance. Table 2-2 illustrates the types of affordance in the literature and their units of analysis. 


\begin{tabular}{|c|c|c|c|c|c|c|c|c|c|c|c|c|c|c|c|c|c|c|c|c|c|}
\hline \multirow{3}{*}{\begin{tabular}{|l} 
Author (s) \\
$\begin{array}{l}\text { Unit of } \\
\text { Analysis }\end{array}$ \\
\end{tabular}} & \multicolumn{21}{|c|}{ Types of Affordance } \\
\hline & \multicolumn{3}{|c|}{$\begin{array}{l}\text { Subjective } \\
\text { Affordance }\end{array}$} & \multicolumn{3}{|c|}{$\begin{array}{c}\text { Objective } \\
\text { Affordance }\end{array}$} & \multicolumn{3}{|c|}{$\begin{array}{l}\text { Behavioral } \\
\text { Affordance }\end{array}$} & \multicolumn{3}{|c|}{$\begin{array}{c}\text { Individual } \\
\text { Affordance }\end{array}$} & \multicolumn{3}{|c|}{$\begin{array}{l}\text { Interactive } \\
\text { Affordance }\end{array}$} & \multicolumn{3}{|c|}{$\begin{array}{c}\text { Static } \\
\text { Affordance }\end{array}$} & \multicolumn{3}{|c|}{$\begin{array}{c}\text { Emergent } \\
\text { Affordance }\end{array}$} \\
\hline & $\mathrm{O}$ & G & I & $\mathrm{O}$ & G & I & $\mathrm{O}$ & $\mathrm{G}$ & $\mathrm{I}$ & $\mathrm{O}$ & G & I & $\mathrm{O}$ & G & I & $\mathrm{O}$ & G & I & $\mathrm{O}$ & G & I \\
\hline Norman & & & $X$ & & & $\mathrm{X}$ & & & & & & $\mathrm{X}$ & & & & & & & & & $\mathrm{X}$ \\
\hline $\begin{array}{l}\text { Fayard and } \\
\text { Weeks }\end{array}$ & & & & & & & & & $\mathrm{X}$ & & & $\mathrm{X}$ & & & $\mathrm{X}$ & & & & & & $\mathrm{X}$ \\
\hline $\begin{array}{l}\text { Grgic, Still et } \\
\text { al. }\end{array}$ & & & & & & $\mathrm{X}$ & & & & & & $\mathrm{X}$ & & & $\mathrm{X}$ & & & $\mathrm{X}$ & & & \\
\hline Lu and Cheng & & & $\mathrm{X}$ & & & $\mathrm{X}$ & & & & & & $\mathrm{X}$ & & & $\mathrm{X}$ & & & & & & $\mathrm{X}$ \\
\hline Hutchby & & & $X$ & & & $\mathrm{X}$ & & & & & & $X$ & & & $\mathrm{X}$ & & & & & & $\mathrm{X}$ \\
\hline $\begin{array}{l}\text { Zammuto et } \\
\text { al. }\end{array}$ & & & & $\mathrm{X}$ & & & $\mathrm{X}$ & $\mathrm{X}$ & & & & & & & $\mathrm{X}$ & & & $\mathrm{X}$ & & & \\
\hline $\begin{array}{l}\text { Markus and } \\
\text { Silver }\end{array}$ & & & $\mathrm{X}$ & & & $\mathrm{X}$ & & & & & & $\mathrm{X}$ & & & $\mathrm{X}$ & & & & & & $\mathrm{X}$ \\
\hline $\begin{array}{l}\text { Bloomfield et } \\
\text { al. }\end{array}$ & & & & & & & & & & & & & & & $\mathrm{X}$ & & & & & & $\mathrm{X}$ \\
\hline Leonardi & & & $\mathrm{X}$ & & & & & & & & & & & & $\mathrm{X}$ & & & $\mathrm{X}$ & & & \\
\hline Jungr et al. & & & & & $\mathrm{X}$ & $\mathrm{X}$ & & & & & & & & & $\mathrm{X}$ & & & $\mathrm{X}$ & & & \\
\hline $\begin{array}{l}\text { Tansley, Sacks } \\
\text { et al. }\end{array}$ & & & & & & & & & $\mathrm{X}$ & & & & & & $\mathrm{X}$ & & & & & & $\mathrm{X}$ \\
\hline Turner & & & & & & $\mathrm{X}$ & & & $\mathrm{X}$ & & & & & & $\mathrm{X}$ & & & & & & $\mathrm{X}$ \\
\hline $\begin{array}{l}\text { Kaptelinin and } \\
\text { Nardi }\end{array}$ & & & & & & & & & $\mathrm{X}$ & & & & & & $\mathrm{X}$ & & & & & & $\mathrm{X}$ \\
\hline $\begin{array}{l}\text { Goel, Johnson } \\
\text { et al. }\end{array}$ & & & $\mathrm{X}$ & & & & & & $\mathrm{X}$ & & & & & & $\mathrm{X}$ & & & $\mathrm{X}$ & & & \\
\hline $\begin{array}{l}\text { Wagner, } \\
\text { Vollmar et al. }\end{array}$ & & & & & & $\mathrm{X}$ & & & $\mathrm{X}$ & & & $\mathrm{X}$ & & & & & & $\mathrm{X}$ & & & \\
\hline $\begin{array}{l}\text { Volkoff and } \\
\text { Strong }\end{array}$ & & & & $\mathrm{X}$ & $\mathrm{X}$ & & $\mathrm{X}$ & $\mathrm{X}$ & & & & & $\mathrm{X}$ & $\mathrm{X}$ & & & & & $\mathrm{X}$ & $\mathrm{X}$ & \\
\hline $\begin{array}{l}\text { Strong, } \\
\text { Volkoff et al. }\end{array}$ & & & & $\mathrm{X}$ & & $\mathrm{X}$ & & & & & & & $\mathrm{X}$ & & & & & & $\mathrm{X}$ & & \\
\hline Hartson & & & $\mathrm{X}$ & & & $\mathrm{X}$ & & & $\mathrm{X}$ & & & $\mathrm{X}$ & & & & & & $\mathrm{X}$ & & & \\
\hline $\begin{array}{l}\text { Chen, Qian et } \\
\text { al. }\end{array}$ & & & $\mathrm{X}$ & & & $\mathrm{X}$ & & & & & & $\mathrm{X}$ & & & & $\mathrm{X}$ & & $\mathrm{X}$ & & & \\
\hline $\begin{array}{l}\text { Groshek and } \\
\text { Tandoc }\end{array}$ & & & & $\mathrm{X}$ & & & & & & $\mathrm{X}$ & & & & & & $\mathrm{X}$ & & & & & \\
\hline $\begin{array}{l}\text { Chen, Xu et } \\
\text { al. }\end{array}$ & & & & $\mathrm{X}$ & & & & & & X & & & & & & $\mathrm{X}$ & & & & & \\
\hline $\begin{array}{l}\text { Oshlyansky et } \\
\text { al. }\end{array}$ & & & & & & $\mathrm{X}$ & & & $\mathrm{X}$ & & & $\mathrm{X}$ & & & & & & & & & $\mathrm{X}$ \\
\hline Wang, Li et al. & & & & $\mathrm{X}$ & & & & & & $\mathrm{X}$ & & & & & & $\mathrm{X}$ & & & & & \\
\hline $\begin{array}{l}\text { Bang, Lee et } \\
\text { al. }\end{array}$ & & & & & & $\mathrm{X}$ & & & & & & $\mathrm{X}$ & & & & & & $\mathrm{X}$ & & & \\
\hline $\begin{array}{l}\text { Argyris and } \\
\text { Monu }\end{array}$ & & & & $\mathrm{X}$ & & & & & & $\mathrm{X}$ & & & & & & $\mathrm{X}$ & & & & & \\
\hline Seet and Goh & & & $X$ & & & & & & & & & X & & & & & & $\mathrm{X}$ & & & \\
\hline
\end{tabular}




\begin{tabular}{|l|l|l|l|l|l|l|l|l|l|l|l|l|l|l|l|l|l|l|l|l|l|} 
Grgecic et al. & & & & & & $\mathrm{X}$ & & & & & & $\mathrm{X}$ & & & & & & $\mathrm{X}$ & & & \\
\hline Abhari et al. & & & $\mathrm{X}$ & & & $\mathrm{X}$ & & & & & & & & & $\mathrm{X}$ & & $\mathrm{X}$ & & \\
\hline
\end{tabular}

O:organization

G: group

I: individual

Table 2-2: Types of Affordance and Unit of Analysis

The following table (Table 2-3) provides an overview of the articles included in the table. Articles mentioned subjective affordance, objective affordance, and behavioral affordance. Individual affordance, interactive affordance, static affordance, and emergent affordance take $36 \%, 74 \%, 36 \%, 46 \%, 57 \%, 57 \%$ and $43 \%$ out of all 28 articles. Within the subjective affordance group, $100 \%$ of the articles were on the individual level. Within the objective affordance group. $35 \%$ of the articles were on organization level; $10 \%$ on group level; and 55\% were on the individual level. Within the behavioral affordance group, $20 \%$ of the articles were on organization level, $20 \%$ and $60 \%$ for group level and individual level. For individual affordance, $31 \%$ were on organization level, $0 \%$ and $69 \%$ on the group and individual level. For interactive affordance group, $13 \%$ were on organization level, $6 \%$ and $81 \%$ are on group level and individual level. Within the Static affordance group, $31 \%$ are on organization level, $0 \%$ and $69 \%$ are on group level and individual level. Lastly, for emergent affordance, $17 \%$ are on organization level, $8 \%$ on a group level, and $75 \%$ on the individual level. We observed most of the research so far in information systems focuses on objective (functional) affordance with the unit of analysis on the individual level.

\begin{tabular}{|c|c|c|c|c|c|c|c|c|}
\hline $\begin{array}{c}\text { Type of } \\
\text { Affordance }\end{array}$ & $\begin{array}{c}\text { \# of } \\
\text { articles }\end{array}$ & $\begin{array}{c}\% \text { of } \\
\text { all }\end{array}$ & Org & $\%$ & Group & $\%$ & Individual & $\%$ \\
\hline Subjective & 10 & 36 & 0 & 0 & 0 & 0 & 10 & 100 \\
\hline Objective & 20 & 74 & 7 & 35 & 2 & 10 & 11 & 55 \\
\hline
\end{tabular}




\begin{tabular}{|c|c|c|c|c|c|c|c|c|}
\hline Behavioral & 10 & 36 & 2 & 20 & 2 & 20 & 6 & 60 \\
\hline Individual & 13 & 46 & 4 & 31 & 0 & 0 & 9 & 69 \\
\hline Interactive & 16 & 57 & 2 & 13 & 1 & 6 & 13 & 81 \\
\hline Static & 16 & 57 & 5 & 31 & 0 & 0 & 11 & 69 \\
\hline Emergent & 12 & 43 & 2 & 17 & 1 & 8 & 9 & 75 \\
\hline
\end{tabular}

Table 2-3: Frequency for Different Types of Affordance

\subsubsection{Application of Affordance}

Affordance as a bridging concept that connects users and artifacts has gained extreme popularity in information communication technology, information systems, human-computer interaction, and user interface design. We noticed multiple streams of research in how affordance is utilized in these studies.

The first stream concerns the conceptual development of affordance (Hutchby, 2001; Lu \& Cheng, 2013; Norman, 1999; Wagner, Vollmar, \& Wagner, 2014). They tried to clarify the boundary of affordance and proposed certain types of affordance in understanding design and human technology interactions. For instance, Normal (1999) posits that there was real affordance and perceived affordance. He argues that what is being designed as functionalities does not necessarily translate to what people perceive the functionalities would be. Moreover, constraints and conventions also play roles in shaping what is real affordance versus perceived affordance. Hutchby (2001) articulates that affordances are not just functional but also relational aspects of an object's material presence in the world with the possibility to be laminated or compounded. Such conceptual development efforts have significantly advanced the understanding of what affordances are and have provided theoretical bases for subsequent research.

The stream following conceptual development focuses on discovering and testing affordances in real-world settings. For instance, in studying organizational changes, 
Leonardi (2011) investigates how a change in technology in an organization would influence the routines before and after the change. Volkoff and Strong (2013) link the concept of affordances more firmly and thoroughly to its critical realist roots by explaining how affordances are a particular case of generative mechanisms. Others mention the functional affordances of various technology artifacts such as HER systems, social media, and mobile e-commerce technology as providing essential evidence for the role of affordance plays in human-technology interaction.

\subsection{System Integration in Healthcare}

System integration plays a critical role in delivering a comprehensive and continuous patient-centered care. IT system adoption has shown significant effects on healthcare outcomes in hospitals, for instance, patient safety (Menachemi, Saunders, Chukmaitov, Matthews, \& Brooks, 2007), financial performance (Thrasher, Craighead, \& Byrd, 2010), and service effectiveness (Richey, Roath, Whipple, \& Fawcett, 2010). Integrated healthcare information technology (HIT) should support both internal integration and external integration. An internal integrated HIT standardizes communications, processes, and data schema across units while an external integrated HIT enables knowledge transfer among stakeholders in the healthcare network (Nazir \& Pinsonneault, 2012). System integration plays a crucial role in healthcare processes regarding two dimensions. 1) Care coordination. Patient care is coordinated among multiple providers. The implementation of integrated systems as a key component requires the coordination of diverse efforts from the hospital, its employees, its partners, and most importantly its users (Wu, Chen, \& Greenes, 2009). 2) Continuity of care. Patients' clinical information should be available to all providers at the point of care and 
patients through the integrated systems (McCarthy, Mueller, \& Wrenn, 2009). The integrated system should also assist patients' transitions throughout the entire care processes.

\subsection{Exploitation versus Exploration}

March (1991) puts forth the twin processes and discusses their role in organizational learning. Traditionally, exploration and exploitation represent two fundamentally distinct approaches to organizational learning. Exploration implies firm behaviors characterized by search, discovery, experimentation, and innovation, while exploitation implies behaviors characterized by refinement, implementation, efficiency, production, and selection (He \& Wong, 2004).

The literature in organizational learning has progressively indicated the necessity for firms to achieve a balance between exploration and exploitation. The balance is embedded in the concept of ambidextrous organizations. He and Wong (2004) empirically test the joint effects of a firm's strategic focus on exploration and exploitation to find if a balance exists between the two are positively related to firm performance. A strategic imbalance has a negative effect on a firm's performance. Other researchers have found that a firm's size plays a crucial role in the balance of strategic focus. Large firms possess resources, capabilities, and experience to benefit from being an ambidextrous organization, but they are unlikely to do so. They tend to focus on the exploitative side of the equation (Voss \& Voss, 2013).

However, the industry investigated in the most research on the notion of exploration and exploitation thus far, are manufacturing firms with products to offer. In the healthcare industry, we find that throughout the system integration processes, 
healthcare organizations also engage in two types of activities: exploration and exploitation, especially since the use of electronic health records (EHR). Consistent with other industries, the issue of balancing exploration and exploitation for the healthcare industry is also exhibited in distinctions made between the refinement of existing technology and the invention of a new one.

Subramani (2004) defines IT use for exploitation as using the system to perform structured, repetitive processes. IT use for exploration is using the system to perform unstructured processes. As a result, the outcomes for exploitation activities are usually clearly definable (e.g., cost reduction, process consistency, process efficiency) while the outcomes for exploration activity are soft benefits that are difficult to evaluate in advance (e.g., shared understanding, a greater understanding of operating environment).

\subsection{Absorptive Capacity}

Absorptive capacity (AC) denotes "the ability of a firm to identify, assimilate, and exploit knowledge from the environment (Cohen \& Levinthal, 1990)." Although AC is rooted in organizational learning, it is considered to be a multilevel and transdisciplinary construct and is seen as an explanation for innovation and exploitation/exploration orientations (Volberda, Foss, \& Lyles, 2010). AC has two sub-processes: potential and realized. Potential AC describes acquisition and assimilation of knowledge while realized AC describes transformation and exploitation of knowledge (Zahra \& George, 2002).

Implementations of IS can be considered as a process of knowledge transfer. For the knowledge transfer to be effective between the sources and the recipients direct and intimate interaction between them is required (Jong-Hun Park et al., 2007). AC captures 
the recipients' ability to absorb the knowledge transferred in the process. AC affects implementation performance by the recipients assimilating and applying the knowledge.

In our research, $\mathrm{AC}$ inherits its original definition and demonstrates the extent to which an individual or an organization can identify, assimilate, and exploit the knowledge WeChat entails. Consistent with Volberda et al. (2010), AC serves as an essential component in explaining subsequent system adoption and integration activities that can be either exploitative or explorative.

\subsection{Diffusion of Innovation Theory}

Diffusion of innovation (DOI) theory (Rogers, 1983) seeks to explain how, why, and at what rate innovations and technologies spread. Although Rogers initially developed the theory in the 1960s, it remains a useful tool for assessing behaviors related to adopting a new technological innovation. Diffusion is defined as a process by which an innovation is communicated through specific channels over a period among the members of a social system. Innovation denotes an idea, practice, or object that is perceived to be new by the unit of adoption.

There are five categories of adopters: innovators, early adopters, early majority, late majority, and laggards (Rogers, 1962). Innovators are willing to take risks with the highest social status, financial liquidity, and means to interact with other innovators. Their risk tolerance allows them to adopt technologies that may ultimately fail. Early adopters have higher social status, financial liquidity, and advanced education and are relatively forward socially than the late adopters. Early majority adopters employ an innovation after a varying degree of time that is significantly longer than the innovators and early adopters. They have above average social status, financial liquidity, and 
advanced education. Late majority approaches innovation with skepticism and caution. They have a below average social status, financial liquidity, and advanced education. Finally, the laggards are the last to adopt an innovation. They typically tend to be focused on traditions and have the lowest social status, financial liquidity, and advanced education.

Rogers further proposes five characteristics of innovation that influence the adoption of an innovation: relative advantage, compatibility, complexity, trialability, and observability. Table 2-4 provides a brief description of each characteristic. In addition to the five characteristics, prior conditions such as previous practice, needs, innovativeness, and norms of the social systems are also considered adoption research (Sin Tan, Choy Chong, Lin, \& Cyril Eze, 2009).

\begin{tabular}{|l|l|}
\hline Relative advantage & $\begin{array}{l}\text { The degree to which the innovation is perceived to be better than what } \\
\text { it supersedes }\end{array}$ \\
\hline Compatibility & $\begin{array}{l}\text { The degree to which innovation is consistent with existing values, past } \\
\text { experiences, needs }\end{array}$ \\
\hline Complexity & The degree to which the innovation is difficult to understand and use \\
\hline Trialability & The degree to which the innovation can experiment on a limited basis. \\
\hline Observability & The degree to which of visibility of the innovation results. \\
\hline
\end{tabular}

Table 2-4: Innovation Characteristics

The diffusion of innovation theory is very useful in explaining adoption behavior. However, it is not without its limitations. For instance, the theory does not consider social norms and standards of acceptance towards an innovation. The weight of the social aspects is undetermined but generally accepted as a more significant influence than technology characteristics. Hayden (2014) points out that diffusion of innovation theory does not consider an individual's resources or social systems. 
In our study, we identified each dimension of the characteristics associated with WeChat patient portal and assessed their roles as one of the determinants for affordance. The other determinants accounted for the limitation of diffusion of innovation theory and for the individual aspects.

\subsection{Contextual Affordance}

\subsubsection{Contextualism}

Contextualism has primarily emerged in the 1970s as a third worldview in addition to mechanism and organism (Morris, 1988). However, it has not been taken as a dominant view but rather as integration of mechanism and organism. Even though contextualism entails similar notions to other views such as transnationalism, constructivism, and perspectivism, it is an exciting new alternative to understanding human behavior. One of the root metaphors of contextualism is the historic event. Thus, human behavior persistently evolves. Each interaction is the distinctive product of historical activity in the current context, as well as being the historical context for the next interaction (Morris, 1988).

The application of contextualism is burgeoning. In the cognitive and behavioral psychology discipline, the merits of using cognitive causality have been debated for a long time in the explanation of human behavior. Some argue that it is not merely an empirical matter but, the causality must be understood in the contexts of pre-analytic philosophical assumptions of the researchers (Hayes \& Wilson, 1995).

In the information systems discipline, Eshraghian, Hafezieh, and Harwood (2015) posit that social-cultural and institutional context of technology designers and users can affect the way the users perceive and actualize affordances. In a more comprehensive 
view, in evaluating information systems, Stockdale and Standing (2006) state that one should consider not only the organizational context but also the environmental, not just internal context but external context.

\subsubsection{Contexts and Affordance}

Scholars often address affordance concerning interactions among actors, artifacts or processes without carefully considering the unique context in which they are embedded. For instance, Volkoff and Strong (2013) advocate that affordance is a special case of generative mechanisms. They address technology-induced generative mechanisms that interact with affordances during an IT-enabled change process. They did not, however, address non-technology related generative mechanisms that interact with affordances.

Second, we mentioned that even though the call for addressing contexts when application affordance is not new, there is still a lack of conceptualization of such affordance. The evidence is overwhelming. Markus and Silver (2008) note that no explanation of IT effects would be complete without careful conceptualizations of users and use environments. These environments include users' characteristics, goals, their interpretation of technology, their work practices, and institutional contexts. Zammuto et al. (2007) argue that a technology object should be recognized as a social object rather than a vehicle carrying functionality. Affordance bridges technology and organization and cannot be separated from social characteristics of organizations such as expertise, jobs, processes, or structures. Avgerou (2001) argues that it is crucial to associate technology with the context within which it is embedded in information systems (IS) research. They identify three principles to address such an association. First, technology 
innovation should be considered with socio-organizational change. Second, the analysis should consider not only the local organizational but also the national and international context. Third, the analysis should not only consider both the technical decisions and actions involved in the process but also the cultural, social and cognitive forces of the processes. In a similar vein, Stockdale and Standing (2006) identify the need for a more holistic process for evaluating IS and proposes an evaluation framework that reflects the social, political and cultural factors. According to their review, the inner or organizational context includes: organizational structure, goals and strategies, culture, political structures, hierarchical structures, social structures and processes, and stakeholders. Outer or external context includes national economic situations, government policies and legislation, market structures and conditions, a competitive environment, industry sector, globalization, privatization, culture influences, and technological developments.

When scholars consider context, it remains a bubble that contains the interactions of actor and technology. It may explain differences at a more abstract level (e.g., organizations or groups). However, by bubbling the context, it naturally diminishes the differences at the individual level and becomes impossible to attribute the effects of such differences to their source.

Based on the arguments above, we propose contextual affordance; an integrative conceptual framework could be used to understand affordances in action. This framework captures existing affordances but most importantly extends affordances by considering the cultural-historical contexts of the actor. 


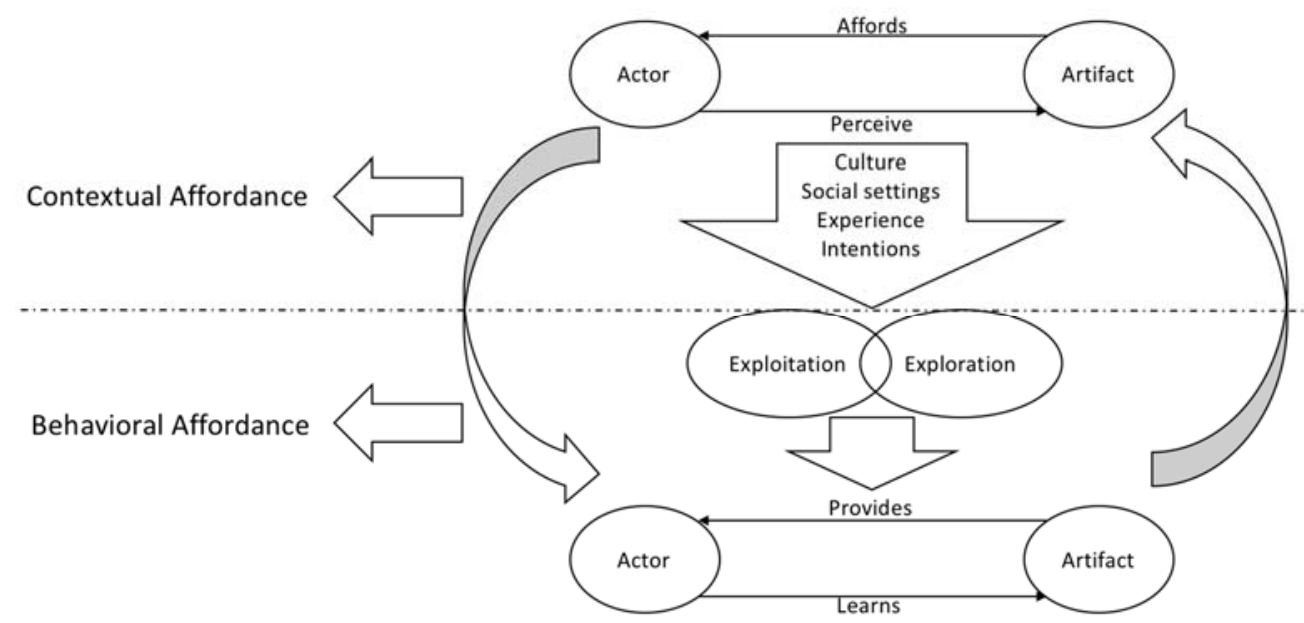

Figure 2-1: Contextual Affordance

Figure 2-1 illustrates the concept of contextual affordance and its relationship with artifacts and actor in time. In our research, exploration denotes IT functions that are experimental, providing new alternatives to existing ones based on new knowledge and skills. Exploitation, in contrast, describes IT functions that are incremental, providing refinement and extension of existing ones based on what is already known. Adoptions and trade-offs between exploration and exploitation of the organization process create dynamic outcomes. The WeChat platform enables a patient to immediately complete online scheduling, registration, and payment processes. These features of WeChat are a result of the integration of WeChat with healthcare information systems (HIT) and a refinement of existing processes, thus exploitative by nature. In contrast, WeChat platform also brings out disruptive features such as online consulting that enable a patient to consult with a physician by choice, a discussion group that unites patients with similar disease for sharing experience and supporting each other, push notifications, and medicine adherence alerts that are integral in the patients' social media feeds. These features are innovative, new, experimental, and thus explorative by nature. 


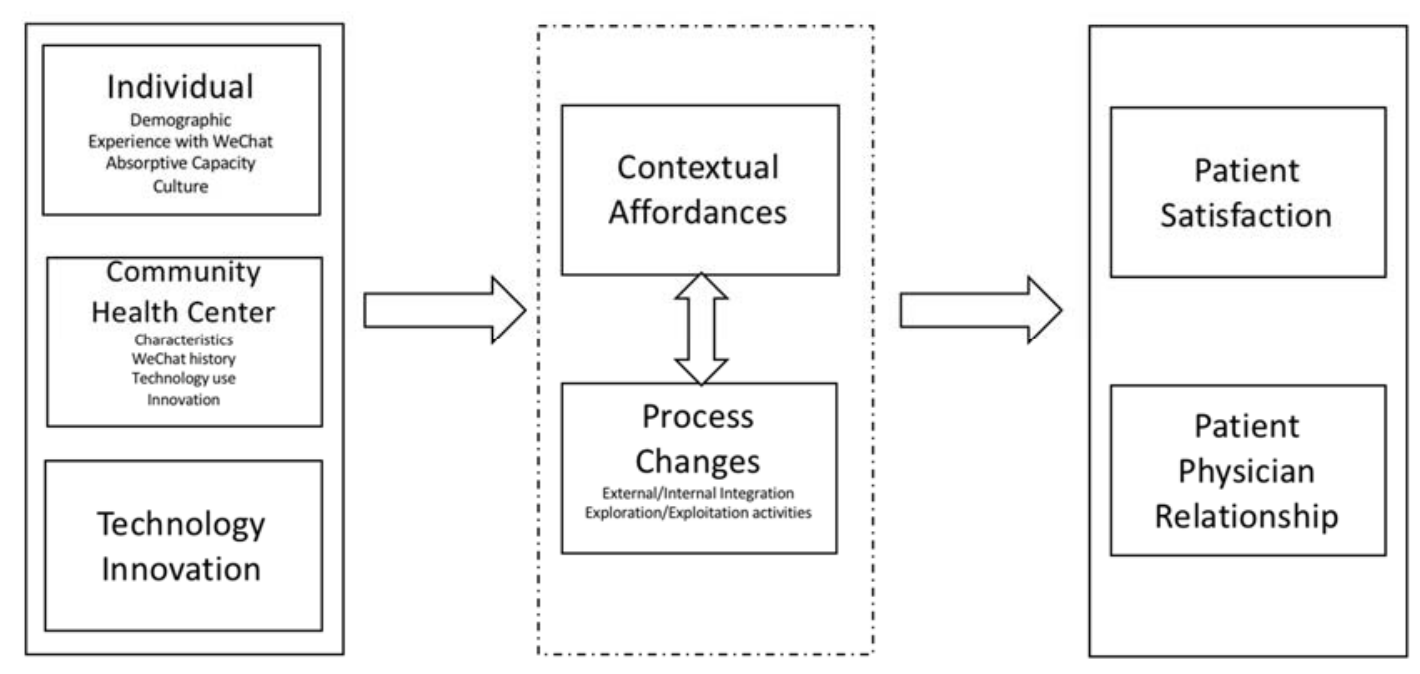

Figure 2-2: Conceptual Mapping

\subsubsection{General versus Specific Contextual Affordance}

We further argue that there are two different types of contextual affordances: general contextual affordance and specific contextual affordance. They are distinctive and affect behavior differently. General contextual affordance is distal, continuous, rigorous and stable. It does not change easily over time. It describes an individual's conventional preferences and thus is long-term oriented. It serves as a baseline for an individual to decide specific contextual affordance as it is immediate, disruptive, unstable, and easy to change, thus making it short-term oriented. When specific contextual affordance is present, the baseline for the individual is temporarily elasticated, and the behavioral outcome for this individual is modified for that single occurrence. We define specific contextual affordance as the perceived action possibilities afforded to the actor that is in specific healthcare contexts by the artifact when the interactions 
happened. General contextual affordance is the perceived action possibilities afforded to the actor that is in general contexts by the artifact before the interactions happen. 


\section{CHAPTER 3 . RESEARCH MODEL AND HYPOTHESES DEVELOPMENT}

\subsection{Research Model}

The conceptual model incorporates both contextual affordance and behavioral affordance, which play the intermediate roles of bridging determinants (such as individual absorptive capacity, organization innovativeness, and technology characteristics) with process changes (such as explorative and exploitative system integration) and healthcare outcomes (such as patient satisfaction, physician satisfaction and patient-physician relationship). The research model consists of four layers: the determinants of contextual affordance, the focal variable of affordance, process variables, and outcome variables. Individual and organizational demographic information are included as control variables as demographics have significant effects on healthcare outcome (Shavers, 2007). Figure 3-1 illustrates the research model for this study.

\section{$\underline{\text { Determinates }} \quad \underline{\text { Affordance }} \quad \underline{\text { Process }} \quad \underline{\text { Outcomes }}$}

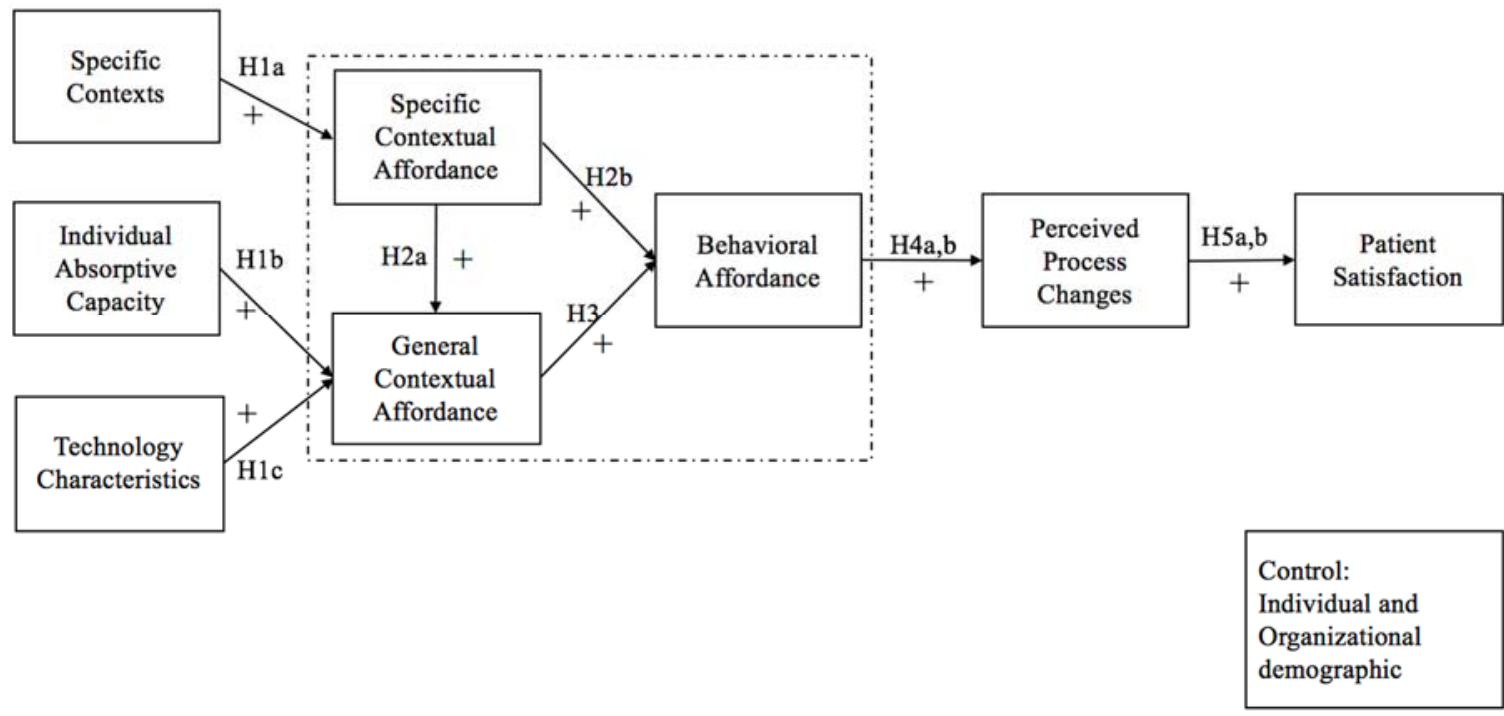

Figure 3-1: Research Model 


\subsubsection{Specific Context and Specific Contextual Affordance}

We define specific contexts as the contextual factors related to the actor (e.g., disease type, beliefs, value, and norm). Some of the contexts are very specific to the Chinese culture. Especially in the healthcare industry, each patient with different disease types will likely respond differently to a particular technology. For instance, chronic disease versus acute disease. Chronic disease will likely require frequent and repetitive visits to a healthcare facility. Thus a particular technology such as patient portal may have more attraction to chronic patients than acute patients and perceived to be more useful. Other specific contexts such as culture norm also contribute to how a patient will perceive what they can do with the technology (Oshlyansky, Thimbleby, \& Cairns, 2004). For instance, if a patient has a preference to go to large hospitals, even though some smaller hospitals provide mobile patient portal services, the patient will not use them. Thus, we posit that specific contexts positively influence a patient's perception of specific contextual affordance.

Hypothesis 1a: The level of specific context positively affects the level of specific contextual affordance; the higher the specific context, the higher the specific contextual affordance.

\subsubsection{Absorptive Capacity and General Contextual Affordance}

Patients' satisfaction is related to both individual characteristics of patients and institutional characteristics of healthcare organizations (Hikmet, Bhattacherjee, Menachemi, Kayhan, \& Brooks, 2008; Young, Meterko, \& Desai, 2000). In this research, these characteristics should include AC, socioeconomic status (SES), education, specialization, experience in the current position, experience in current organization, 
experience in using WeChat, etc. All these characteristics shape how an individual perceives adopts and uses WeChat. We control for aforementioned individual demographic information except for AC. We define $\mathrm{AC}$ at the individual level as the ability of an individual to identify, assimilate, and exploit knowledge. AC determines users' level of contextual affordance. We posit that:

Hypothesis 1b: The level of individual absorptive capacity positively affects the level of contextual affordance, the higher the individual absorptive capacity, the higher the contextual affordance.

\subsubsection{Technology Characteristics and General Contextual Affordance}

Based on the diffusion of innovation theory by Rogers (1983), scholars have empirically tested the significant associations among technology characteristics and IT adoptions across industries (Hsu, Lu, \& Hsu, 2007; Sin Tan et al., 2009). Relative advantage, compatibility, complexity, trialability, and observability each contribute to how an organization perceives WeChat platform, for individuals in the organization to examine the fit between organization culture and WeChat, evaluate the feasibility of implementing WeChat, and foresee the potential results of adopting WeChat. Individual patients evaluate technology characteristics, and the general contextual affordance is determined by the evaluation. We posit that:

Hypothesis 1c: The technology characteristics of a healthcare organization affect the level of contextual affordance; the higher the technology characteristics, the higher the contextual affordance. 


\subsubsection{Specific Contextual Affordance, General Contextual Affordance}

As discussed earlier, specific contextual affordance and general affordance are distinctive and affect each patient's behavior differently. Specific contextual affordance is more immediate and unstable, easy to change. The time for it to be in effect is when a patient needs to decide on whether to use the patient portal or not. When specific contextual affordance is present, the more stable and distal general contextual affordance serving as the baseline for the patient will be temporarily elasticated. Thus, the general affordance is influenced by specific contextual affordance. We further propose that specific contextual affordance is state-like and general contextual affordance is trait-like (George, 1991). Consistent with the state-trait distinction in cognitive phycology we posit that:

Hypothesis H2a: Specific contextual affordance positively affects general contextual affordance; the higher level of the specific contextual affordance, the higher level of the general contextual affordance

\subsubsection{Specific Contextual Affordance and Behavioral Affordance}

In general, how a patient perceives what a patient portal can do for them will influence how often they will use them. The more the patient can do with the patient portal, they more likely they will frequently use the portal. By definition, specific contextual affordance describes the perceived action possibilities afforded to the patient by the patient portal when a patient interacts with the patient portal. Specific contextual affordance, therefore, contributes to the subsequent behavioral affordance (e.g., what functionalities of the patient portal do the patient use and how often the patient uses those functionalities). Affordance is a bridging concept that connects other determinants such 
as Rogers' 1983 diffusion of innovation theory and the subsequent adoption behavior. Based on the above arguments, we further posit that:

Hypothesis H2b: Specific contextual affordance positively affects behavioral affordance; the higher level of the specific contextual affordance, the higher level the behavioral affordance

\subsubsection{General Contextual Affordance and Behavior Affordance}

Previously, several types of affordance were mentioned: objective affordance, subjective affordance, behavior affordance, and interactive affordance. The notion of contextual affordance is subjective by nature. When Norman (1999) articulates subjective affordance, it is the general perception of the actor on the action possibilities of the artifact. He touches upon the notion of conventions (culture) from a system design perspective and posits that when designing, a designer should rely on conventional interpretations. Contextual affordance, on the other hand, considers cultural-historical factors that shape an individual actor's perception. As a result, it directly influences how an individual behaves towards WeChat. This affordance in action, which we previously described as behavioral affordance, translates subjective affordance into subsequent actual use behaviors. We posit that

Hypothesis 3: Contextual affordance positively affects behavioral affordance; the higher the contextual affordance, the higher the behavioral affordance.

\subsubsection{Behavioral Affordances and Clinical Process Changes}

How an individual user perceives WeChat directly affects how this individual uses WeChat. Contextual affordance and behavioral affordance capture how an individual perceives and acts upon WeChat when contextual factors are taken into 
consideration. The notion of process changes perceptions, in this case, is deeply embedded in the system integration activities that can be either explorative or exploitative. Literature supports the notion that objective affordance generally positively influences outcomes (Grgecic, Holten, \& Rosenkranz, 2015). In this research, contextual affordance and behavior affordance work together iteratively and influences the extent to which the user perceives process changes regarding either with an explorative focus or exploitative focus.

Hypothesis 4a: Behavioral affordance positively affects perceived explorative clinical process changes; the higher the behavioral affordance, the higher the perceived explorative clinical process changes.

Hypothesis 4b: Behavioral affordance positively affects perceived exploitative clinical process changes; the higher the behavioral affordance, the higher the perceived exploitative clinical process changes.

\subsubsection{Clinical Process Changes and Patient Satisfaction}

Physicians bring their extensive training, professional knowledge, and valuable experience to the delivery of quality care for patients. The implementation of WeChat connects and changes the way physicians interact with the patients. Physicians' mental and physical wellbeing affects not only their ability in properly serving the patients but also the organization's ability to sustain their reputation and performance. The traditional "whatever my doctor says" mentality that patients believed in has changed as technology fast advances, and an excess amount of information becomes available to patients. It changes patients' perceptions and intentions about physicians' roles in their seeking care from medical intervention (Murray et al., 2003). New improvements, as well as conflicts, 
are deriving from these new interactions. Improved decision-making, increased efficiency, and strengthened communication channels positively influence the encounters between patients and physicians (Ball \& Lillis, 2001). Conflicts emerge more and more at the same time. Process changes are known to influence organizational performance (Burke \& Litwin, 1992). Patient satisfaction, physician satisfaction, and physician-patient relationships remain major outcome measures in the complex healthcare systems (Williams \& Skinner, 2003). This research looks at how contextual affordance, behavior affordance, clinical processes (system integration, exploitation, and exploration) relate to and influence these three outcome variables. The clinical process is a good intermediate outcome in influencing patient satisfaction (Marley, Collier, \& Meyer Goldstein, 2004). Improved clinical processes increase the effectiveness of service delivery and mitigate occurrences of medical errors. It subsequently affects patients' experiences throughout the clinical stage and overall satisfaction. The above formulations of the interaction effects make no assumption about which strategic focus has more influence on patient satisfaction, but rather the twin processes work together and jointly contribute to patient satisfaction. We posit that:

Hypothesis 5a: In a healthcare organization, social media enabled explorative clinical process changes positively affect patient satisfaction; the higher level of explorative changes, the higher patient satisfaction.

Hypothesis 5b: In a healthcare organization, social media enabled exploitative clinical process changes positively affect patient satisfaction; the higher level of exploitative changes, the higher patient satisfaction. 


\section{CHAPTER 4 . RESEARCH METHODOLOGY}

This section presents details about the context of the study, the procedures used to develop the survey items, and the procedures used for data collection.

\subsection{Scale Development}

To test our hypotheses, we adapted items from the previous research for established constructs. We developed measures for specific contexts, specific contextual affordance, general contextual affordance, and behavioral affordance. For the scale development, we first reviewed the relevant literature and extracted items based on the relevance to our study contexts. As part of a more extensive study, field visits were conducted in the early phase of this research. Field visits in the natural settings within the hospitals and community healthcare centers were essential for deepening our understanding of the research domain. The field studies included field observations and field interviews. The first field observation was completed in 2015. We visited three hospitals in Guangzhou, Zhuhai, and Shaoguan. For each hospital, we gathered the history of the hospital by closely observing the hospitals' daily operations across different departments. During the same visit, we interviewed hospital employees including physicians, nurses, administrators, and management that covered a range of issues including WeChat patient portal adoptions, usage, obstacles, history, and outlooks. All the interviews were recorded, transcribed, and translated into English by a Ph.D. student. We then extracted relevant items from the transcriptions from the interviews. These two sources were the basis for our initial item generation. After we had the initial set of items, we conducted three rounds of q-sorting and then proceeded with pilot testing. We pilot tested the survey items with subject experts and patients to ensure the items were easy to 
understand and covered the scope of our study. The final set of items used in the survey were the results of a few rounds of iterations with the subject experts and patients from the pilot testing. In the following section, we detailed the procedures for each construct.

A comprehensive literature review was conducted once the research model was finalized. For most constructs, measures validated in previous studies were adapted. For constructs unique to this research, multiple operational measures based on field interviews and literature were developed. Measures developed or adopted in this research were either reflective or formative. Details of the measures and the primary literature sources are in Appendix A and B. We used the Likert scale from 1 to 7 (1 indicates strongly disagree, seven indicates strongly agree).

Bloomfield et al. (2010) noted that affordances of technological objects cannot be reduced to their material constitution but are in inextricably bound up with specific, historically situated modes of engagement and ways of life. Consistent with this notion, we developed items that captured the contexts of patients' preferences in their healthcare processes. The items captured what the patients wanted in general, such as preferred time and location to see the doctor and the preferences of the patients based on their disease conditions. The contexts also captured patients' personal preferences and local cultural norms. We included an item about the patient's preference for large hospitals over community health centers. Many causes lead to a booming demand for healthcare, driven by a growing middle class, improved health insurance coverage and an aging population. However, there was a constant lack of public confidence in rural and community healthcare. People perceived small facilities as a sign of the low quality of care; it was safer being treated for everything from a light cold to severe emphysema despite 
government efforts to encourage patients to use smaller local hospitals. We think it was an important aspect that should be captured in this research.

For absorptive capacity, we adopted four items from previous researches (Martelo-Landroguez \& Cegarra-Navarro, 2014; Saraf, Liang, Xue, \& Hu, 2013; Volberda et al., 2010) to capture the ability of a patient to recognize, assimilate and apply new knowledge. The unit of analysis for previous instruments on absorptive capacity was mostly organizational; we thus modified the items to the individual level and our study context.

For the measurement of technology characteristics, we adapted items from widely accepted instruments (Moore \& Benbasat, 1991) on perceptions of adopting an information technology innovation based on the five innovation characteristics proposed by Rogers (1983) throughout his work on diffusion of innovation (DOI). We modified the items to fit in our study contexts. In addition to the five items, we added two more items that captured the perception of efficiency and convenience of the WeChat client.

For contextual affordance, we developed measures by using scale development procedures similar to those recommended by Churchill (1979). An illustration of the procedures can be found in Figure 4-1. There were three components in the literature review: identifying relevant literature, structuring the review, and theoretical development. For the focal concept of affordance, we searched the keywords/phrases affordance, affordance measures, affordance technology, subjective affordance, objective affordance. After initial search and review, we extended the search criteria to included other relevant theories or empirical researches such as social materialism, social media affordance in healthcare, social media healthcare, mobile health structuration, 
contextualism. We then follow the recommendations by Webster and Watson (2002) in writing a literature review, extensively classifying, clarifying, and concluding the literature on affordance. Based on the literature review, we proposed the concept of contextual affordance. There were two parts in field study: field observations and interviews. The majority of the field study was done at an early phase of this research two years ago in China. All the interviews were recorded, transcribed, and safely stored. Field observation photos and notes were safely stored.

We defined general contextual affordance as the perceived action possibilities afforded to the actor that is in general contexts by the artifact before the interactions happen. We define specific contextual affordance as the perceived action possibilities afforded to the actor that is in specific healthcare contexts by the artifact when the interactions happen. We created items for each affordance capturing patients' perceptions towards what the WeChat patient portal could do for them in two different settings; the general sense and one specific to the patient's disease type. We used four items as the behavioral affordance to capture the actual patient portal functional usages from patients.

For systems integration, the constructs covered two distinct aspects observed in organizational processes. Explicitly, in our research contexts, we incorporated internal system integration and external system integration as well as explorative and exploitative healthcare process innovations. Figure 4-2 illustrates the twin $2 \times 2$ processes we captured. We adapted items from Guthrie, Brampton, and Wyke (2000), (Guthrie, Saultz, Freeman, \& Haggerty, 2008), Uijen (2012), and Voss and Voss (2013)) for exploration versus exploitation. 


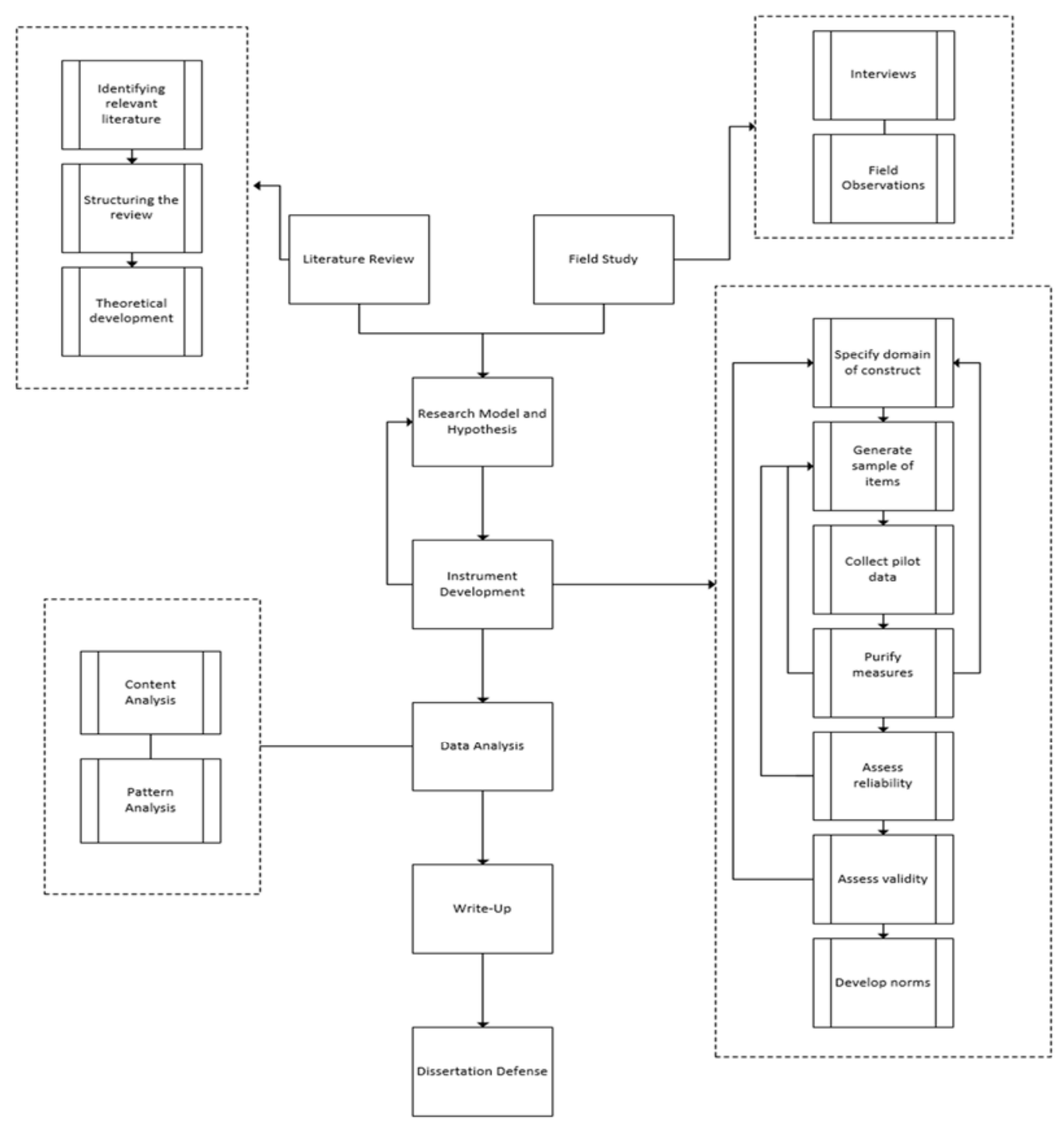

Figure 4-1: Scale Development procedure (Churchill Jr, 1979) 

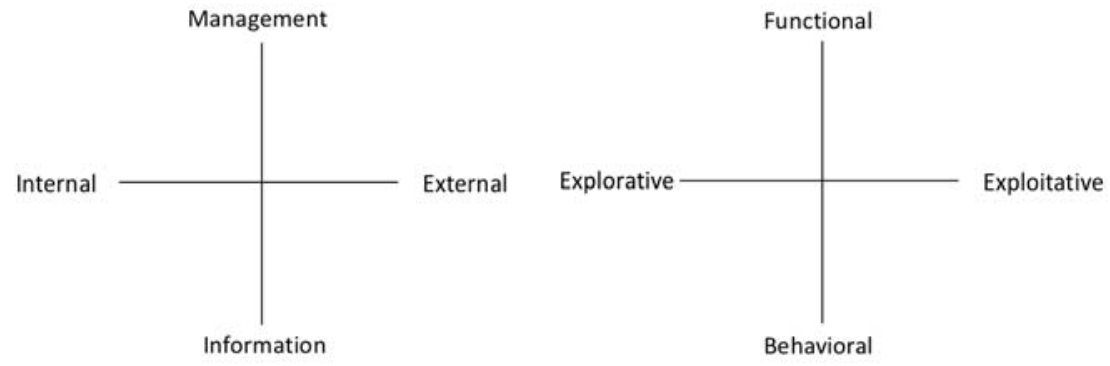

Figure 4-2: The Twin Processes

We also adopted eight items based on the eight organizational affordances observed in healthcare organizations (Strong et al., 2014). These affordances captured the process changes in association with the adaptation of information technology.

For patient satisfaction and patient-physician relationships, the main goals were to capture patients' satisfaction over time, care quality, and overall experience with the physicians in their care seeking process. The patient-physician relationship was captured by whether the physician provided enough emotional support and consideration for a patient in the care process.

Table 4-1 presents operational definitions for all constructs. For a complete list of items used for questionnaire surveys, refer to Appendix.

\begin{tabular}{|l|l|l|}
\hline Construct & Operational Definitions & Key Source(s) \\
\hline $\begin{array}{l}\text { Specific } \\
\text { Contexts }\end{array}$ & $\begin{array}{l}\text { The contextual factors related to the actor } \\
\text { (e.g., disease type, beliefs, value, norm) }\end{array}$ & $\begin{array}{l}\text { (Bloomfield et al., } \\
\text { 2010; Goel, Johnson, } \\
\text { Junglas, \& Ives, 2013) }\end{array}$ \\
\hline $\begin{array}{l}\text { Absorptive } \\
\text { Capacity }\end{array}$ & $\begin{array}{l}\text { The ability of a patient to recognize, } \\
\text { assimilate and apply new knowledge }\end{array}$ & $\begin{array}{l}\text { (Saraf et al., 2013; } \\
\text { Volberda et al., 2010) }\end{array}$ \\
\hline $\begin{array}{l}\text { Technology } \\
\text { Characteristics }\end{array}$ & $\begin{array}{l}\text { The perceived efficiencies gained by the } \\
\text { patient portal relative to current tools or } \\
\text { procedures }\end{array}$ & $\begin{array}{l}\text { (Moore \& Benbasat, } \\
\text { 1991; Rogers, 1983) }\end{array}$ \\
\hline $\begin{array}{l}\text { Specific } \\
\text { Contextual } \\
\text { Affordance }\end{array}$ & $\begin{array}{l}\text { The perceived action possibilities afforded to } \\
\text { the actor that is in specific healthcare } \\
\text { contexts by the artifact when the interactions } \\
\text { happen }\end{array}$ & $\begin{array}{l}\text { (Anderson \& Robey, } \\
\text { 2017; Strong et al., } \\
\text { 2014) }\end{array}$ \\
\hline
\end{tabular}




\begin{tabular}{|l|l|l|}
\hline $\begin{array}{l}\text { General } \\
\text { Aontextual } \\
\text { Affordance }\end{array}$ & $\begin{array}{l}\text { The perceived action possibilities afforded to } \\
\text { the actor that is in general contexts by the } \\
\text { artifact before the interactions happen }\end{array}$ & $\begin{array}{l}\text { (Anderson \& Robey, } \\
\text { 2017; Strong et al., } \\
\text { 2014) }\end{array}$ \\
\hline $\begin{array}{l}\text { Behavioral } \\
\text { Affordance }\end{array}$ & $\begin{array}{l}\text { To what extent the action possibilities } \\
\text { afforded to the actor are realized (e.g., the } \\
\text { actual usage of functions) }\end{array}$ & $\begin{array}{l}\text { (Anderson \& Robey, } \\
\text { 2017) }\end{array}$ \\
\hline $\begin{array}{l}\text { System } \\
\text { Integration }\end{array}$ & $\begin{array}{l}\text { To what extent, patients' perception of the } \\
\text { system supporting horizontal processes } \\
\text { within a healthcare organization regarding } \\
\text { both workflow and information flow }\end{array}$ & (Guthrie et al., 2008) \\
\hline $\begin{array}{l}\text { Exploration } \\
\text { versus } \\
\text { Exploitation }\end{array}$ & $\begin{array}{l}\text { To what extent the processes are disruptive } \\
\text { and provide new alternatives based on new } \\
\text { knowledge and skill that ultimately can } \\
\text { replace current processes } \\
\text { To what extent the processes are incremental } \\
\text { and provide refinements based on what is } \\
\text { already known that considered to be an } \\
\text { alternative }\end{array}$ & (March 1991) \\
\hline $\begin{array}{l}\text { To what extend patients are satisfied with } \\
\text { their experiences in the hospitals }\end{array}$ & (Kane, Maciejewski, \\
Satisfaction \\
\hline $\begin{array}{l}\text { Patient- } \\
\text { Physician } \\
\text { Relationship }\end{array}$ & $\begin{array}{l}\text { To what extend the doctors know the patient } \\
\text { Patient }\end{array}$ & (Elwyn et al., 2013) \\
\hline
\end{tabular}

Table 4-1: Definition of Constructs

We conducted three rounds of q-sorting, and the items were pre-tested before being used. According to pre-test results, we dropped the items that were difficult to understand, and we modified the wording to some of the original items. The survey was also tested with numerous domain experts to ensure the content validity of the survey. We made changes accordingly.

\subsection{Sample Selection and Data Collection}

This study was conducted in China in hospitals A, B, C, and D. All hospitals were ranked at tire 3 (large hospital with 500 and more beds). They were public leading large urban hospitals that were perceived to be the best in its region. Two of the four hospitals were university-affiliated. All hospitals had implemented a WeChat based patient portal 
by the time data collected. The data collected for this study were part of a larger data collection effort aimed at examining the dyadic relationship between physician, patient and their perceptions on the contextual affordance of social media enabled platforms.

To obtain sufficient samples to test our hypothesis, we collected at least 200 complete surveys from the patients going to the community health centers and 400 from tier 3 hospitals across different provinces, cities, and districts in Southern China. We used both the paper-based survey and electronic survey that was set up for an iPad. For the paper-based survey, we printed, distributed and filed them on site at the end of each day.

For the electronic survey, the patient used iPads to fill out the surveys, and they were securely stored and sent back to the researcher. Due to the availability of the physicians, time differences and the geographic distance we collected matched data. The data collection was done in three phases in six months. In the first phase of fieldwork, monthlong interview sessions in which hospital management and selected physicians shared information about WeChat related implementation and discussed the feasibility of collecting dyadic data. In the second phase of fieldwork, the initial pilot testing among physicians and patients was conducted. We observed extreme difficulty in collecting a significant amount of completed surveys due to the length of the surveys and the nature of tier 3 hospital (patients from all over the country spending days at the hospital to get treated). We shortened the survey so that it was taken in approximately 15 minutes. In the third phase of fieldwork, we had several research teams that consisted of medical students and medical residents in each hospital to collect the data. Each member of the research team had at least one hour of training by the researcher before data collection to ensure 
adherence to local law, patient privacy, and research integrity. The primary researcher supervised all research teams.

We deemed that convenience sampling was the best way to obtain survey responses. Convenience sampling is a type of nonprobability sampling in which people are sampled because they are easy to find (Lavrakas, 2008). Considering the traffic in community health centers and large hospitals, we deemed this was the most appropriate method. Unlike probability sampling methods, convenience sampling does not require random samples, and the only criterion is whether the participants agree to participate. As a result, there was a possibility of sampling error and lack of representation. To mitigate the potential sampling error, we carefully considered positions, age groups, and units/specialties for physicians to best achieve the representation of comprehensive demographic characteristics. Target respondents were hospital physicians and their patients. Small gifts were given to the participants who completed the survey questionnaire as incentives and tokens for appreciation. These gifts were not used to encourage anyone to participate in this research unwillingly but were deemed to be appropriate in the Chinese culture. Only volunteer respondents were recruited.

Research sites included at least ten community health centers and four tier 3 hospitals. As of 2011, there were 32,812 community health centers (CHCs) and 37,374 township health centers (National Bureau of Statistics of China, 2012). The CHCs in China are facing many problems in delivering their services, attributable to the different speeds of development among centers, lack of resources, and imbalance in the sizes of CHCs, making it difficult for them to meet citizens' needs. Nevertheless, the CHCs were considered the central primary institutions for offering essential medical and public 
health services. They were regarded as the primary networks for medical treatment and public health surveillance (Pan, Dib, Wang, \& Zhang, 2006). The research found that the CHCs were not able to fulfill their designated mission because of the limited diagnostic capacity and poor competency of the primary care practitioners (Zhou et al., 2013). For tier 3 hospitals, research Site A was a growing teaching hospital with thirty-nine clinical units, over 800 patient beds and an outpatient annual volume at 410, 000. Research site B and $\mathrm{C}$ were research and teaching hospitals in southwest China that had a history of over 137 years. Site B had over 2,200 employees and over 1450 patient beds with 11 national ranked specialty units. Site C had 2327 employees and over 1450 patient beds with eight state-recognized specialty units and ten city-recognized specialty units treating over one million patients annually. Research site D was built in 1914 with over 8,000 employees and 4,300 patient beds. Site $\mathrm{D}$ was recognized as one of the most prominent research/teaching hospitals in the country treating over five million patients annually. Their daily outpatient volume was actively around 20,000 patients.

All research sites recently incorporated WeChat based patient portal. We observed WeChat patient portal marketing campaigns and advertisements across different facilities. For a patient to enroll in the patient portal, the patient needed to scan the QR code or search the hospital/community health centers' username and subscribe to their public accounts. All accounts were identified with the patients' phone numbers and other registration information. Once the patient was registered, he/she could access specific functions through the patient portal.

The initial items were developed in English and translated into Chinese by Ph.D. students with domain knowledge and native Chinese skills. To ensure the validity of the 
translation, they were translated back into English by two other Ph.D. students with native Chinese skills. We compared the two Chinese to English versions to the original English version to make sure they were translated correctly. By this triangulation method, the validity of the survey translation was met. There was a researcher on each site to ensure a smooth data collection process as well as a secured data management environment once a survey was filed.

After the survey data collection, we conducted data refining procedures based on three criteria: completeness, consistency, and uniformity. A survey sample that had more than one-third blank answers were considered incomplete. We took out the incomplete survey samples. A survey sample that had a clear pattern of misrepresentation were considered inconsistent. For example, in a survey, one-third of the answers were the same number. We took out the inconsistent survey samples. For uniformity purposes, we unified the unit of some questions. We converted minutes into hours. After these data refining procedures, there was a total of 352 patient survey responses out of the 450 surveys sent out. The survey response rate was $78.2 \%$. For demographic information, we observed some missing values. Average daily time spent on WeChat had the most substantial amount of missing value at $27(8.4 \%)$ of the total sample of 352 . For other categories, the missing value percentages were at $2.6 \%, 2.8 \%, 3.8 \%, 6.6 \%$ for the purpose for visiting, sex, education, and year started using WeChat.

$36.1 \%$ of the respondents answered others are accompanying in the survey process. In the Chinese culture, it is common for the family to go with the patient, help and be there for their entire care seeking processes. We observed the same number of 
first-time patients and patients at the hospital for follow-up at 28.4\%. Table 4-2 illustrates the results of frequency analysis.

\begin{tabular}{|c|c|c|c|}
\hline \multicolumn{4}{|c|}{ Purpose for visiting } \\
\hline & Frequency & Percentage & Cumulative Percentage \\
\hline Frist timer & 100 & 28.4 & 28.4 \\
\hline Follow up & 100 & 28.4 & 56.8 \\
\hline Accompany & 127 & 36.1 & 92.9 \\
\hline Not specified & 16 & 4.5 & 97.4 \\
\hline Missing & 9 & 2.6 & 100 \\
\hline Total & 352 & 100 & \\
\hline
\end{tabular}

Table 4-2: Frequency for Purpose for Visiting

In the sex category, there was $52.3 \%$ male and $44.9 \%$ female. We observed a moderately even sample for both sexes, which indicated that we covered both gender types evenly. Table 4-3 illustrates the results of frequency analysis.

\begin{tabular}{|c|c|c|c|}
\hline \multicolumn{5}{|c|}{ Sex } \\
\hline & Frequency & Percentage & Cumulative Percentage \\
\hline Male & 158 & 52.3 & 52.3 \\
\hline Female & 184 & 44.9 & 97.2 \\
\hline Missing & 10 & 2.8 & 100 \\
\hline Total & 352 & 100 & \\
\hline
\end{tabular}

Table 4-3: Frequency of sex

In the education category, a small percentage $(0.9 \%)$ reported having a doctoral degree, $7.1 \%$ of respondents reported having a graduate degree, and $30.7 \%$ had a bachelor's degree. $22.2 \%$ of respondents reported having either a degree from a technical college or vocational school. $24.5 \%$ of respondents reported having a high school degree, and $10.5 \%$ of respondents reported finishing primary school. Table $4-4$ illustrates the results of frequency analysis. 


\begin{tabular}{|c|c|c|c|}
\hline \multicolumn{4}{|c|}{ Education } \\
\hline & Frequency & Percentage & Cumulative Percentage \\
\hline Doctoral & 3 & .9 & .9 \\
\hline Graduate & 25 & 7.1 & 8 \\
\hline Bachelor & 108 & 30.7 & 38.7 \\
\hline Technical College & 59 & 16.8 & 55.5 \\
\hline Vocational & 20 & 5.7 & 61.2 \\
\hline Senior High & 58 & 16.5 & 77.7 \\
\hline Junior High & 28 & 8 & 85.7 \\
\hline Primary School & 37 & 10.5 & 96.2 \\
\hline Missing & 14 & 3.8 & 100 \\
\hline Total & 352 & 100 & \\
\hline
\end{tabular}

Table 4-4: Frequency for Education

Out of all respondents, 47.7\% reported first using WeChat between the year 2011 and 2014 while 32.7\% reported first using WeChat in between the year 2015 and 2018 . $13 \%$ of respondents either could not recall or decided not to disclose this information. Table 4-5 illustrates the results of frequency analysis.

\begin{tabular}{|c|c|c|c|}
\hline \multicolumn{4}{|c|}{ The year started using WeChat (year) } \\
\hline & Frequency & Percentage & Cumulative Percentage \\
\hline $2011-2014$ & 168 & 47.7 & 47.7 \\
\hline $2015-2018$ & 115 & 32.7 & 80.4 \\
\hline Not specified & 46 & 13 & 93.4 \\
\hline Missing & 23 & 6.6 & 100 \\
\hline Total & 352 & 100 & \\
\hline
\end{tabular}

Table 4-5: Frequency for Purpose for Year Started Using WeChat

Lastly, $13 \%$ of respondents reported using WeChat under one hour each day. However, we observed the majority of respondents used WeChat for 2-4 hours a day (33.5\%) following by 5-9 hours a day (29\%). There was $10 \%$ of respondents reported using WeChat more than 10 hours a day. Table 4-6 illustrates the results of frequency analysis. 


\begin{tabular}{|c|c|c|c|}
\hline \multicolumn{4}{|c|}{ Average daily time spent on WeChat (hours) } \\
\hline & Frequency & Percentage & Cumulative Percentage \\
\hline $0-1$ & 46 & 13 & 13 \\
\hline $2-4$ & 118 & 33.5 & 46.5 \\
\hline $5-9$ & 102 & 29 & 75.5 \\
\hline$>10$ & 38 & 10.1 & 85.6 \\
\hline Not sure & 21 & 6 & 91.6 \\
\hline Missing & 27 & 8.4 & 100 \\
\hline Total & 352 & 100 & \\
\hline
\end{tabular}

Table 4-6: Frequency for Average Time Spent on WeChat

\subsection{Testing for Common Method Bias}

Common method bias (CMB) happens when variations in responses are caused by the instruments rather than the actual respondents' attitudes the instruments attempt to uncover. If the instruments introduced a bias, then the variances we observed from the samples could have been contaminated by the 'noise' stemmed from the biased instruments.

Podsakoff, MacKenzie, Lee, and Podsakoff (2003) provided us with many insights in their article and served as one of the most cited papers on common method biases in behavioral research. They mentioned that Harman's single-factor test was one of the most widely used techniques that had been used by researchers to address the issue of a conventional method. Conventionally, researchers using this technique used all of the variables in their study for exploratory factor analysis and examined the unrotated factor solution to determine the number of factors that were necessary to account for the variance in the variables. The underlying assumption of this technique was that if a substantial amount of common method was is present, either (a) a single factor would emerge from the factor analysis or (b) one general factor would account for the majority 
of the covariance among the measures. More recently, some researchers used this technique.

The recommended procedure produced two tables (see appendix 8-D and 8-E): total variance explained and component matrix. The most significant single factor accounted for $32.79 \%$ of the total $69.8 \%$ variance explained which was well below $50 \%$. The CMB was not an issue in this research. 


\section{CHAPTER 5 . DATA ANALYSIS}

This study used structural equation modeling (SEM), specifically Partial Least Square (PLS) path modeling. PLS was chosen over other SEM modeling methods because the goal was predicting key target constructs patient satisfaction and patientphysician relationships and identifying essential driver constructs technology characteristics, contexts, mediation effects through affordances, and processes change. There were multiple formative constructs mixed with reflective constructs as part of the structural model. The structural model was complex with many constructs and indicators. Lastly, in the process of data collection, we collected as many samples as we could. However, compared to the number of indicators in the model, the sample size was relatively small (Hair Jr, Hult, Ringle, \& Sarstedt, 2016).

There were two stages in data analysis: (1) the measurement model in which the reliability and validity of the measurements were tested, and (2) the structural model in which the hypotheses were tested. Partial least square (PLS) was utilized to accommodate the exploratory nature of the research model using SmartPLS.

\subsection{Descriptive Statistics}

There was a total of 352 patient survey responses. The number of missing values, mean median, minimum and maximum value for each indicator and the standard deviation for each indicator are listed in Table 5-1. 


\begin{tabular}{|c|c|c|c|c|c|c|}
\hline & Missing & Mean & Median & Min & Max & SD \\
\hline sc1 & 13.00 & 4.27 & 4.00 & 1.00 & 7.00 & 1.78 \\
\hline sc2 & 2.00 & 4.60 & 5.00 & 1.00 & 7.00 & 1.70 \\
\hline sc3 & 6.00 & 4.40 & 4.00 & 1.00 & 7.00 & 1.64 \\
\hline sc4 & 6.00 & 5.00 & 5.00 & 1.00 & 7.00 & 1.67 \\
\hline tc1 & 3.00 & 5.03 & 5.00 & 1.00 & 7.00 & 1.63 \\
\hline tc2 & 2.00 & 5.13 & 5.00 & 1.00 & 7.00 & 1.61 \\
\hline tc3 & 2.00 & 5.07 & 5.00 & 1.00 & 7.00 & 1.67 \\
\hline tc4 & 3.00 & 4.58 & 5.00 & 1.00 & 7.00 & 1.71 \\
\hline tc5 & 1.00 & 4.88 & 5.00 & 1.00 & 7.00 & 1.72 \\
\hline tc6 & 6.00 & 4.85 & 5.00 & 1.00 & 7.00 & 1.70 \\
\hline tc7 & 2.00 & 5.15 & 5.00 & 1.00 & 7.00 & 1.64 \\
\hline gc1 & 4.00 & 5.25 & 6.00 & 1.00 & 7.00 & 1.76 \\
\hline gc2 & 6.00 & 5.38 & 6.00 & 1.00 & 7.00 & 1.65 \\
\hline gc3 & 2.00 & 5.03 & 5.00 & 1.00 & 7.00 & 1.76 \\
\hline gc4 & 6.00 & 5.23 & 6.00 & 1.00 & 7.00 & 1.66 \\
\hline sca1 & 9.00 & 4.29 & 4.00 & 1.00 & 7.00 & 1.78 \\
\hline sca2 & 4.00 & 4.83 & 5.00 & 1.00 & 7.00 & 1.78 \\
\hline sca3 & 1.00 & 4.82 & 5.00 & 1.00 & 7.00 & 1.75 \\
\hline sca4 & 2.00 & 4.90 & 5.00 & 1.00 & 7.00 & 1.72 \\
\hline ac1 & 2.00 & 4.23 & 4.00 & 1.00 & 7.00 & 1.84 \\
\hline ac2 & 2.00 & 4.32 & 4.00 & 1.00 & 7.00 & 1.84 \\
\hline ac3 & 2.00 & 4.54 & 5.00 & 1.00 & 7.00 & 1.79 \\
\hline ac4 & 2.00 & 4.65 & 5.00 & 1.00 & 7.00 & 1.78 \\
\hline ba1 & 2.00 & 4.32 & 4.00 & 1.00 & 7.00 & 1.94 \\
\hline ba2 & 2.00 & 4.26 & 4.00 & 1.00 & 7.00 & 1.94 \\
\hline ba3 & 4.00 & 4.10 & 4.00 & 1.00 & 7.00 & 1.87 \\
\hline ba4 & 4.00 & 3.86 & 4.00 & 1.00 & 7.00 & 1.89 \\
\hline exp1 & 7.00 & 4.59 & 5.00 & 1.00 & 7.00 & 1.65 \\
\hline exp2 & 9.00 & 4.52 & 5.00 & 1.00 & 7.00 & 1.66 \\
\hline exp3 & 8.00 & 4.63 & 5.00 & 1.00 & 7.00 & 1.62 \\
\hline exp4 & 8.00 & 4.51 & 5.00 & 1.00 & 7.00 & 1.66 \\
\hline exp5 & 10.00 & 4.56 & 5.00 & 1.00 & 7.00 & 1.68 \\
\hline exo1 & 9.00 & 4.30 & 4.00 & 1.00 & 7.00 & 1.74 \\
\hline exo2 & 13.00 & 4.38 & 4.00 & 1.00 & 7.00 & 1.70 \\
\hline exo3 & 12.00 & 4.48 & 5.00 & 1.00 & 7.00 & 1.66 \\
\hline exo4 & 8.00 & 4.60 & 5.00 & 1.00 & 7.00 & 1.74 \\
\hline sat1 & 7.00 & 4.70 & 5.00 & 1.00 & 7.00 & 1.53 \\
\hline
\end{tabular}




\begin{tabular}{|c|c|c|c|c|c|c|} 
sat2 & 7.00 & 4.55 & 5.00 & 1.00 & 7.00 & 1.59 \\
\hline sat3 & 10.00 & 4.61 & 5.00 & 1.00 & 7.00 & 1.57 \\
\hline sat4 & 11.00 & 4.90 & 5.00 & 1.00 & 7.00 & 1.43 \\
\hline
\end{tabular}

Table 5-1: Descriptive Statistics

\subsection{Measurement Model}

The goal of the measurement model was to access the validity and adequacy of the measurement scales. We conducted a series of procedures to validate our measurement model. For both adopted and developed contextual affordance measure, we conducted factor analysis and confirmed convergent validity by examining both the average variance extracted (AVE) and indicator loadings. Satisfactory AVE values should be higher than 0.5 (Fornell \& Larcker, 1981). We used a composite reliability index to assess the reliability and $\chi^{2}$ difference test to assess discriminant validity. (Alternatively, we also compared the square root of the AVE for each construct with the correlation between the construct and other constructs. Ideally, the square root of the AVE should be larger than the correlations between constructs.) (Barclay, Higgins, \& Thompson, 1995). For contextual affordance, we chose the best measurement model that represented the construct. All the tests assumed that all the items developed were reflective measures. For formative measures, separate tests (VIF, confirmatory Tetrad Analysis) that were relevant for validating formative constructs were performed in addition to procedures mentioned previously.

\subsubsection{Determination of formative and reflective constructs}

In the SEM literature, two different measurement models using multiple indicators of latent constructs have been mentioned: the principal factor model (reflective model) and the composite latent variable (formative model) model (Jarvis, MacKenzie, \& 
Podsakoff, 2003). In their assessment, there are four main differences between these two types of measurement models: 1) The direction of causality. For the reflective model, the direction of causality was from construct to measures. For the formative model, the direction of causality went from measure to the construct. 2) The correlation among the measures. For the reflective model, the measures were expected to be correlated and should have possessed internal consistency reliability. For the formative model, there were no expectations that the measures were correlated where an indicator should be dropped. 3) In the reflective model, dropping an indicator from the measurement model did change the meaning of the construct, whereas for a formative model, dropping an indicator from the measurement model changed the meaning of the construct. 4) Measurement error. A reflective model took measurement error into account at the indicator level, while the formative model took measurement error into account at the construct level.

Following the recommendations by Jarvis et al. (2003) for this study, specific contexts, specific contextual affordance, general contextual affordance, and behavioral affordance were specified as formative constructs whereas absorptive capacity, technology characteristics, system integration, exploration and exploitation, patient satisfaction were reflective constructs.

\subsubsection{Reflective Measurement Model Assessment - Reliability}

The reflective model has long been used in the social sciences and is directly based on classical test theory (Hair Jr et al., 2016). Cronbach's alpha was developed by Cronbach in 1951 to provide a measure of the internal consistency of a test or scale. Cronbach's alpha is expressed as a number between 0 and 1 , where a higher value 
indicates higher levels of reliability for the measurement. A generally accepted value is .70 (Hair et al., 2016). Internal consistency describes the extent to which all the items in a test measure the same concept or construct and are connected to the inter-relatedness of the items within the test (Tavakol \& Dennick, 2011). Cronbach's alpha is the most widely used (Hair et al., 2016) and provides an estimate of the reliability based on the inter-correlations of observed indicator variables. A low value indicates the items may be heterogeneous and thus the total scale is not the best way to represent the intended construct.

\begin{tabular}{|c|c|c|c|c|}
\hline & $\begin{array}{l}\text { Cronbach's } \\
\text { Alpha }\end{array}$ & rho A & $\begin{array}{l}\text { Composite } \\
\text { Reliability }\end{array}$ & $\begin{array}{l}\text { Average Variance } \\
\text { Extracted (AVE) }\end{array}$ \\
\hline $\mathrm{AbCa}$ & 0.884 & 0.893 & 0.921 & 0.744 \\
\hline Exploitation & 0.88 & 0.881 & 0.924 & 0.754 \\
\hline Exploration & 0.886 & 0.887 & 0.927 & 0.762 \\
\hline Sat & 0.82 & 0.82 & 0.889 & 0.667 \\
\hline TechCh & 0.902 & 0.904 & 0.923 & 0.631 \\
\hline
\end{tabular}

Table 5-2: Reliability for Reflective Constructs

The Cronbach's alphas for all reflective constructs were satisfactory. The absorptive capacity subscale consisted of 4 items $(\alpha=.88)$. The technology characteristics subscale consisted of 7 items $(\alpha=.90)$. The exploration construct subscale consisted of 4 items $(\alpha=.89)$. The exploitation construct subscale consisted of 4 items ( $\alpha$ $=.88)$, and finally, the satisfaction constructs consisted of 4 items $(\alpha=.82)$. Overall, all reflective constructs demonstrated high reliability. In addition to Cronbach's alpha, Rho_A coefficient and Fronell and Larcker's (1981) composite reliability (CR) for all the reflective constructs were also found to be highly reliable (rho_A $>.7, \mathrm{CR}>.7$ ). In some 
cases, CR was preferred over Cronbach's alpha because CR offered a better estimate of variance shared by the respective indicators and it used the item loadings obtained within the nomological network (Hair et al., 2006). In either case, the results for reliability for the reflective constructs were satisfactory in this study. Table 5-2 provides an overview of reliability for reflective constructs.

\subsubsection{Reflective Measurement Model Assessment - Convergent validity}

Convergent validity refers to the degree of agreement in two or more measures of the same construct. Evidence of convergent validity was assessed by inspection of Average Variance Extracted (AVE). AVE represents the ratio of the total variance that was due to the latent variable. AVE varied from 0 to 1 . An AVE of 0.5 or more indicated satisfactory convergent validity, as the latent construct on average accounts for $50 \%$ or more of the variance in the observed variables (Fornell \& Larcker, 1981). In addition to AVE, outer loadings were used to assess convergent validity. Indicators from the same construct should have higher loadings on the same construct. The standardized outer loadings should be .5 or higher, and ideally, .7 or higher (Hair, 2010) to establish convergent validity. All indicators in the two reflective constructs met these criteria. Results indicated that the AVE for all reflective constructs ranged from .63 to .76. All outer loadings were .7 or higher. These results show that the scales used for absorptive capacity, the technology characteristics, the exploration, the exploitation, and the satisfaction constructs possessed convergent validity. Table 5-3 illustrates an overview of convergent validity assessment. 


\begin{tabular}{|c|c|c|c|c|c|}
\hline & $\mathrm{AbsCa}$ & TechCh & Explor & Exploi & Sat \\
\hline ac1 & 0.83 & & & & \\
\hline $\mathrm{ac} 2$ & 0.87 & & & & \\
\hline ac3 & 0.89 & & & & \\
\hline ac4 & 0.85 & & & & \\
\hline tc 1 & & 0.77 & & & \\
\hline tc 2 & & 0.81 & & & \\
\hline tc 3 & & 0.76 & & & \\
\hline tc 4 & & 0.77 & & & \\
\hline tc 5 & & 0.83 & & & \\
\hline tc 6 & & 0.78 & & & \\
\hline tc 7 & & 0.80 & & & \\
\hline ex1 & & & 0.85 & & \\
\hline ex2 & & & 0.88 & & \\
\hline ex3 & & & 0.88 & & \\
\hline ex4 & & & 0.84 & & \\
\hline ep1 & & & & 0.83 & \\
\hline ep2 & & & & 0.88 & \\
\hline ep3 & & & & 0.85 & \\
\hline ep4 & & & & 0.85 & \\
\hline sa1 & & & & & 0.77 \\
\hline $\mathrm{sa} 2$ & & & & & 0.86 \\
\hline sa3 & & & & & 0.84 \\
\hline sa4 & & & & & 0.75 \\
\hline
\end{tabular}

Table 5-3: Convergent Validity Assessment

\subsubsection{Reflective Measurement Model Assessment - Discriminate validity}

Discriminate validity is the degree to which any single construct is distinctive from the other constructs in the model (Carmines \& Zeller, 1979). Discriminant validity was assessed by the test provided by Fornell and Larcker (1981) in which the pair-wise correlations between factors obtained were compared with the variance extracted estimates for the constructs making up each possible pair. The discriminate validity is adequate when constructs have an AVE loading greater than 0.5 , meaning that at least 
$50 \%$ of measurement variance was captured by the construct (Chin, 1998). Also, discriminate validity is confirmed if the diagonal elements are significantly higher than the off-diagonal values in the corresponding rows and columns. The diagonal elements are the square root of the AVE score for each construct. Our results demonstrated the reflective constructs possessed discriminate validity. Table 5-4 summarizes AVE for the reflective constructs.

\begin{tabular}{|c|c|c|c|c|c|}
\hline & AbsCa & Exploi & Explor & Sat & TechCh \\
\hline AbsCa & 0.86 & & & & \\
\hline Exploi & 0.45 & 0.87 & & & \\
\hline Explor & 0.37 & 0.72 & 0.87 & & \\
\hline Sat & 0.30 & 0.55 & 0.50 & 0.82 & \\
\hline TechCh & 0.50 & 0.38 & 0.42 & 0.29 & 0.79 \\
\hline
\end{tabular}

Table 5-4: Discriminate Validity (AVE)

Examination of the cross-loadings shows that all indicators load high on their respective constructs and relatively low on other constructs in the model. The results of cross-loadings confirmed the results of Fornell and Larcker's criterion. Table 5-5 illustrates the cross-loadings of the items.

\begin{tabular}{|c|c|c|c|c|c|}
\hline & AbsCa & TechCh & Exploration & Exploitation & Sat \\
\hline ac1 & $\mathbf{0 . 8 3}$ & 0.38 & 0.33 & 0.39 & 0.26 \\
\hline ac2 & $\mathbf{0 . 8 8}$ & 0.37 & 0.33 & 0.40 & 0.28 \\
\hline ac3 & $\mathbf{0 . 8 9}$ & 0.45 & 0.31 & 0.36 & 0.22 \\
\hline ac4 & $\mathbf{0 . 8 5}$ & 0.52 & 0.32 & 0.39 & 0.28 \\
\hline tc1 & 0.31 & $\mathbf{0 . 7 8}$ & 0.28 & 0.21 & 0.17 \\
\hline tc2 & 0.37 & $\mathbf{0 . 8 2}$ & 0.30 & 0.23 & 0.15 \\
\hline tc3 & 0.37 & $\mathbf{0 . 7 7}$ & 0.32 & 0.25 & 0.22 \\
\hline tc4 & 0.45 & $\mathbf{0 . 7 8}$ & 0.36 & 0.39 & 0.30 \\
\hline tc5 & 0.42 & $\mathbf{0 . 8 4}$ & 0.36 & 0.36 & 0.26 \\
\hline tc6 & 0.45 & $\mathbf{0 . 7 9}$ & 0.35 & 0.32 & 0.22 \\
\hline tc7 & 0.44 & $\mathbf{0 . 8 0}$ & 0.36 & 0.31 & 0.26 \\
\hline
\end{tabular}




\begin{tabular}{|l|l|l|l|l|l|} 
ex1 & 0.30 & 0.39 & $\mathbf{0 . 8 6}$ & 0.63 & 0.44 \\
\hline ex2 & 0.31 & 0.39 & $\mathbf{0 . 8 9}$ & 0.59 & 0.45 \\
\hline ex3 & 0.31 & 0.36 & $\mathbf{0 . 8 9}$ & 0.64 & 0.41 \\
\hline ex4 & 0.38 & 0.33 & $\mathbf{0 . 8 5}$ & 0.64 & 0.43 \\
\hline ep1 & 0.37 & 0.29 & 0.64 & $\mathbf{0 . 8 5}$ & 0.48 \\
\hline ep2 & 0.42 & 0.33 & 0.61 & $\mathbf{0 . 8 9}$ & 0.48 \\
\hline ep3 & 0.37 & 0.36 & 0.63 & $\mathbf{0 . 8 7}$ & 0.44 \\
\hline ep4 & 0.38 & 0.32 & 0.61 & $\mathbf{0 . 8 7}$ & 0.50 \\
\hline sa1 & 0.26 & 0.25 & 0.42 & 0.42 & $\mathbf{0 . 7 8}$ \\
\hline sa2 & 0.25 & 0.19 & 0.35 & 0.46 & $\mathbf{0 . 8 7}$ \\
\hline sa3 & 0.17 & 0.16 & 0.38 & 0.46 & $\mathbf{0 . 8 5}$ \\
\hline sa4 & 0.30 & 0.34 & 0.46 & 0.46 & $\mathbf{0 . 7 6}$ \\
\hline
\end{tabular}

Table 5-5: Cross-loadings

Heterotrait-monotrait (HTMT) ratio of correlations is a new criterion for assessment of discriminant validity in variance-based structural equation modeling proposed by Henseler, Ringle, \& Sarstedt (2015). They critiqued using Fornell Larcker criterion. The examination of cross-loadings sometimes did not reliably detect the lack of discriminant validity in everyday research situations as they seemed to have an unacceptable low sensitivity regarding assessing discriminant validity (Henseler et al., 2015). The HTMT approach was an estimate of the correlation between the constructs. If the indicators of two constructs exhibit an HTMT value that is smaller than one, the true correlation between the constructs is the most likely different from one, and they should differ. We noted that SmartPLS's equation in calculating HTMT was slightly different from what was being proposed by Henseler et al. (2015). Instead of using the correlations between indicators, SmartPLS used the absolute value of the correlation between indicators. There have been some debates about what exactly the threshold should be for HTMT value. However, it is generally accepted that the HTMT value should be 
below .85 (Kline, 2015) or .9 (Teo, Srivastava, \& Jiang, 2008). The following table provides the results for HTMT assessment. The HTMT values for all reflective constructs are well below the cutoff point of .85. The HTMT test confirmed the results from Fornell Larcker and examination of cross-loadings. The discriminant validity for all reflective constructs was established. Table 5-6 summarizes the HTMT values for reflective constructs.

\begin{tabular}{|c|c|c|c|c|c|}
\hline & AbsCa & Exploitation & Exploration & Sat & TechCh \\
\hline AbsCa & & & & & \\
\hline Exploitation & 0.51 & & & & \\
\hline Exploration & 0.43 & 0.81 & & & \\
\hline Sat & 0.36 & 0.65 & 0.58 & & \\
\hline TechCh & 0.56 & 0.43 & 0.47 & 0.33 & \\
\hline
\end{tabular}

Table 5-6: HTMT Values for Reflective Constructs

\subsubsection{Formative Measurement Model Assessment - Content Validity}

The assessment for formative constructs is different from reflective constructs.

Formative indicators do not need to have high internal consistency. Diamantopoulos and Winklhofer (2001) proposed four critical issues in the formative constructs: content specification, indicator specification, indicator collinearity and external validity. Under a formative measurement, the latent variable is determined by its indicators rather than vice versa. Thus, to establish content validity of the formative construct, breadth of definition is important to causal indicators. It is imperative to ensure that the indicators developed for a formative construct have captured the intended scope of the latent variable.

Because contextualized affordance is a novel concept, there has not been much literature existing for us to utilize. However, we extensively reviewed the available 
literature to gain as much insight as we could for the latent variable. Subject matter experts' interviews and iterative measure developments were used to confirm the content validity. During the interviewing phase, we asked them about the WeChat patient portal functionalities, usage, implementation including difficulties in implementing the portal, results of adoption and their opinions on why some people were using it some were not. We collected the feedback and decided on a set of functionalities to include in the survey items. We then incorporated context factors and differentiated general and specific context according to the interviews. During the pilot testing phase, we collected feedback from subject experts and modified the measurement accordingly. The subject area experts were asked their opinions on the content validity of the survey items. The subject area experts confirmed the final set of items, and content validity was established.

\subsubsection{Formative Measurement Model Assessment - Collinearity}

Multi-collinearity is an issue particular to formative indicators (Diamantopoulos \& Winklhofer, 2001) because the formative measurement model is based on multiple regression, hence the stability of the indicator coefficients are affected by the sample size and the strength of the indicator intercorrelations. Extreme collinearity among the indicators makes it difficult to separate the distinct variance of the latent variable explained by an indicator. The VIF value should be higher than .20. Different values for the upper bond have been used. However, in our tests, each indicator's tolerance (VIF) value was far below the common cut-off threshold of 10 (Diamantopoulos \& Winklhofer, 2001). The multi-collinearity was not an issue in our formative constructs. Table 5-7 illustrates the VIF value for each indicator. 


\begin{tabular}{|c|c|}
\hline & VIF \\
\hline $\mathrm{sc} 1$ & 1.25 \\
\hline $\mathrm{sc} 2$ & 1.29 \\
\hline $\mathrm{sc} 3$ & 1.06 \\
\hline $\mathrm{sc} 4$ & 1.09 \\
\hline $\mathrm{sca} 1$ & 1.35 \\
\hline $\mathrm{sca} 2$ & 2.04 \\
\hline $\mathrm{sca} 3$ & 3.29 \\
\hline $\mathrm{sca} 4$ & 2.82 \\
\hline $\mathrm{gc} 1$ & 2.29 \\
\hline $\mathrm{gc} 2$ & 2.53 \\
\hline $\mathrm{gc} 3$ & 1.67 \\
\hline $\mathrm{gc} 4$ & 1.64 \\
\hline $\mathrm{ba} 1$ & 2.20 \\
\hline $\mathrm{ba} 2$ & 3.18 \\
\hline $\mathrm{ba} 3$ & 2.99 \\
\hline $\mathrm{ba} 4$ & 2.02 \\
\hline
\end{tabular}

Table 5-7: VIF Values for Formative Constructs

The outer weight of an indicator was used to measure the contribution of the indicator to a construct with the latent variable scores as the dependent variable and formative indicators as the independent variable in a multiple regression analysis. The values of outer weight express each indicators' relative contribution to the construct. The outer weight of the formative indicators is listed in Table 5-8. We observed small to moderate weights for most of the items from .15 to .39 . It is likely that one or more in indicators would have had low or even non-significant outer weights when many indicators were forming a single construct. 


\begin{tabular}{|c|c|c|c|}
\hline & BehAff & GenCAff & SpecCAff \\
\hline $\mathrm{gc} 1$ & & 0.20 & \\
\hline $\mathrm{gc} 2$ & & 0.37 & \\
\hline $\mathrm{gc} 3$ & & 0.37 & \\
\hline $\mathrm{gc4}$ & & 0.32 & \\
\hline $\mathrm{sca} 1$ & & & 0.36 \\
\hline $\mathrm{sca} 2$ & & & 0.21 \\
\hline $\mathrm{sca} 3$ & & & 0.29 \\
\hline sca4 & & & 0.36 \\
\hline ba1 & 0.20 & & \\
\hline ba2 & 0.39 & & \\
\hline ba3 & 0.15 & & \\
\hline ba4 & 0.43 & & \\
\hline
\end{tabular}

Table 5-8: Outer Weights

We retained all items and then used bootstrapping to test further if the outer weights in formative measurement models were significantly different from zero. Table 5-9 illustrates the outer weights from bootstrapping.

\begin{tabular}{|c|c|c|c|c|c|}
\hline & $\begin{array}{c}\text { Original } \\
\text { Sample } \\
(\mathrm{O})\end{array}$ & $\begin{array}{c}\text { Sample } \\
\text { Mean (M) }\end{array}$ & $\begin{array}{c}\text { Standard } \\
\text { Deviation } \\
\text { (STDEV) }\end{array}$ & T value & P Values \\
\hline sca1 -> SpecCAff & 0.324 & 0.321 & 0.08 & 4.033 & 0.000 \\
\hline sca2 -> SpecCAff & 0.233 & 0.24 & 0.096 & 2.436 & 0.015 \\
\hline sca3 - SpecCAff & 0.285 & 0.269 & 0.103 & 2.769 & 0.006 \\
\hline sca4 -> SpecCAff & 0.369 & 0.375 & 0.1 & 3.705 & 0.000 \\
\hline ga1 -> GenCAff & 0.206 & 0.214 & 0.1 & 2.061 & 0.040 \\
\hline ga2 -> GenCAff & 0.367 & 0.353 & 0.099 & 3.695 & 0.000 \\
\hline ga3 -> GenCAff & 0.367 & 0.361 & 0.108 & 3.394 & 0.001 \\
\hline ga4 -> GenCAff & 0.314 & 0.318 & 0.106 & 2.968 & 0.003 \\
\hline ba1 - BehAff & 0.206 & 0.2 & 0.108 & 1.906 & $\mathbf{0 . 0 5 7}$ \\
\hline ba2 -> BehAff & 0.385 & 0.379 & 0.141 & 2.735 & 0.006 \\
\hline ba3 -> BehAff & 0.146 & 0.146 & 0.14 & 1.042 & $\mathbf{0 . 2 9 8}$ \\
\hline ba4 -> BehAff & 0.424 & 0.427 & 0.111 & 3.807 & 0.000 \\
\hline
\end{tabular}

Table 5-9: Outer Weights from Bootstrapping 
The results showed a significant $\mathrm{p}$-value $(<.05)$ for most formative indicators. Two items in behavioral affordance turned out to be insignificant with p-values at .06 and .30. However, items with insignificant outer weights were not automatically removed because it may have altered the meaning of the latent construct. Even with the insignificant p-values, we decided to retain the items as they uniquely contributed to the construct theoretically. Hair Jr et al. (2016) suggested that if the theory-driven conceptualization of the constructs strongly supports the indicator, the indicator should be retained. Because the subject experts confirmed the content validity of our items, none of the two items were removed.

\subsubsection{Formative Measurement Model Assessment - Confirmatory Tetrad Analysis}

Confirmatory tetrad Analysis (CTA) is an assessment routine for measurement models. The conceptualization employs a bootstrapping procedure to accomplish an appropriate statistical test examining vanishing tetrads in CTA. The approach allowed distinguishing a formative indicator specification from a reflective indicator specification.

The tests results showed the significance for the non-redundant tetrads from a bootstrapping procedure in SmartPLS. If a reflective measurement model was included in the analysis, the tetrads should have been nonsignificant. If a formative measurement model was included in the analysis, the tetrads should have been significant ( $p$-value $<$ 0.05). Our analysis showed at least one significant $\mathrm{p}$-value for behavioral affordance, general contextual affordance, and specific contextual affordance, but not for specific contexts. We encountered a misspecification issue. The specific contexts should be reflective measurement according to CTA result. We then ran separate tests on specific contexts to assess its validity as a reflective construct. The Cronbach's alpha for specific 
contexts was .81, roh_A coefficient was assessed to be .81 , composite reliability value was .88 , and the AVE was .64 . The tests confirmed the validity and reliability for specific contexts as a reflective construct. After thorough consideration, and because theoretically, it made sense that specific contexts can be either reflective or formative, we accepted and treated specific context construct as reflective. Table 5-10 illustrates the results for confirmatory tetrad analysis.

\begin{tabular}{|c|c|c|c|c|c|c|}
\hline $\begin{array}{c}\text { Model-implied } \\
\text { non-redundant } \\
\text { vanishing tetrad }\end{array}$ & $\begin{array}{c}\text { Original } \\
\text { Sample } \\
(\mathrm{O})\end{array}$ & $\begin{array}{c}\text { Bootstrap } \\
\text { t-value }\end{array}$ & P Values & Bias & CI Low & CI Up \\
\hline 1:ba1234 & 1.92 & 3.62 & 0.00 & 0.01 & 0.87 & 2.96 \\
\hline 2:ba1243 & 1.79 & 3.13 & 0.00 & 0.01 & 0.66 & 2.91 \\
\hline 1:gc1234 & 2.22 & 4.15 & 0.00 & 0.02 & 1.16 & 3.26 \\
\hline 2:gc1243 & 2.21 & 4.28 & 0.00 & 0.01 & 1.19 & 3.22 \\
\hline 1: sc1234 & -0.29 & 1.03 & $\mathbf{0 . 3 0}$ & 0.01 & -0.84 & 0.25 \\
\hline 2: sc1243 & 0.14 & 0.64 & $\mathbf{0 . 5 2}$ & 0.00 & -0.29 & 0.57 \\
\hline 1: sca1234 & 0.82 & 2.75 & 0.01 & 0.00 & 0.23 & 1.40 \\
\hline 2: sca1243 & 0.29 & 0.82 & 0.41 & 0.00 & -0.41 & 1.00 \\
\hline
\end{tabular}

Table 5-10: Confirmatory Tetrad Analysis

\subsection{Structural Model}

The next step was testing the hypothesized relationships among various latent constructs in the structural model having validated the measurement modeling. First, we examined the model fit, followed by the coefficient of determination, path coefficients and the discussion of mediating effects.

\subsubsection{Model fit}

There were three main approaches for going from a theoretical perspective to an SEM model in which the covariance structure among constructs was analyzed. The first approach mainly concerned confirmatory research where research hypothesized a specific 
theoretical model. The theoretical model was either confirmed or unconfirmed based on a chi-square statistical test of significance and meeting the acceptable model-fit criteria. For the second approach, the researcher created a limited number of theoretically different models to determine which model the data fits best. This approach produced a chi-square difference test to compare each of the models. For the third approach, when the sample data did not fit the initial model at an acceptable model-fit criterion level, modification indices were used to add or delete paths in the model to arrive at a finishing best model. We took the first approach since our theoretic model was exploratory by nature.

Two absolute fit measures evaluated the model fit: chi-square and standardized root mean square residual (SRMR) and a relative fit measure, NFI. The model presented had a significant chi-square $(\chi 2=1807.45, \mathrm{p}<.001)$. This means that the reproduction of the correlation matrix based upon the path coefficients of the sample data was significantly different from the hypothesized model. A significant chi-square implied that the observed and implied variance-covariance matrices differed and may be due to sampling variation. Jöreskog and Sörbom (1989) and Bentler (1990) both advised against the sole use of the chi-square in judging the overall fit of the model because of the sensitivity of the chi-square to sample size. As sample size increases, power increases. Consequently, the chi-square test uncovered small discrepancies between the observed and predicted covariances and suggested that the model did not fit the data. A goodfitting model could have been rejected owing to trivial but statistically significant differences between the observed and predicted values. Because the chi-square model fit, the criterion was sensitive to sample size and SRMR was also interpreted. The SRMR for 
the model was reported at $.06<$ the recommended value of .08 and the model was considered as a fit. The relative fit measure Norm Fit Index (NFI) assessed the model by comparing the $\chi 2$ value of the model to the $\chi 2$ of the null model (Hooper, Coughlan, \& Mullen, 2008). Values for NFI ranged between 0 and 1, with 1 indicating a perfect fit. The data for the hypothesized model reported NFI value of .81, which indicated an acceptable fit.

\subsubsection{Coefficient of determination $\left(R^{2}\right)$}

Having established the appropriateness of the measures, the nest step is to provide evidence supporting the theoretical model as exemplified by the structural potion of the model (Esposito Vinzi, Chin, Henseler, \& Wang, 2010). A major emphasis in PLS analysis is on variance explained and established the significance of all path estimates. $R^{2}$ value of the endogenous constructs is used to assess the predictive power of the structural model, it represents the amount of variance in the construct in question that is explained by the model. Table 5-11 illustrates the $R^{2}$ values of the endogenous constructs.

\begin{tabular}{|c|c|c|}
\hline & R Square & $\begin{array}{c}\text { R Square } \\
\text { Adjusted }\end{array}$ \\
\hline BehAff & 0.29 & 0.29 \\
\hline Exploitation & 0.19 & 0.19 \\
\hline Exploration & 0.25 & 0.24 \\
\hline GenCAff & 0.38 & 0.38 \\
\hline Sat & 0.32 & 0.32 \\
\hline SpecCAff & 0.31 & 0.30 \\
\hline
\end{tabular}

\subsubsection{Path Coefficients}

The sample consisted of $\mathrm{n}=352, R^{2}=.32$ and was interpreted as $32 \%$ of the variance in patients' satisfaction was explained by exploration and exploitation in 
processes change, behavioral affordance, specific contextual affordance, general contextual affordance, specific contexts, absorptive capacity, and technology characteristics. Table 5-12 represents the details of path analysis results with the effects of exploration and exploitation in processes change, behavioral affordance, specific contextual affordance, general contextual affordance, specific contexts, absorptive capacity and technology characteristics on patients' satisfaction.

\begin{tabular}{|c|c|c|c|c|c|}
\hline & $\begin{array}{c}\text { Original } \\
\text { Sample } \\
(\mathrm{O})\end{array}$ & $\begin{array}{l}\text { Sample } \\
\text { Mean } \\
\text { (M) }\end{array}$ & $\begin{array}{l}\text { Standard } \\
\text { Deviation } \\
\text { (STDEV) }\end{array}$ & $\begin{array}{c}\text { T Statistics } \\
(|\mathrm{O} / \mathrm{STDEV}|)\end{array}$ & $\begin{array}{c}\mathrm{P} \\
\text { Values }\end{array}$ \\
\hline AbsCa $->$ GenCAff & 0.09 & 0.09 & 0.04 & 2.02 & 0.04 \\
\hline BehAff -> Exploitation & 0.43 & 0.44 & 0.05 & 8.84 & 0 \\
\hline BehAff -> Exploration & 0.49 & 0.5 & 0.05 & 10.71 & 0 \\
\hline Exploitation $->$ Sat & 0.4 & 0.41 & 0.06 & 6.59 & 0 \\
\hline Exploration -> Sat & 0.21 & 0.2 & 0.07 & 3.16 & 0 \\
\hline GenCAff $->$ BehAff & 0.15 & 0.16 & 0.06 & 2.61 & 0.01 \\
\hline SpeC -> SpecCAff & 0.36 & 0.36 & 0.05 & 6.83 & 0 \\
\hline SpecCAff -> BehAff & 0.43 & 0.43 & 0.06 & 6.93 & 0 \\
\hline SpecCAff $->$ GenCAff & 0.33 & 0.33 & 0.06 & 6 & 0 \\
\hline TechCh $->$ GenCAff & 0.48 & 0.48 & 0.06 & 8.2 & 0 \\
\hline
\end{tabular}

Table 5-12: Path Coefficients

Using the data collected, we extracted a saturated model with SmartPLS. We hypothesized that specific context was one of the factors that determined specific contextual affordance (SCA). Absorptive capacity and technology characteristics were determinants for general contextual affordance (GCA). SCA and GCA further influenced the perceived process changes represented by exploitation and exploration. The behavioral affordance mediated the influence. Lastly, for the exploitation and exploration influence patients' satisfaction, there were two mediating effects in the model. 
First, we hypothesized that specific contexts would have a positive effect on specific contextual affordance. We found significant paths from specific contexts to SCA ( $\beta=.36, p<0.01)$ supporting our hypothesis H1a that specific contexts had a significant positive influence on specific contextual affordance. Such results indicated the importance of realizing patients' increased demands in preferences, cultural, and norms to perceive more actionable possibilities of the patient portal had to offer in contexts when the interactions happened. We referred to this as the specific contextual affordance.

Second, we hypothesized that absorptive capacity at the individual level for patients would have a positive effect on general contextual affordance. We found that the path from the absorptive capacity to GCA $(\beta=.09, \mathrm{p}<0.05)$ to be significant, supporting our hypothesis $\mathrm{H} 1 \mathrm{~b}$ that absorptive capacity had a significant positive influence on general contextual affordance. Such results indicated that the increased level of ability for a patient to recognize, assimilate, and apply new knowledge contributed to the number of action possibilities the patient perceived in contexts before the interactions happened, to which we refer as the general contextual affordance.

Third, we further hypothesized that the degree of the perceived technology characteristics for patients would have a positive effect on general contextual affordance. We found the path from technology characteristics to $\operatorname{GCA}(\beta=.48, \mathrm{p}<0.01)$ to be significant, supporting our hypothesis H1c that the degree of perceived technology characteristics had a positive influence on GCA. Such results suggested that the increased level of efficiencies gained by the patient portal compare to other tools perceived by a patient also contributed to the number of action possibilities the patient perceived in contexts before the interactions happened. 
Next, we hypothesized that the degree of SCA would have a positive effect on GCA. We found a significant path from SCA to be GCA $(\beta=.33, \mathrm{p}<0.01)$, thus supporting hypothesis H2a that the degree of SCA had a positive influence on GCA. Such results indicated that the increased amount of action possibilities the patient perceived in contexts when the interactions happened increased the number of action possibilities the patient perceived before the interactions happen.

We further hypothesized that the degree of SCA would have a positive effect on behavioral affordance, and that path from SCA to behavioral affordance $(\beta=.43, \mathrm{p}<0.01)$ was found to be significant, supporting hypothesis $\mathrm{H} 2 \mathrm{~b}$ that the degree of SCA will have a positive influence on behavioral affordance. This result indicated that increased amount of action possibilities the patient perceived in contexts when the interactions happened contributed to the realization of the contextual affordance.

We then hypothesized that the degree of general contextual affordance would positively affect behavioral affordance. We found the path from general contextual affordance to behavioral affordance to be significant $(\beta=.15, \mathrm{p}<0.01)$. Thus, H3 was supported that the degree of general contextual affordance positively affected behavioral affordance. This indicated that the increased amount of action possibilities the patient perceived before the interactions happened contributed to the realization of the contextual affordance.

We hypothesized that the behavioral affordance would positively affect the perceptions of process changes concerning exploration and exploitation. We found significant paths from behavioral affordance to both exploitation and exploration $(\beta=.43$, $\mathrm{p}<0.01$ for exploitation and $\beta=.49, \mathrm{p}<0.01$ for exploration, respectively). $\mathrm{H} 4 \mathrm{a}$ and $\mathrm{H} 4 \mathrm{~b}$ 
were supported. These results suggested that the increased amount of affordance being realized for a patient to perceived clinical process changes.

Lastly, we hypothesized that the perceived level of exploration and exploitation clinical process changes would have positive influences on patient satisfaction. We found significant paths from exploration and exploitation to patient satisfaction $(\beta=.21, p<0.01$ for exploration and $\beta=.40, \mathrm{p}<0.01$ for exploitation, respectively). Thus, H5a and H5b were supported. These results indicated that increased level of clinical process changes perceived for a patient either in an explorative or exploitative fashion, the patient was more likely to be satisfied with their experiences in the hospitals. Figure 5-1 illustrates the path coefficients of the model.

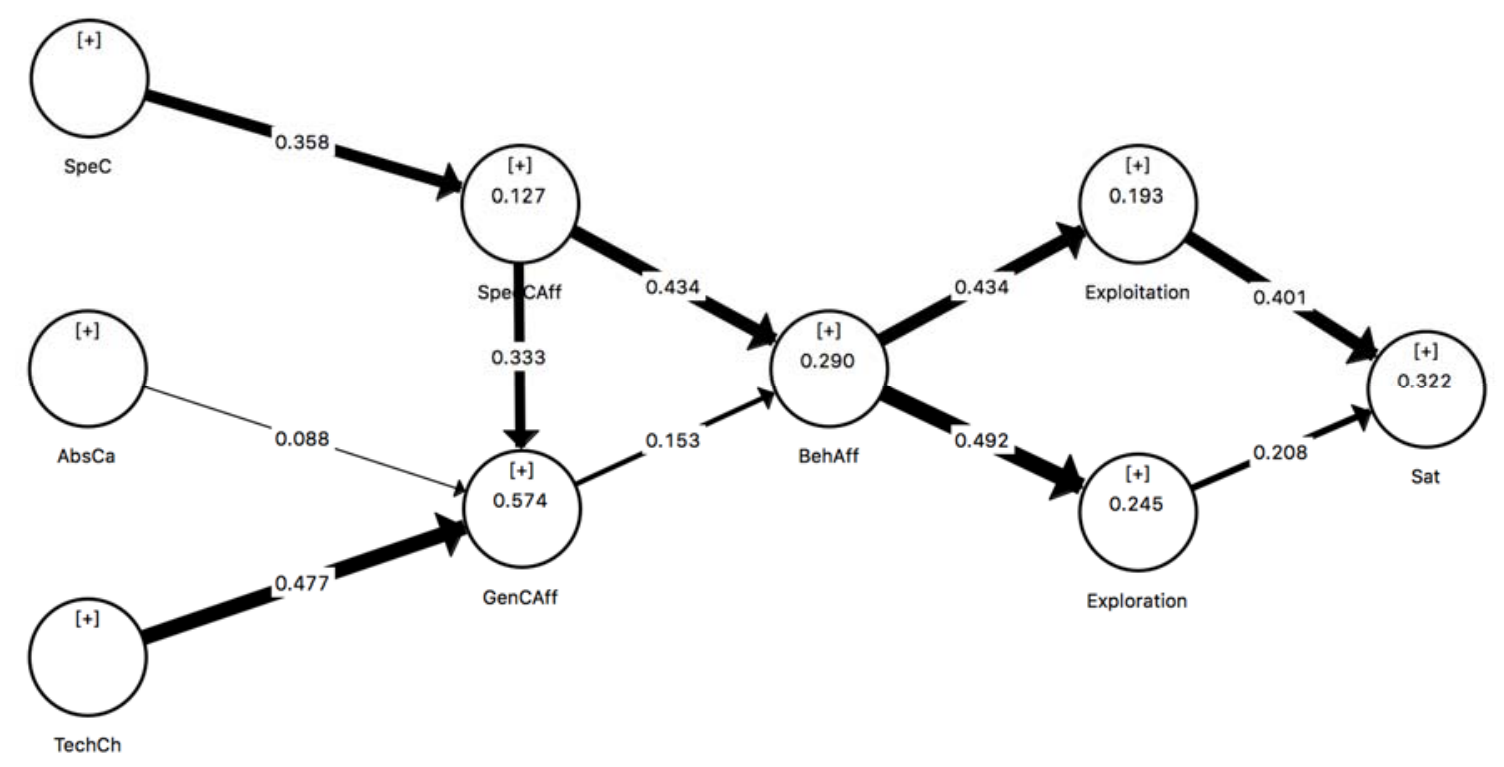

Figure 5-1: Path Coefficients of the Structural Model 
Table 5-13 summarizes the results of hypotheses testing.

\begin{tabular}{|l|c|}
\hline \multicolumn{1}{|c|}{ Hypotheses } & Results \\
\hline H1a: Specific context positively affects specific contextual affordance & Supported \\
\hline H1b: Individual absorptive capacity positively affects general contextual affordance & Supported \\
\hline H1c: Technology characteristics positively affect general contextual affordance & Supported \\
\hline H2a: Specific contextual affordance positively affects general contextual affordance & Supported \\
\hline H2b: Specific contextual affordance positively affects behavioral affordance & Supported \\
\hline H3: General contextual affordance positively affects behavioral affordance & Supported \\
\hline H4a: Behavioral affordance positively affects explorative clinical process changes & Supported \\
\hline H4b: Behavioral affordance positively affects exploitative clinical process changes & Supported \\
\hline H5a: Explorative clinical process changes positively affect patient satisfaction & Supported \\
\hline H5b: Exploitative clinical process changes positively affect patient satisfaction & Supported \\
\hline
\end{tabular}

Table 5-13: Hypotheses Testing Results

\subsubsection{Mediating effects}

With mediation analysis, we gained insight and acquired a deep understanding about the mechanisms of action of patient portal adoption and post-adoption evaluation concerning satisfaction through process changes (Gunzler, Chen, Wu, \& Zhang, 2013). Such information provided added dimensions to understand the effects of affordance, which can stimulate the identification of more efficacious and cost-efficient approaches to improve patient satisfaction.

We observed that specific contextual affordance mediated the effects from specific contexts to behavioral affordance. This mediating effect was found to be significant $(\mathrm{p}<.01)$. The result suggested a full mediation effect indicating that specific contextual affordance thoroughly explains the association between specific contexts and behavioral affordance. General contextual affordance mediated the effects from an absorptive capacity to behavioral affordance. This mediating effect was not significant $(\mathrm{p}>.05)$. The results suggested a partial mediation indicating that general contextual 
affordance partially explained the association between specific contexts and behavioral affordance. There might have been some other uncovered reasons, general contextual affordance mediated the effects from technology characteristics to behavioral affordance. This mediating effect was found to be significant $(\mathrm{p}<.01)$. The result suggested a full mediation indicating that general contextual affordance thoroughly explained the association between technology characteristics and behavioral affordance. General contextual affordance mediated the effect of specific contextual affordance to behavioral affordance. This mediating effect was found to be significant. This result suggested a full mediation indicating that general contextual affordance thoroughly explains the association between specific contextual affordance and behavioral affordance $(\mathrm{p}<.05)$.

Furthermore, the effects of specific contextual affordance to perceived explorative and exploitative process changes were mediated by behavioral affordance $(\mathrm{p}<.01$ for both exploration and exploitation), the mediating effects of behavioral affordance were found to be significant. The results indicated a full mediation from behavioral affordance, and behavioral affordance fully explains the association between specific contextual affordance and clinical process changes. The effects of general contextual affordance to perceived explorative and exploitative process changes were mediated by behavioral affordance ( $\mathrm{p}<.05$ for both exploration and exploitation). The mediating effects of behavioral affordance were found to be significant suggesting a full mediation effect. Behavioral affordance fully explained the association between general contextual affordance and clinical process changes. We further observed that the effects of behavioral affordance on patient satisfaction was mediated by the perceived explorative and exploitative clinical process changes $(\mathrm{p}<.01)$. The mediating effect of perceived 
process changes were found to be significant, suggesting a full mediation effect. The clinical process changes fully explained the association between behavioral affordance and patient satisfaction.

To summarize, all hypotheses were supported in our analysis. A patient's who has certain conditions and preferences will likely have a higher level of perceived specific contextual affordance. A patient with higher level of absorptive capacity and better assessment of technology characteristics will likely have a higher level of general contextual affordance. A patient with a higher level of perceived specific contextual affordance will have a higher level of general contextual affordance and more likely to use patient portal when they could. A patient with a higher level of perceived general contextual affordance was also contributed to their actual usage of the patient portal. The higher the level of usage, the higher level of perceived processes change will occur. Despite the nature of processes change being either explorative or exploitative, the more they perceive they changes, then the patients were likely to be more satisfied. We also included the table for total indirect effects and total effects in Table 5-14 and Table 5-15.

\begin{tabular}{|c|c|c|c|c|c|}
\hline & $\begin{array}{c}\text { Original } \\
\text { Sample } \\
(\mathrm{O})\end{array}$ & $\begin{array}{c}\text { Sample } \\
\text { Mean } \\
(\mathrm{M})\end{array}$ & $\begin{array}{c}\text { Standard } \\
\text { Deviation } \\
(\text { STDEV })\end{array}$ & $\begin{array}{c}\text { T Statistics } \\
(\mid \mathrm{O} / \text { STDEV })\end{array}$ & $\begin{array}{c}\mathrm{P} \\
\text { Values }\end{array}$ \\
\hline AbsCa $>$ GCA $>$ BehAff & 0.01 & 0.01 & 0.01 & 1.33 & 0.18 \\
\hline TechCh $>$ GCA $>$ BehAff & 0.07 & 0.08 & 0.03 & 2.48 & 0.01 \\
\hline SpecCAff $>$ GCA $>$ BehAff & 0.05 & 0.05 & 0.02 & 2.4 & 0.02 \\
\hline SpeC $>$ SCA $>$ BehAff & 0.17 & 0.18 & 0.03 & 5.16 & 0 \\
\hline SpecCAff $>$ BA $>$ Exploitation & 0.21 & 0.21 & 0.04 & 5.84 & 0 \\
\hline SpecCAff $>$ BA $>$ Exploration & 0.24 & 0.24 & 0.04 & 6.44 & 0 \\
\hline GenCAff $>$ BA $>$ Exploitation & 0.07 & 0.07 & 0.03 & 2.38 & 0.02 \\
\hline GenCAff $>$ BA $>$ Exploration & 0.08 & 0.08 & 0.03 & 2.41 & 0.02 \\
\hline $\begin{array}{c}\text { BehAff }>\text { Exploration and } \\
\text { Exploitation }>\text { Sat }\end{array}$ & 0.28 & 0.28 & 0.03 & 8.2 & 0 \\
\hline
\end{tabular}


Table 5-14: Total Indirect Effects

\begin{tabular}{|c|c|c|c|c|c|}
\hline & $\begin{array}{c}\text { Original } \\
\text { Sample } \\
\text { (O) }\end{array}$ & $\begin{array}{l}\text { Sample } \\
\text { Mean } \\
\text { (M) }\end{array}$ & $\begin{array}{l}\text { Standard } \\
\text { Deviation } \\
\text { (STDEV) }\end{array}$ & $\begin{array}{c}\text { T Statistics } \\
(|\mathrm{O} / \mathrm{STDEV}|)\end{array}$ & $\begin{array}{c}\mathrm{P} \\
\text { Values }\end{array}$ \\
\hline AbsCa -> BehAff & 0.01 & 0.01 & 0.01 & 1.33 & 0.18 \\
\hline AbsCa -> Exploitation & 0.01 & 0.01 & 0 & 1.25 & 0.21 \\
\hline AbsCa -> Exploration & 0.01 & 0.01 & 0.01 & 1.27 & 0.2 \\
\hline AbsCa $->$ GenCAff & 0.09 & 0.09 & 0.04 & 2.02 & 0.04 \\
\hline $\mathrm{AbsCa}->\mathrm{Sat}$ & 0 & 0 & 0 & 1.25 & 0.21 \\
\hline BehAff $->$ Exploitation & 0.43 & 0.44 & 0.05 & 8.84 & 0 \\
\hline BehAff -> Exploration & 0.49 & 0.5 & 0.05 & 10.71 & 0 \\
\hline BehAff -> Sat & 0.28 & 0.28 & 0.03 & 8.2 & 0 \\
\hline Exploitation $->$ Sat & 0.4 & 0.41 & 0.06 & 6.59 & 0 \\
\hline Exploration $->$ Sat & 0.21 & 0.2 & 0.07 & 3.16 & 0 \\
\hline GenCAff -> BehAff & 0.15 & 0.16 & 0.06 & 2.61 & 0.01 \\
\hline GenCAff $->$ Exploitation & 0.07 & 0.07 & 0.03 & 2.38 & 0.02 \\
\hline GenCAff -> Exploration & 0.08 & 0.08 & 0.03 & 2.41 & 0.02 \\
\hline GenCAff $->$ Sat & 0.04 & 0.04 & 0.02 & 2.38 & 0.02 \\
\hline SpeC -> BehAff & 0.17 & 0.18 & 0.03 & 5.16 & 0 \\
\hline SpeC -> Exploitation & 0.08 & 0.08 & 0.02 & 4.2 & 0 \\
\hline SpeC -> Exploration & 0.09 & 0.09 & 0.02 & 4.33 & 0 \\
\hline SpeC -> GenCAff & 0.12 & 0.12 & 0.03 & 4.12 & 0 \\
\hline SpeC -> Sat & 0.05 & 0.05 & 0.01 & 4.02 & 0 \\
\hline SpeC $->$ SpecCAff & 0.36 & 0.36 & 0.05 & 6.83 & 0 \\
\hline SpecCAff $->$ BehAff & 0.48 & 0.48 & 0.05 & 8.93 & 0 \\
\hline SpecCAff -> Exploitation & 0.21 & 0.21 & 0.04 & 5.84 & 0 \\
\hline SpecCAff -> Exploration & 0.24 & 0.24 & 0.04 & 6.44 & 0 \\
\hline SpecCAff $->$ GenCAff & 0.33 & 0.33 & 0.06 & 6 & 0 \\
\hline SpecCAff -> Sat & 0.13 & 0.13 & 0.02 & 5.5 & 0 \\
\hline TechCh $->$ BehAff & 0.07 & 0.08 & 0.03 & 2.48 & 0.01 \\
\hline TechCh -> Exploitation & 0.03 & 0.03 & 0.01 & 2.29 & 0.02 \\
\hline TechCh -> Exploration & 0.04 & 0.04 & 0.02 & 2.31 & 0.02 \\
\hline TechCh -> GenCAff & 0.48 & 0.48 & 0.06 & 8.2 & 0 \\
\hline TechCh $->$ Sat & 0.02 & 0.02 & 0.01 & 2.3 & 0.02 \\
\hline
\end{tabular}

Table 5-15: Total Effects 


\section{CHAPTER 6 . DISCUSSION}

\subsection{Summary of Results}

The 'do or do not' dilemma organizations are facing motivated this research. With social media enabled platforms such as the WeChat, patient portal served to be a powerful tool for organizations to gain a competitive advantage and satisfy ever-changing customer demands. The investment seems to be advantageous for these organizations. In the process of investing in new technology, however, the results are mixed because the influences of the contexts on the process of adopting, implementing, and dissimilating these technologies are largely ignored (Orlikowski \& Scott, 2008). How an organization should take into consideration the interaction between technology and context in its planning and assessment of technological investment and usage became the centerpiece of this dissertation.

Much of the literature to date had focused on either the conceptual development of affordances and were limited to the affordances at a functional level. However, the perspective side of affordance and the inherent contexts in which the actors interact with technology has been noted but largely ignored. Relatively little empirical research has explicitly examined if and when contextual affordances impact individual adoption and their effects on organizational process changes and outcomes. Our study responded to calls for research examining different contexts when studying the relationship between a technology-the artifact and an actor-the social (Orlikowski \& Scott, 2008).

From a social-technical perspective, we built upon previous research and used the lens of affordance as our main theoretical base. We attempted to conceptualize contextual affordance and distinguished specific contextual affordance with general contextual 
affordance. We further developed measurements and empirically tested our hypotheses in large hospitals in China. Rather than assume that affordance was isolated and materialistic, our contingency hypotheses answered the calling for considering contexts in the application of affordance with a focus on affordances that were embedded within the user's historical and cultural contexts rather than just the materialistic aspects of affordance.

We proposed that the level of patient satisfaction depended on whether process changes strategically complemented one another and produced a positive interaction through the twin concept of exploration and exploitation processes. Such perceptions process changes of exploration and exploitation were further influenced by a set of contextual affordances: general contextual affordance, specific contextual affordance, and behavioral affordance. The contextual affordance was defined as the perceived action possibilities afforded to the actor that was specific/general healthcare contexts by the artifact when the interactions happened. Specific contextual affordance was more immediate and unstable, easy to change and time for it to be in effect was when a patient needed to decide on whether to use the patient portal or not. When specific contextual affordance was present, the more stable and distal general contextual affordance serving as the baseline for the patient was temporarily elasticated. There were a few determinants for such affordances: specific contexts such as patients' preferences, cultural norm, and beliefs influenced by patients' specific contextual affordance. How they perceived technology characteristics and the level of absorptive capacity they possessed determined the general contextual affordance. 
We tested our hypotheses using 352 samples collected from four large hospitals in southwest China during a six-month period. We used structural equation modeling and empirically examined the effects of proposed constructs on patients' satisfaction. The results provided compelling support for the proposed contingency effects. Patients in large hospitals yielded a higher level of satisfaction when the general and specific contextual affordance levels were high through perceived clinical processes demonstrating changes either were explorative or exploitative. Furthermore, the specific contextual affordance was positively influenced by patients' personal preferences, cultural norms, and beliefs. The general contextual affordance was positively influenced by absorptive capacity as well as perceived innovative characteristics of the patient portal. The results demonstrated the roles of various affordances in predicting perceptions of processes change, patient satisfaction, and patient-physician relationship in a Chinese healthcare context.

On a further note, we drew from established theory in psychology literature and attempted to capture the distinctive aspects of general contextual affordance and specific contextual affordance. Two sets of affordances were similar yet possessed competing characteristics. General contextual affordance was stable, distal and consistent as a baseline for a user where specific contextual affordance was unstable, immediate, and prone to current situations as a trigger point for a user. Our investigation was noteworthy for incorporating and differentiating several competing nature constructs. For instance, explorative and exploitative processes, specific and general contextual affordance, internal and external system integration. We asked for their opinions and expectations in experiencing WeChat patient portal. 
One of the interesting findings related to the effects of explorative and exploitative process changes on patient satisfaction. The results showed that the patient pays more attention to strategic emphases on the exploitative side rather than the explorative side. This means as healthcare facilities trying to be more innovative and implementing an evolutionary technology should not ignore the incremental improvements on what they already have.

Overall, the findings of this research enriched our understanding of the phenomenon of sociotechnical interactions through the lens of affordance. This provided appealing evidence and supported for organizations to invest in innovative technology such as WeChat patient portal confidently. However, this investment comes with conditions. The contextual aspects of the users are critical in determining their adopting behavior. On top of adopting, the post-adoption perceptions toward process changes have a substantial effect on a positive result.

\subsection{Contributions}

This study made significant contributions to both academia and the industry. We rigorously set the scope of affordances in the healthcare research contexts. Based on extensive literature reviews and field studies, we combined the affordances with contexts and investigated the dimensions of these affordances. We developed measurements for these affordances and tested the validity and reliability of the measurements.

Following the conceptualization and operationalization of contextual affordances, we found the most crucial determinants that influenced such affordances in the healthcare contexts in China were based on literature reviews and interviews from subject experts. 
Subsequently, we empirically tested the effects of contextual affordances in several healthcare facilities in southern China. In light of the patient portal implementations across these healthcare facilities, the processes in which patients seeking treatments had drastically changed before and after the implementations. The results of healthcare facilities' technology investments are promising regarding patient satisfaction when the contextual aspects are thoroughly considered.

\subsubsection{Theoretical Implications}

Theoretically, this study extended the current understanding of affordance by considering contextual dimensions of affordance, and by examining the relationships between contextual affordance and its determinants and consequences. The dimensions, operationalization, and measurement of contextual affordance were validated through our empirical tests using structural equation modeling. Our separation of specific versus general contextual affordance fostered a novel approach in differentiating two existing forms. However, understudied affordances provided the first step towards a more comprehensive and realistic view of using the lens of affordance for human-technology interaction in information systems research. Our theory differs from most current approaches to studying system implementation using affordance because it focuses on the contextual aspects of the system user from a "state" versus "trait" point of view at an adequate detailed level. The study empirically reveals the determinants of such affordances and the roles of these affordances in influencing the patient satisfaction as an outcome through the clinical process changes.

Our theory was distinct from previous approaches in three key ways. First, our theory focused on a range of affordances and their roles in emerging healthcare 
organizations embedded within the technology user group rather than focusing solely on the technology as a "one size fits all" solution. Second, our theory was different from many empirical studies that only considered the functional aspects of affordance. Our research examined the inseparability of contexts, actor, and technology through the notion of contextual affordance. Third, our theory further distinguished two forms of contextual affordance, rather than treating them as similar concepts.

The research model we incorporated also extended the current approaches towards an outcome variable by considering two mediating effects. The first one was the mediating effect of contextual affordances by introducing the contextual affordances as mediating factors uncovered additional variances that had not been explained before. To the best of our knowledge, this was the very first attempt to bridge the determinants and adoption behaviors using contextual affordance with a structural equation modeling technique. Using absorptive capacity and technology characteristics to examine the adoption of behavioral alone would not have been able to detect those variances. We further separated contextual affordances into two forms: a more general contextual affordance and a more specific affordance. We were able to observe that the effects of these contextual affordances were dramatically different in influencing adoption behavior. This observed effect added to our understating in utilizing affordance as a bridging concept between users and technology.

The second one was the mediating effect of process changes expressed by the notions of exploitation and exploration between adoption behaviors and outcome variable patient satisfaction. Adoption behavior alone did not automatically guaranty a satisfactory positive result. Empirical studies on the effects of using a certain technology 
were inconsistent. Our approach provided an alternative view in explaining why we kept seeing missed results. Furthermore, the exploration and exploitation were expressed as how the processes were perceived by the patients, either with an explorative focus or exploitative focus. We saw the different degree of effects of these focuses on our outcome variable. These observed effects strengthened our understanding of constructs with competing properties.

\subsubsection{Practical Implications}

Practically, this study sheds new lights on how organizations should go beyond the out-of-context interactions between technologies and users by considering userperceived affordance of technology within the specific contexts of use. By considering the idiosyncratic nature of user context in studying affordance, this study provided an alternative view to the one-size-fits-all approach that has historically proven to be insufficient. This study further offers guidelines and insights that help organizations better plan, control and assess new social media-enabled technologies.

For information systems researchers, the distinctive notion of general and specific contextual affordance provides a foundation for studying and understanding how to design better and implement a user-centric system to improve the outcome. Specifically, in the healthcare context, our empirical evidence suggests that patients' preferences, personal beliefs and cultural norms will influence how they perceive what they could do with technology such as the patient portal. Technology characteristics and the patients' absorptive capacities have influenced how they generally perceive what the technology could do with patient portal. Practitioners thus should focus on improving the functionalities of the patient portal in line with whether they want to strengthen the 
specific contextual affordance since it had a significant influence on general contextual affordance and the subsequent decision to adopt.

The key, however, lies in the first mediating effect we incorporated in this research, contextual affordance. System designers and hospital management could focus on the features and functionalities of the technology, but if they failed to consider the mediating effects of contextual affordance, they might not be able to reach their intended goals. One of the often mentions comments in our field of study was, "We think the system is so great; I just don't understand why not many people are using it.” The contextual affordance may be the missing piece to answering that statement.

Also, we focused on a neglected category in light of the booming healthcare industry in China where large healthcare organizations invested millions of dollars in technology and hoped for the best without a clear scope and strategic focus. Rather than purely focusing on adopting innovative technology, the healthcare organizations should also consider balancing their strategic focus regarding exploration and exploitation. Our study revealed both routes have effects on patient satisfaction. However, patients tend to respond more to exploitative process changes than explorative changes.

Furthermore, to the effect of strategic positions is to consider an all-out innovation or an all-in stagnation with an explorative focus or exploitative focus. Our second mediating effect tapped into the next question practitioners may ask, "Why have we not seen a positive result when everyone is using the system?" Exploration and exploitation mediate the results, and the adoption rate does not automatically guarantee patient satisfaction. Patient satisfaction will only improve through adoption but also 
limited in the effect that the amount of exploration and exploitation process changes are perfectly balanced.

\subsection{Limitations}

Although we only used healthcare industry in which we contributed to internal validity, caution should be used when generalizing these results to other industries, especially in the healthcare contexts, patient well-being, and quality of care are distinctive from other industries such as financial concerns.

A key limitation comes from convenience sampling. We have to be very careful regarding generalizing the results from this study to the entire population due to the potential bias of the sampling technique such as under-representation of sub-groups in the population studied. It also entails a weaker power to identify differences in population subgroups (Lavrakas, 2008). We are still in the process of collecting more data from community health centers in China. This study did not include the survey responses from the physicians.

Secondly, in testing the explorative and exploitative functionalities with patients' perceptions, a chance exists for a delayed effect. Therefore, there is no conclusive time frame for observing those effects. Previous research found it can take several years until these activities can yield benefits and changes (Voss \& Voss, 2013). We surveyed one point of time while the hospitals and community health centers implemented the patient portal at different times. Moreover, to successfully observe the effects, it requires the strategic emphases from each facility in the preceding years after implementation. However, the management heterogeneity across different research sites can potentially increase or decrease observed effects. 
Third, the study is exploratory. To our best knowledge, this study is one of the first attempts to incorporate contexts into affordance and test its effects empirically using the survey instrument in multiple large healthcare facilities across China. Even though all of our hypotheses were supported by the data, the specificity of this study requires a more careful approach in drawing conclusions based on the results of our analysis. The results from this study may not be replicable in other contexts such as in a different country and assessing a different technology.

Also, more efforts should be made regarding categorization of actual exploration and exploitation activities in the healthcare industry. This study focuses on the perception of patients, the end users, and asks them their opinion on the patient portal - the technology adopted. The line distinguishing exploration and exploitation has not yet been explicitly defined. The results of this study are sensitive to each subjects' interpretation of the technology. Considering the limited sample, we used for this research; researchers should be cautious towards any generalization efforts.

\subsection{Future Research}

Although we tried our best to address the potential biases from our sampling methods, future research that explicitly addresses this risk would be instructive. For this research, we only used the patients' survey results which only gave us half of the puzzle.

On the physician side, hospitals are implementing a similar portal. However, the story for the physician is more dedicated compared to introducing the patient portal to patients as the physicians endure more work stress, work-life balance, time management, and specialty. As part of a larger study, we also collected physician-patient matched samples. For future research, we will administer the physician-patients matching data set in the 
analysis. It will be interesting to see how the results will be compared to the patients' data.

Furthermore, due to time constraints, we were only able to measure the affordances at a single point in time. Although we found support for the explorative process change influence patient satisfaction, there is a consensus that exploration has a delayed effect (Voss \& Voss, 2013). Chances of detecting the true effects of exploration might not be present in this research. In the future research, it will be interesting to administrate multi-points of time to measure how affordance changes over time and contributes to exploration. In such way, not only we can detect changes before and after, but also induced the time factor in which aligned with the conceptualization of specific and general affordance.

On a further note, the sample used in this study was from larger, established and reputable hospitals in China. We are in the process of collecting more data in a community healthcare setting. It will be very insightful to compare and contrast between large hospitals and community healthcare to see how we can manipulate the technology to suit each need and mitigate the shortage of healthcare resources in China contexts. 


\section{REFERENCES}

Anderson, C., \& Robey, D. (2017). Affordance potency: Explaining the actualization of technology affordances. Information and Organization, 27(2), 100-115.

Archer, M. S., \& Archer, M. S. (1995). Realist social theory: The morphogenetic approach: Cambridge university press.

Argyris, Y. A., \& Monu, K. (2015). Corporate Use of Social Media: Technology affordance and external stakeholder relations. Journal of Organizational Computing and Electronic Commerce, 25(2), 140-168.

Avgerou, C. (2001). The significance of context in information systems and organizational change. Information systems journal, 11(1), 43-63.

Ball, M. J., \& Lillis, J. (2001). E-health: transforming the physician/patient relationship. international journal of medical informatics, 61(1), 1-10.

Barclay, D., Higgins, C., \& Thompson, R. (1995). The partial least squares (PLS) approach to causal modeling: Personal computer adoption and use as an illustration. Technology studies, 2(2), 285-309.

Bentler, P. M. (1990). Comparative fit indexes in structural models. Psychological bulletin, 107(2), 238.

Bharadwaj, A. S. (2000). A resource-based perspective on information technology capability and firm performance: an empirical investigation. MIS quarterly, 169196.

Bloomfield, B. P., Latham, Y., \& Vurdubakis, T. (2010). Bodies, technologies and action possibilities: When is an affordance? Sociology, 44(3), 415-433.

Burke, W. W., \& Litwin, G. H. (1992). A causal model of organizational performance and change. Journal of management, 18(3), 523-545.

Carmines, E. G., \& Zeller, R. A. (1979). Reliability and validity assessment (Vol. 17): Sage publications.

Chen, Q., Xu, X., Cao, B., \& Zhang, W. (2016). Social media policies as responses for social media affordances: The case of China. Government Information Quarterly, 33(2), 313-324.

Chin, W. W. (1998). The partial least squares approach to structural equation modeling. Modern methods for business research, 295(2), 295-336. 
Churchill Jr, G. A. (1979). A paradigm for developing better measures of marketing constructs. Journal of marketing research, 64-73.

Cohen, W. M., \& Levinthal, D. A. (1990). Absorptive capacity: A new perspective on learning and innovation. Administrative science quarterly, 128-152.

DeSanctis, G., \& Poole, M. S. (1994). Capturing the complexity in advanced technology use: Adaptive structuration theory. Organization Science, 5(2), 121-147.

Diamantopoulos, A., \& Winklhofer, H. M. (2001). Index construction with formative indicators: An alternative to scale development. Journal of marketing research, 38(2), 269-277.

Elwyn, G., Lloyd, A., Joseph-Williams, N., Cording, E., Thomson, R., Durand, M.-A., \& Edwards, A. (2013). Option Grids: shared decision making made easier. Patient education and counseling, 90(2), 207-212.

Eshraghian, F., Hafezieh, N., \& Harwood, S. (2015). Information Artefacts in Practice: Institutional Context and Self-Awareness in Enactment of Collective Affordance.

Esposito Vinzi, V., Chin, W. W., Henseler, J., \& Wang, H. (2010). Handbook of partial least squares: Concepts, methods and applications: Heidelberg, Dordrecht, London, New York: Springer.

Faraj, S., \& Azad, B. (2012). The materiality of technology: An affordance perspective. Materiality and organizing: Social interaction in a technological world, 237-258.

Fayard, A.-L., \& Weeks, J. (2007). Photocopiers and water-coolers: The affordances of informal interaction. Organization studies, 28(5), 605-634.

Fornell, C., \& Larcker, D. F. (1981). Evaluating structural equation models with unobservable variables and measurement error. Journal of marketing research, 39-50.

Furumo, K., \& Melcher, A. (2006). The importance of social structure in implementing ERP systems: A case study using adaptive structuration theory. Journal of Information Technology Case and Application Research, 8(2), 39-58.

George, J. M. (1991). State or trait: Effects of positive mood on prosocial behaviors at work. Journal of applied Psychology, 76(2), 299.

Giddons, A. (1984). The constitution of society: Outline of the theory of structuration. Policy.

Goel, L., Johnson, N. A., Junglas, I., \& Ives, B. (2013). How cues of what can be done in a virtual world influence learning: An affordance perspective. Information \& Management, 50(5), 197-206. 
Gopal, A., Bostrom, R. P., \& Chin, W. W. (1992). Applying adaptive structuration theory to investigate the process of group support systems use. Journal of Management Information Systems, 9(3), 45-69.

Grgecic, D., Holten, R., \& Rosenkranz, C. (2015). The Impact of Functional Affordances and Symbolic Expressions on the Formation of Beliefs. Journal of the Association for Information Systems, 16(7), 580.

Grgic, J. E., Still, M. L., \& Still, J. D. (2016). Effects of Cognitive Load on Affordancebased Interactions. Applied Cognitive Psychology, 30(6), 1042-1051.

Gunzler, D., Chen, T., Wu, P., \& Zhang, H. (2013). Introduction to mediation analysis with structural equation modeling. Shanghai archives of psychiatry, 25(6), 390.

Guthrie, B., Brampton, S., \& Wyke, S. (2000). Does continuity in general practice really matter? Commentary: A patient's perspective of continuity. Bmj, 321(7263), 734736.

Guthrie, B., Saultz, J. W., Freeman, G. K., \& Haggerty, J. L. (2008). Continuity of care matters. BMJ: British Medical Journal (Online), 337.

Haines, M. N. (2009). Understanding enterprise system customization: An exploration of implementation realities and the key influence factors. Information Systems Management, 26(2), 182-198.

Hair, J. F. (2010). Black, WC, Babin, BJ, \& Anderson, RE (2010). Multivariate data analysis, 7.

Hair Jr, J. F., Hult, G. T. M., Ringle, C., \& Sarstedt, M. (2016). A primer on partial least squares structural equation modeling (PLS-SEM): Sage Publications.

Hartson, R. (2003). Cognitive, physical, sensory, and functional affordances in interaction design. Behaviour \& Information Technology, 22(5), 315-338.

Hayden, E. C. (2014). Is the $\$ 1,000$ genome for real? Nature News.

Hayes, S. C., \& Wilson, K. G. (1995). The role of cognition in complex human behavior: A contextualistic perspective. Journal of Behavior Therapy and Experimental Psychiatry, 26(3), 241-248.

He, Z.-L., \& Wong, P.-K. (2004). Exploration vs. exploitation: An empirical test of the ambidexterity hypothesis. Organization Science, 15(4), 481-494.

Henseler, J., Ringle, C. M., \& Sarstedt, M. (2015). A new criterion for assessing discriminant validity in variance-based structural equation modeling. Journal of the academy of marketing science, 43(1), 115-135. 
Hikmet, N., Bhattacherjee, A., Menachemi, N., Kayhan, V. O., \& Brooks, R. G. (2008). The role of organizational factors in the adoption of healthcare information technology in Florida hospitals. Health Care Management Science, 11(1), 1-9.

Hong, W., Chan, F. K., Thong, J. Y., Chasalow, L. C., \& Dhillon, G. (2013). A framework and guidelines for context-specific theorizing in information systems research. Information systems research, 25(1), 111-136.

Hooper, D., Coughlan, J., \& Mullen, M. (2008). Structural equation modelling: Guidelines for determining model fit. Articles, 2.

Hsu, C.-L., Lu, H.-P., \& Hsu, H.-H. (2007). Adoption of the mobile Internet: An empirical study of multimedia message service (MMS). Omega, 35(6), 715-726.

Hutchby, I. (2001). Technologies, texts and affordances. Sociology, 35(2), 441-456.

Janse, B., Huijsman, R., \& Fabbricotti, I. N. (2014). A quasi-experimental study of the effects of an integrated care intervention for the frail elderly on informal caregivers' satisfaction with care and support. BMC health services research, $14(1), 140$.

Jansen, J. J., Van Den Bosch, F. A., \& Volberda, H. W. (2005). Managing potential and realized absorptive capacity: how do organizational antecedents matter? Academy of management journal, 48(6), 999-1015.

Jarvis, C. B., MacKenzie, S. B., \& Podsakoff, P. M. (2003). A critical review of construct indicators and measurement model misspecification in marketing and consumer research. Journal of consumer research, 30(2), 199-218.

Johns, G. (2006). The essential impact of context on organizational behavior. Academy of Management Review, 31(2), 386-408.

Jones, M., Orlikowski, W., \& Munir, K. (2004). Structuration theory and information systems: A critical reappraisal. Social theory and philosophy for information systems, 297-328.

Jones, M. R., \& Karsten, H. (2008). Giddens's structuration theory and information systems research. MIS quarterly, 32(1), 127-157.

Jöreskog, K. G., \& Sörbom, D. (1989). LISREL 7: A guide to the program and applications: Spss.

Kane, R. L., Maciejewski, M., \& Finch, M. (1997). The relationship of patient satisfaction with care and clinical outcomes. Medical care, 35(7), 714-730.

Karsten, H. (2003). Constructing interdependencies with collaborative information technology. Computer Supported Cooperative Work (CSCW), 12(4), 437-464. 
Kline, R. B. (2015). Principles and practice of structural equation modeling: Guilford publications.

Lavrakas, P. J. (2008). Encyclopedia of survey research methods: Sage Publications.

Leonardi, P. M. (2011). When flexible routines meet flexible technologies: Affordance, constraint, and the imbrication of human and material agencies. MIS quarterly, 147-167.

LeRouge, C., \& Webb, H. W. (2004). Appropriating enterprise resource planning systems in colleges of business: extending adaptive structuration theory for testability. Journal of Information Systems Education, 15(3), 315.

Lien, C.-H., Cao, Y., \& Zhou, X. (2017). Service quality, satisfaction, stickiness, and usage intentions: an exploratory evaluation in the context of WeChat services. Computers in Human Behavior, 68, 403-410.

Lien, C. H., \& Cao, Y. (2014). Examining WeChat users' motivations, trust, attitudes, and positive word-of-mouth: Evidence from China. Computers in Human Behavior, 41, 104-111.

Limited, T. E. G. (2016). WeChat's World. Retrieved from http://www.economist.com/news/business/21703428-chinas-wechat-shows-waysocial-medias-future-wechats-world

Lu, J., \& Cheng, L. (2013). Perceiving and interacting affordances: A new model of human-affordance interactions. Integrative Psychological and Behavioral Science, 47(1), 142-155.

March, J. G. (1991). Exploration and exploitation in organizational learning. Organization Science, 2(1), 71-87.

Markus, M. L., Tanis, C., \& Van Fenema, P. C. (2000). Enterprise resource planning: multisite ERP implementations. Communications of the ACM, 43(4), 42-46.

Marley, K. A., Collier, D. A., \& Meyer Goldstein, S. (2004). The role of clinical and process quality in achieving patient satisfaction in hospitals. Decision Sciences, 35(3), 349-369.

Martelo-Landroguez, S., \& Cegarra-Navarro, J.-G. (2014). Linking knowledge corridors to customer value through knowledge processes. Journal of Knowledge Management, 18(2), 342-365.

Mazmanian, M., Cohn, M. L., \& Dourish, P. (2014). Dynamic Reconfiguration in Planetary Exploration: A Sociomaterial Ethnography. MIS quarterly, 38(3), 831848. 
McCarthy, D., Mueller, K., \& Wrenn, J. (2009). Henry Ford Health System: A Framework for System Integration, Coordination, Collaboration, and Innovation: Commonwealth Fund.

Melville, N., Kraemer, K., \& Gurbaxani, V. (2004). Review: Information technology and organizational performance: An integrative model of IT business value. MIS quarterly, 28(2), 283-322.

Menachemi, N., Saunders, C., Chukmaitov, A., Matthews, M. C., \& Brooks, R. G. (2007). Hospital adoption of information technologies and improved patient safety: a study of 98 hospitals in Florida. Journal of Healthcare Management, 52(6).

Miranda, S. M., \& Bostrom, R. P. (1993). The impact of group support systems on group conflict and conflict management. Journal of Management Information Systems, 10(3), 63-95.

Moore, G. C., \& Benbasat, I. (1991). Development of an instrument to measure the perceptions of adopting an information technology innovation. Information systems research, 2(3), 192-222.

Morris, E. K. (1988). Contextualism: The world view of behavior analysis. Journal of Experimental Child Psychology, 46(3), 289-323.

Murray, E., Lo, B., Pollack, L., Donelan, K., Catania, J., White, M., .. . Turner, R. (2003). The impact of health information on the internet on the physician-patient relationship: patient perceptions. Archives of internal medicine, 163(14), 17271734.

Nazir, S., \& Pinsonneault, A. (2012). IT and firm agility: an electronic integration perspective. Journal of the Association for Information Systems, 13(3), 150.

Niederman, F., Briggs, R. O., de Vreede, G.-J., \& Kolfschoten, G. L. (2008). Extending the contextual and organizational elements of adaptive structuration theory in GSS research. Journal of the Association for Information Systems, 9(10/11), 633.

Norman, D. A. (1999). Affordance, conventions, and design. interactions, 6(3), 38-43.

Orlikowski, W. J. (2008). Using technology and constituting structures: A practice lens for studying technology in organizations Resources, co-evolution and artifacts (pp. 255-305): Springer.

Orlikowski, W. J., \& Scott, S. V. (2008). Sociomateriality: challenging the separation of technology, work and organization. The academy of management annals, 2(1), $433-474$. 
Oshlyansky, L., Thimbleby, H., \& Cairns, P. (2004). Breaking affordance: culture as context. Paper presented at the Proceedings of the third Nordic conference on Human-computer interaction.

Pan, X., Dib, H. H., Wang, X., \& Zhang, H. (2006). Service utilization in community health centers in China: a comparison analysis with local hospitals. BMC health services research, 6(1), 93.

Parmiggiani, E., \& Mikalsen, M. (2013). The facets of sociomateriality: A systematic mapping of emerging concepts and definitions. Paper presented at the Scandinavian Conference on Information Systems.

Pérotin, V., Zamora, B., Reeves, R., Bartlett, W., \& Allen, P. (2013). Does hospital ownership affect patient experience? An investigation into public-private sector differences in England. Journal of health economics, 32(3), 633-646.

Podsakoff, P. M., MacKenzie, S. B., Lee, J.-Y., \& Podsakoff, N. P. (2003). Common method biases in behavioral research: A critical review of the literature and recommended remedies. Journal of applied Psychology, 88(5), 879.

Richey, R. G., Roath, A. S., Whipple, J. M., \& Fawcett, S. E. (2010). Exploring a governance theory of supply chain management: barriers and facilitators to integration. Journal of Business Logistics, 31(1), 237-256.

Rogers, E. M. (1962). Diffusion of Innovations. New York: Free Press of Glencoe.

Rogers, E. M. (1983). Diffusion of Innovations. New York, NY: Free Press.

Saraf, N., Liang, H., Xue, Y., \& Hu, Q. (2013). How does organisational absorptive capacity matter in the assimilation of enterprise information systems? Information systems journal, 23(3), 245-267.

Shavers, V. L. (2007). Measurement of socioeconomic status in health disparities research. Journal of the national medical association, 99(9), 1013.

Sin Tan, K., Choy Chong, S., Lin, B., \& Cyril Eze, U. (2009). Internet-based ICT adoption: evidence from Malaysian SMEs. Industrial Management \& Data Systems, 109(2), 224-244.

Stiles, W. B., Putnam, S. M., Wolf, M. H., \& James, S. A. (1979). Interaction exchange structure and patient satisfaction with medical interviews. Medical care, 667-681.

Stockdale, R., \& Standing, C. (2006). An interpretive approach to evaluating information systems: A content, context, process framework. European journal of operational research, 173(3), 1090-1102. 
Stonebraker, M., \& Cetintemel, U. (2005). " One size fits all": an idea whose time has come and gone. Paper presented at the Data Engineering, 2005. ICDE 2005. Proceedings. 21st International Conference on.

Strong, D. M., Volkoff, O., Johnson, S. A., \& Pelletier, L. R. (2014). A Theory of ClinicEHR Affordance Actualization.

Subramani, M. (2004). How do suppliers benefit from information technology use in supply chain relationships? MIS quarterly, 45-73.

Tavakol, M., \& Dennick, R. (2011). Making sense of Cronbach's alpha. International journal of medical education, 2, 53.

Teo, T. S., Srivastava, S. C., \& Jiang, L. (2008). Trust and electronic government success: An empirical study. Journal of Management Information Systems, 25(3), 99-132.

Thompson, J. B. (1984). Studies in the Theory of Ideology: Univ of California Press.

Thrasher, E. H., Craighead, C. W., \& Byrd, T. A. (2010). An empirical investigation of integration in healthcare alliance networks. Decision Support Systems, 50(1), 116127.

Treem, J. W., \& Leonardi, P. M. (2013). Social media use in organizations: Exploring the affordances of visibility, editability, persistence, and association. Annals of the International Communication Association, 36(1), 143-189.

Turner, P., \& Turner, S. (2002). An affordance-based framework for CVE evaluation People and Computers XVI-Memorable Yet Invisible (pp. 89-103): Springer.

Uijen, A. A. (2012). Continuity of care Perspective of the patient with a chronic illness.

Venkatesh, V., Thong, J. Y., Chan, F. K., Hu, P. J. H., \& Brown, S. A. (2011). Extending the two-stage information systems continuance model: Incorporating UTAUT predictors and the role of context. Information systems journal, 21(6), 527-555.

Volberda, H. W., Foss, N. J., \& Lyles, M. A. (2010). Perspective-Absorbing the concept of absorptive capacity: How to realize its potential in the organization field. Organization Science, 21(4), 931-951.

Volkoff, O., \& Strong, D. M. (2013). Critical Realism and Affordances: Theorizing ITAssociated Organizational Change Processes. MIS quarterly, 37(3), 819-834.

Voss, G. B., \& Voss, Z. G. (2013). Strategic ambidexterity in small and medium-sized enterprises: Implementing exploration and exploitation in product and market domains. Organization Science, 24(5), 1459-1477. 
Wagner, D., Vollmar, G., \& Wagner, H.-T. (2014). The impact of information technology on knowledge creation. Journal of Enterprise Information Management, 27(1), 31.

Wang, P., Li, H., \& Suomi, R. (2016). VALUE CO-CREATION IN BUSINESS VIA SOCIAL MEDIA: A TECHNOLOGY AFFORDANCE APPROACH.

Webster, J., \& Watson, R. T. (2002). Analyzing the past to prepare for the future: Writing a literature review. MIS quarterly, xiii-xxiii.

Williams, E. S., \& Skinner, A. C. (2003). Outcomes of physician job satisfaction: a narrative review, implications, and directions for future research. Health care management review, 28(2), 119-139.

Wu, J.-H., Chen, Y.-C., \& Greenes, R. A. (2009). Healthcare technology management competency and its impacts on IT-healthcare partnerships development. international journal of medical informatics, 78(2), 71-82.

Young, G. J., Meterko, M., \& Desai, K. R. (2000). Patient satisfaction with hospital care: effects of demographic and institutional characteristics. Medical care, 38(3), 325334.

Zahra, S. A., \& George, G. (2002). Absorptive capacity: A review, reconceptualization, and extension. Academy of Management Review, 27(2), 185-203.

Zammuto, R. F., Griffith, T. L., Majchrzak, A., Dougherty, D. J., \& Faraj, S. (2007). Information technology and the changing fabric of organization. Organization Science, 18(5), 749-762.

Zhou, W., Dong, Y., Lin, X., Lu, W., Tian, X., Yang, L., \& Zhang, X. (2013). Community health service capacity in China: a survey in three municipalities. Journal of evaluation in clinical practice, 19(1), 167-172. 


\section{APPENDICES}

8-A All survey questionnaire items in English

\begin{tabular}{|c|c|c|c|}
\hline Constructs & $\begin{array}{l}\text { Item } \\
\text { ID }\end{array}$ & Items & $\begin{array}{l}\text { Key } \\
\text { Reference }\end{array}$ \\
\hline $\begin{array}{l}\text { Specific } \\
\text { Context }\end{array}$ & $\mathrm{Sc}$ & $\begin{array}{l}\text { I normally want my appointment at a } \\
\text { specific time } \\
\text { I normally go to the same healthcare } \\
\text { facility for all my healthcare needs } \\
\text { I normally see the same doctor } \\
\text { I wish to go to Tier } 3 \text { hospitals for all } \\
\text { my healthcare needs } \\
\text { All visits to the hospitals are for my } \\
\text { chronical conditions } \\
\text { My condition requires a lot of time to } \\
\text { manage } \\
\text { I visit healthcare facility frequently } \\
\text { My condition needs frequent } \\
\text { communication with my doctor }\end{array}$ & $\begin{array}{l}\text { (Bloomfield } \\
\text { et al., 2010; } \\
\text { Goel et al., } \\
2013 \text {; } \\
\text { Turner \& } \\
\text { Turner, } \\
\text { 2002) }\end{array}$ \\
\hline $\begin{array}{l}\text { Absorptive } \\
\text { Capacity }\end{array}$ & Ac & $\begin{array}{l}\text { I have frequent interactions with new } \\
\text { mobile applications } \\
\text { I collect information on new mobile } \\
\text { applications through informal means } \\
\text { I periodically scan for new mobile } \\
\text { applications to use } \\
\text { I quickly analyze and interpret } \\
\text { available mobile technology }\end{array}$ & $\begin{array}{l}\text { (Jansen, } \\
\text { Van Den } \\
\text { Bosch, \& } \\
\text { Volberda, } \\
\text { 2005; } \\
\text { Martelo- } \\
\text { Landroguez } \\
\text { \& Cegarra- } \\
\text { Navarro, } \\
\text { 2014; Saraf } \\
\text { et al., 2013) }\end{array}$ \\
\hline $\begin{array}{l}\text { Technology } \\
\text { Characteristics }\end{array}$ & Tc & $\begin{array}{l}\text { Using patient portal is better in } \\
\text { arranging what I need to do in my } \\
\text { care seeking processes } \\
\text { Using patient portal improves the } \\
\text { quality of my care seeking } \\
\text { I believe patient portal is easy to use } \\
\text { Using patient portal fits into my } \\
\text { lifestyle } \\
\text { I would try to use patient portal to } \\
\text { deal with my care seeking needs } \\
\text { I have seen other people using patient } \\
\text { portal in the hospital } \\
\text { The positive results of using patient } \\
\text { portal is apparent to me }\end{array}$ & $\begin{array}{l}\text { (Moore \& } \\
\text { Benbasat, } \\
\text { 1991; } \\
\text { Rogers, } \\
\text { 1983) }\end{array}$ \\
\hline
\end{tabular}




\begin{tabular}{|c|c|c|c|}
\hline & & $\begin{array}{l}\text { I feel it's very convenient to use } \\
\text { patient portal } \\
\text { I expect to save time in making an } \\
\text { appointment and other care seeking } \\
\text { processes } \\
\text { My family and friends are using } \\
\text { patient portal } \\
\text { My doctors want me to use patient } \\
\text { portal } \\
\text { I believe that it is fast and easy to } \\
\text { learn how to use patient portal } \\
\text { My mobile phone satisfies the basic } \\
\text { requirements for installation and } \\
\text { operation of patient portal }\end{array}$ & \\
\hline $\begin{array}{l}\text { Specific } \\
\text { Contextual } \\
\text { Affordance }\end{array}$ & Sca & $\begin{array}{l}\text { Based on my conditions, I think using } \\
\text { the patient portal makes it easy } \\
\text { to...online } \\
\text { see the doctors I want to see } \\
\text { get the time when I want to see the } \\
\text { doctors } \\
\text { get the location where I want to see } \\
\text { the doctors } \\
\text { pay for the fees related to my visit } \\
\text { view my lab reports and medical } \\
\text { history } \\
\text { consult with doctors } \\
\text { communicate with other patients like } \\
\text { me } \\
\text { ask questions through instant } \\
\text { messages }\end{array}$ & $\begin{array}{l}\text { (Anderson } \\
\text { \& Robey, } \\
\text { 2017; Goel } \\
\text { et al., 2013; } \\
\text { Strong et } \\
\text { al., 2014) }\end{array}$ \\
\hline $\begin{array}{l}\text { General } \\
\text { Contextual } \\
\text { Affordance }\end{array}$ & Gca & $\begin{array}{l}\text { In general, compared to in } \\
\text { person/phone, I think using patient } \\
\text { portal makes... possible online } \\
\text { seeing the doctors I want to see } \\
\text { getting the time when I want to see } \\
\text { the doctors } \\
\text { getting the location where I want to } \\
\text { see the doctors } \\
\text { paying for the fees related to my visit } \\
\text { accessing my lab reports and medical } \\
\text { history } \\
\text { consulting with doctors } \\
\text { communicating with other patients } \\
\text { like me }\end{array}$ & $\begin{array}{l}\text { (Anderson } \\
\text { \& Robey, } \\
\text { 2017; Goel } \\
\text { et al., 2013; } \\
\text { Strong et } \\
\text { al., 2014) }\end{array}$ \\
\hline
\end{tabular}




\begin{tabular}{|c|c|c|c|}
\hline & & $\begin{array}{l}\text { asking questions through instant } \\
\text { messages } \\
\text { receiving health related news and } \\
\text { information }\end{array}$ & \\
\hline $\begin{array}{l}\text { System } \\
\text { Integration }\end{array}$ & $\mathrm{Si}$ & $\begin{array}{l}\text { My care seeking processes are } \\
\text { consistent across the same facility } \\
\text { I have continuous communication } \\
\text { with my doctors in this facility } \\
\text { The waiting time of each processes is } \\
\text { reduced } \\
\text { The hospital staff knows the record } \\
\text { of every step of my care seeking } \\
\text { processes } \\
\text { All information related to me in my } \\
\text { care seeking process can be accessed } \\
\text { anytime } \\
\text { The facility staff and I can easily } \\
\text { reach an agreement } \\
\text { My medical history can easily be } \\
\text { transferred from previous hospitals } \\
\text { My medical history can easily be } \\
\text { transferred to new hospitals } \\
\text { The processes for me to transfer to a } \\
\text { new hospital is consistent and smooth } \\
\text { Regardless of which hospital I go to, } \\
\text { the staff all know my medical history } \\
\text { well } \\
\text { Regardless of which hospital I go to, } \\
\text { the staff and I can easily reach an } \\
\text { agreement } \\
\text { Regardless of which hospital I go to, } \\
\text { the staff knows the record of every } \\
\text { step of my care seeking processes. }\end{array}$ & $\begin{array}{l}\text { (Guthrie et } \\
\text { al., 2000; } \\
\text { Guthrie et } \\
\text { al., 2008; } \\
\text { Uijen, } \\
\text { 2012) }\end{array}$ \\
\hline Exploration & Epr & $\begin{array}{l}\text { Using patient portal is a revolutionary } \\
\text { new experience for me } \\
\text { Using patient portal enables me to } \\
\text { experiment new radical healthcare } \\
\text { innovations } \\
\text { Using patient portal completely } \\
\text { changed how I see a doctor } \\
\text { I have never imagined I could use } \\
\text { patient portal for my entire healthcare } \\
\text { processes } \\
\text { The patient portal refreshed my view } \\
\text { on traditional healthcare }\end{array}$ & $\begin{array}{l}\text { (Voss \& } \\
\text { Voss, 2013) }\end{array}$ \\
\hline
\end{tabular}




\begin{tabular}{|c|c|c|c|}
\hline Exploitation & Epi & $\begin{array}{l}\text { Patient portal improved my known } \\
\text { care seeking experience } \\
\text { Patient portal makes it possible for } \\
\text { me to come to this hospital for my all } \\
\text { healthcare needs } \\
\text { Using patient portal makes my } \\
\text { frequent visits to this hospital } \\
\text { acceptable } \\
\text { The care seeking process is improved } \\
\text { although the general structure of such } \\
\text { processes is still the same } \\
\text { Patient portal improved how I } \\
\text { interact with hospital staff }\end{array}$ & $\begin{array}{l}\text { (Voss \& } \\
\text { Voss, 2013) }\end{array}$ \\
\hline $\begin{array}{l}\text { Process } \\
\text { Affordance }\end{array}$ & $\mathrm{Pa}$ & $\begin{array}{l}\text { Capturing and archiving digital data } \\
\text { about patients } \\
\text { Accessing and using patient } \\
\text { information anytime from anywhere } \\
\text { Coordinating patient care across sites, } \\
\text { facilities, and providers } \\
\text { Standardizing data, processes, and } \\
\text { roles } \\
\text { Monitoring organizational operations } \\
\text { Substituting healthcare professionals } \\
\text { for each other } \\
\text { Incorporating rich information into } \\
\text { clinical decision making } \\
\text { Shifting work across roles. }\end{array}$ & $\begin{array}{l}\text { (Strong et } \\
\text { al., 2014) }\end{array}$ \\
\hline $\begin{array}{l}\text { Patient } \\
\text { Satisfaction }\end{array}$ & Ps & $\begin{array}{l}\text { I was satisfied with the amount of } \\
\text { time the doctor spent with me during } \\
\text { my visit. } \\
\text { I was satisfied with the waiting time } \\
\text { during the visit. } \\
\text { I was satisfied with the total time for } \\
\text { my visit } \\
\text { I received appropriate treatments for } \\
\text { my illness } \\
\text { I understand my illness much better } \\
\text { after seeing the doctor } \\
\text { After talking to the doctor, I felt } \\
\text { much better about my problems } \\
\text { I think my treatment plan was the } \\
\text { most appropriate }\end{array}$ & $\begin{array}{l}\text { (Janse, } \\
\text { Huijsman, } \\
\& \\
\text { Fabbricotti, } \\
\text { 2014; Kane } \\
\text { et al., 1997; } \\
\text { Pérotin, } \\
\text { Zamora, } \\
\text { Reeves, } \\
\text { Bartlett, \& } \\
\text { Allen, } \\
\text { 2013) }\end{array}$ \\
\hline $\begin{array}{l}\text { Patient } \\
\text { Physician } \\
\text { Relationship }\end{array}$ & Ppr & $\begin{array}{l}\text { The doctor encourages me to ask } \\
\text { questions }\end{array}$ & $\begin{array}{l}\text { (Elwyn et } \\
\text { al., 2013; } \\
\text { Stiles, }\end{array}$ \\
\hline
\end{tabular}




\begin{tabular}{|l|l|l|}
\hline & $\begin{array}{l}\text { The doctor answers my questions } \\
\text { sufficiently } \\
\text { I understand the explanations } \\
\text { provided by the doctor } \\
\text { The doctor is considerate to my state } \\
\text { of mind } \\
\text { The doctor makes me feel } \\
\text { comfortable discussing all of my } \\
\text { problems } \\
\text { I feel the doctor is familiar with my } \\
\text { medical/health history } \\
\text { I feel the doctor understands my } \\
\text { healthcare needs }\end{array}$ & \\
\hline
\end{tabular}

8-B: All survey questionnaire items in Chinese

\begin{tabular}{|c|c|c|c|}
\hline Constructs & $\begin{array}{l}\text { Item } \\
\text { ID }\end{array}$ & Items & $\begin{array}{l}\text { Key } \\
\text { Reference }\end{array}$ \\
\hline $\begin{array}{l}\text { Specific } \\
\text { Context }\end{array}$ & $\mathrm{Sc}$ & $\begin{array}{l}\text { 1.一般情况下, 我去医院看病需要 } \\
\text { 选择特定的时间 } \\
\text { 2.一般情况下, 我选择去同一家医 } \\
\text { 院地点看病 } \\
\text { 3.一般情况下, 我都选择看同一个 } \\
\text { 医生 } \\
\text { 4. 基本上, 我看病更希望到三甲医 } \\
\text { 院 } \\
\text { 5. 基本上, 我每次去医院看病, 都 } \\
\text { 是与慢性病有关 } \\
\text { 6. 基于我的病情, 我需要花很多时 } \\
\text { 间在看病上 } \\
\text { 7. 基于我的病情, 我需要经常去医 } \\
\text { 院 } \\
\text { 8. 基于我的病情, 我需要经常与医 } \\
\text { 生沟通 }\end{array}$ & \\
\hline $\begin{array}{l}\text { Absorptive } \\
\text { Capacity }\end{array}$ & Ac & $\begin{array}{l}\text { 1. 我经常下载尝试新的手机 APP } \\
\text { 2. 我经常在生活中关注和收集新的 } \\
\text { 手机 APP 相关信息 } \\
\text { 3. 每隔一段时间, 我会寻找发现最 } \\
\text { 前沿和流行的手机 APP } \\
\text { 4. 只要能用手机 APP 做的事情, 我 } \\
\text { 现在都会应用手机 APP 来完成 } \\
\text { 5. 我能够很快的学习和理解新的手 } \\
\text { 机 APP }\end{array}$ & \\
\hline
\end{tabular}




\begin{tabular}{|c|c|c|}
\hline $\begin{array}{l}\text { Technology } \\
\text { Characteristics }\end{array}$ & Tc & 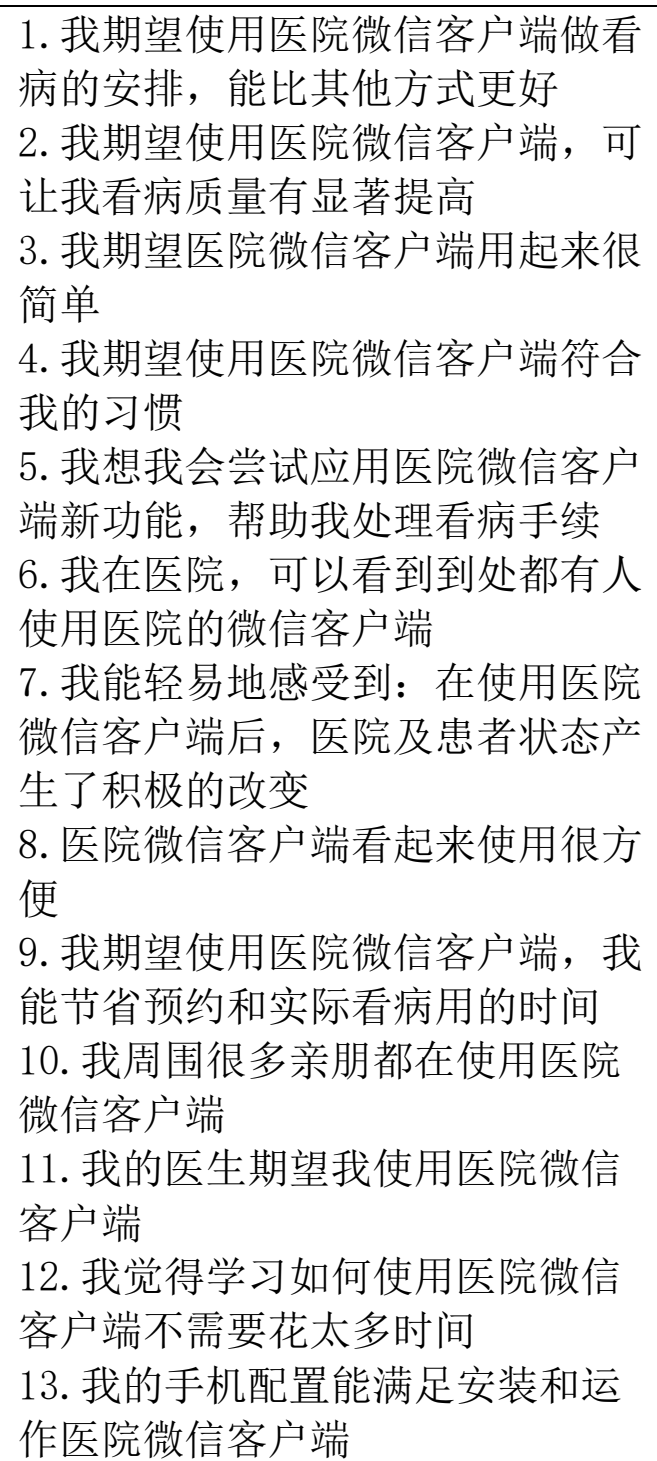 \\
\hline $\begin{array}{l}\text { Specific } \\
\text { Contextual } \\
\text { Affordance }\end{array}$ & Sca & $\begin{array}{l}\text { 基于我的具体病情, 我认为使用这 } \\
\text { 家医院微信客户端, 可以很容易地 } \\
\text { 在网上 } . \cdots \\
\text { 1. 预约到我想要看的医生 } \\
\text { 2. 预约到我想要的看病时间 } \\
\text { 3. 预约到我想要的看病医院地点 } \\
\text { 4 支付看病相关的所有费用 } \\
\text { 5. 查看我的所有化验报告和病历 } \\
\text { 6. 随时和医生互动咨询 } \\
\text { 7. 随时与其他患者交流 } \\
\text { 8. 随时通过短信问医务人员问题 }\end{array}$ \\
\hline
\end{tabular}




\begin{tabular}{|c|c|c|}
\hline $\begin{array}{l}\text { General } \\
\text { Contextual } \\
\text { Affordance }\end{array}$ & Gca & $\begin{array}{l}\text { 一般来说, 相对于通过面对面或电 } \\
\text { 话, 我更希望通过医院微信客户 } \\
\text { 端, 实现随时随地在网上... } \\
\text { 1. 预约医生 } \\
\text { 2. 预约看病时间 } \\
\text { 3. 预约看病医院地点 } \\
\text { 4. 支付费用 } \\
\text { 5. 查看化验报告和病历 } \\
\text { 6. 网上和医生互动咨询 } \\
\text { 7. 网上与其他患者交流 } \\
\text { 8. 通过短信问医务人员问题 } \\
\text { 9. 了解医院推送的健康教育信息、 } \\
\text { 医疗资讯 }\end{array}$ \\
\hline $\begin{array}{l}\text { System } \\
\text { Integration }\end{array}$ & $\mathrm{Si}$ & $\begin{array}{l}\text { 1. 我看病过程的各个环节, 现在连 } \\
\text { 接更连贯 } \\
\text { 2. 我和我的医生之间, 现在保持持 } \\
\text { 续性的沟通关系 } \\
\text { 3. 我看病过程中各个环节, 现在排 } \\
\text { 队减少了 } \\
\text { 4. 医院医务人员, 现在很了解我看 } \\
\text { 病每个环节的记录 } \\
\text { 5. 我看病过程的每个环节中, 与我 } \\
\text { 相关的数据信息, 现在都能及时查 } \\
\text { 取 } \\
\text { 6. 我看病过程的每个环节中, 现在 } \\
\text { 医务人员相互之间协调很一致 } \\
\text { 7. 我和各个医务人员, 现在很容易 } \\
\text { 达成一致意见 } \\
\text { 8. 我在其他医院的病历数据, 现在 } \\
\text { 很容易传输到这家医院 } \\
\text { 9. 我在这家医院病历数据, 现在很 } \\
\text { 容易传输到其他医院 } \\
\text { 10. 我若要更换医院, 现在转诊过 } \\
\text { 程各环节连接很紧密 } \\
\text { 11. 现在我在不同医院看病, 不同 } \\
\text { 医院的医务人员都很了解我的病情 } \\
\text { 12. 现在我到不同医院看病, 不同 } \\
\text { 医院的医务人员很容易和我达成一 } \\
\text { 致意见见 }\end{array}$ \\
\hline
\end{tabular}




\begin{tabular}{|c|c|c|}
\hline & & $\begin{array}{l}\text { 13. 现在我到不同医院看病, 不同 } \\
\text { 医院的医务人员都能清晰了解我既 } \\
\text { 往诊疗过程各个环节的情况 }\end{array}$ \\
\hline Exploration & Epr & $\begin{array}{l}\text { 1. 使用医院微信客户端, 对我来说 } \\
\text { 是全新的体验 } \\
\text { 2. 使用医院微信客户端, 我可以不 } \\
\text { 断尝试新的看病方式 } \\
\text { 3. 在以前, 我从未想过可以用医院 } \\
\text { 微信客户端, 完成我看病的各个环 } \\
\text { 节 } \\
\text { 4. 医院微信客户端的创新, 刷新了 } \\
\text { 我对传统医疗的认知 } \\
\text { 5. 使用医院微信客户端, 完全改变 } \\
\text { 了我看病的方式 }\end{array}$ \\
\hline Exploitation & Epi & $\begin{array}{l}\text { 1. 医院微信客户端改善了我一直以 } \\
\text { 来对传统看病的体验 } \\
\text { 2. 我所有的病, 都可以到这一家医 } \\
\text { 院来看 } \\
\text { 3. 使用医院微信客户端, 让我觉得 } \\
\text { 即使频繁到医院看病也不是一件难 } \\
\text { 事 } \\
\text { 4. 在医院, 尽管看病过程大致没 } \\
\text { 变, 但每个步骤的具体细节是有所 } \\
\text { 改善的 } \\
\text { 5. 医院微信客户端改善了我在看病 } \\
\text { 过程中与不同医务人员的互动方式 }\end{array}$ \\
\hline $\begin{array}{l}\text { Process } \\
\text { Affordance }\end{array}$ & $\mathrm{Pa}$ & $\begin{array}{l}\text { 1. 我现在能轻易获取和存储我的诊 } \\
\text { 疗信息 } \\
\text { 2. 我现在可以随时随地查阅和处理 } \\
\text { 我的诊疗信息 } \\
\text { 3. 现在我在医院看病过程中, 不同 } \\
\text { 科室的医务人员相互之间协调很好 } \\
\text { 4. 现在即使我在医院找不同的医生 } \\
\text { 看病, 诊疗的过程都很一致标准化 } \\
\text { 5. 我现在可以查询既往在医院每个 } \\
\text { 阶段的看病记录 } \\
\text { 6. 现在如果我想找的医务人员不 } \\
\text { 在, 其他医护人员也可以满足我的 } \\
\text { 需求 }\end{array}$ \\
\hline
\end{tabular}




\begin{tabular}{|c|c|c|}
\hline & & $\begin{array}{l}\text { 7. 现在医生能根据我个人情况和完 } \\
\text { 整历史信息, 给予我最适合的治疗 } \\
\text { 方案 } \\
\text { 8. 现在医生给我的治疗方案, 与我 } \\
\text { 不断变化的需求和状况, 保持一致 } \\
\text { 连贯 } \\
\text { 9. 现在我在医院看病过程中, 我很 } \\
\text { 清楚每一步要找哪位工作人员 }\end{array}$ \\
\hline $\begin{array}{l}\text { Patient } \\
\text { Satisfaction }\end{array}$ & Ps & $\begin{array}{l}\text { 1. 我对医生给我的会诊时间很满意 } \\
\text { 2. 我对在医院等待的时间很满意 } \\
\text { 3. 我对这次看病所花的总时间很满 } \\
\text { 意 } \\
\text { 4. 我的病症得到了恰当的治疗 } \\
\text { 5. 在看过医生之后, 我对我的病情 } \\
\text { 有更好的了解 } \\
\text { 6. 在跟医生交流之后, 我对我的病 } \\
\text { 情感觉好很多 } \\
\text { 7. 我觉得医生选择的治疗方案, 对 } \\
\text { 我而言是最合适的 }\end{array}$ \\
\hline $\begin{array}{l}\text { Patient } \\
\text { Physician } \\
\text { Relationship }\end{array}$ & $\mathrm{Ppr}$ & $\begin{array}{l}\text { 1. 医生鼓励我问问题 } \\
\text { 2. 医生会充分地回答我的问题 } \\
\text { 3. 我能理解医生给予的解释 } \\
\text { 4. 医生对我很体贴 } \\
\text { 5. 医生让我很自如地讨论我的病情 } \\
\text { 6. 我感觉医生对我的医疗历史很了 } \\
\text { 解 } \\
\text { 7. 我感觉医生对我的医疗保健需求 } \\
\text { 很了解 }\end{array}$ \\
\hline
\end{tabular}

8-C: KMO and Bartless's Test

\begin{tabular}{|l|l|r|}
\hline \multicolumn{3}{|c|}{ KMO and Bartlett's Test } \\
\hline $\begin{array}{l}\text { Kaiser-Meyer-Olkin Measure of } \\
\text { Sampling Adequacy. }\end{array}$ & .909 \\
\hline $\begin{array}{l}\text { Bartlett's Test of } \\
\text { Sphericity }\end{array}$ & Approx. Chi-Square & 8452.732 \\
\cline { 2 - 3 } & df & 903 \\
\cline { 2 - 3 } & Sig. & .000 \\
\hline
\end{tabular}


8-D: Principal Component Analysis - Total Variance Explained

\begin{tabular}{|c|c|c|c|c|c|c|}
\hline \multicolumn{7}{|c|}{ Total Variance Explained } \\
\hline \multirow[b]{2}{*}{ Component } & \multicolumn{3}{|c|}{ Initial Eigenvalues } & \multicolumn{3}{|c|}{$\begin{array}{c}\text { Extraction Sums of Squared } \\
\text { Loadings }\end{array}$} \\
\hline & Total & \begin{tabular}{|c|}
$\%$ of \\
Variance
\end{tabular} & $\begin{array}{c}\text { Cumulative } \\
\%\end{array}$ & Total & \begin{tabular}{c|}
$\%$ of \\
Variance \\
\end{tabular} & $\begin{array}{l}\text { Cumulati } \\
\text { ve } \%\end{array}$ \\
\hline 1 & 14.098 & 32.787 & 32.787 & 14.098 & 32.787 & 32.787 \\
\hline 2 & 4.269 & 9.927 & 42.714 & 4.269 & 9.927 & 42.714 \\
\hline 3 & 2.553 & 5.938 & 48.651 & 2.553 & 5.938 & 48.651 \\
\hline 4 & 2.242 & 5.214 & 53.865 & 2.242 & 5.214 & 53.865 \\
\hline 5 & 1.790 & 4.164 & 58.029 & 1.790 & 4.164 & 58.029 \\
\hline 6 & 1.483 & 3.450 & 61.479 & 1.483 & 3.450 & 61.479 \\
\hline 7 & 1.299 & 3.020 & 64.498 & 1.299 & 3.020 & 64.498 \\
\hline 8 & 1.248 & 2.902 & 67.401 & 1.248 & 2.902 & 67.401 \\
\hline 9 & 1.049 & 2.439 & 69.840 & 1.049 & 2.439 & 69.840 \\
\hline 10 & .974 & 2.265 & 72.105 & & & \\
\hline 11 & .895 & 2.081 & 74.186 & & & \\
\hline 12 & .764 & 1.776 & 75.963 & & & \\
\hline 13 & .741 & 1.723 & 77.686 & & & \\
\hline 14 & .698 & 1.622 & 79.308 & & & \\
\hline 15 & .629 & 1.462 & 80.770 & & & \\
\hline 16 & .596 & 1.385 & 82.155 & & & \\
\hline 17 & .552 & 1.284 & 83.439 & & & \\
\hline 18 & .518 & 1.206 & 84.645 & & & \\
\hline 19 & .473 & 1.100 & 85.745 & & & \\
\hline 20 & .452 & 1.052 & 86.797 & & & \\
\hline 21 & .436 & 1.013 & 87.810 & & & \\
\hline 22 & .408 & .948 & 88.757 & & & \\
\hline 23 & .384 & .893 & 89.651 & & & \\
\hline 24 & .358 & .832 & 90.483 & & & \\
\hline 25 & .353 & .821 & 91.304 & & & \\
\hline 26 & .309 & .720 & 92.024 & & & \\
\hline 27 & .302 & .703 & 92.727 & & & \\
\hline 28 & .283 & .657 & 93.384 & & & \\
\hline 29 & .276 & .642 & 94.026 & & & \\
\hline 30 & .252 & .586 & 94.611 & & & \\
\hline
\end{tabular}




\begin{tabular}{|l|r|r|r|l|l|l|}
\hline 31 & .243 & .564 & 95.176 & & & \\
\hline 32 & .237 & .551 & 95.727 & & & \\
\hline 33 & .214 & .497 & 96.224 & & & \\
\hline 34 & .210 & .488 & 96.712 & & & \\
\hline 35 & .200 & .465 & 97.177 & & & \\
\hline 36 & .190 & .442 & 97.619 & & & \\
\hline 37 & .182 & .423 & 98.041 & & & \\
\hline 38 & .168 & .392 & 98.433 & & & \\
\hline 39 & .154 & .359 & 98.792 & & & \\
\hline 40 & .150 & .348 & 99.140 & & & \\
\hline 41 & .139 & .322 & 99.462 & & & \\
\hline 42 & .122 & .284 & 99.746 & & & \\
\hline 43 & .109 & .254 & 100.000 & & & \\
\hline \multicolumn{7}{|l|}{ Extraction Method: Principal Component Analysis. } \\
\hline
\end{tabular}

8-E: Principal Component Analysis - Component Matrix

\begin{tabular}{|l|c|c|c|c|c|c|c|c|c|}
\hline \multicolumn{10}{|c|}{ Component Matrix } \\
\hline & \multicolumn{10}{c|}{ Component } \\
\cline { 2 - 10 } & 1 & 2 & 3 & \multicolumn{1}{c|}{4} & \multicolumn{1}{c|}{5} & \multicolumn{1}{c|}{6} & \multicolumn{1}{c|}{7} & \multicolumn{1}{c|}{8} & \multicolumn{1}{c|}{9} \\
\hline$@ 23 \mathrm{n}$ & .596 & -.468 & .266 & -.098 & .017 & .007 & .000 & -.036 & -.136 \\
\hline$@ 23 \mathrm{p}$ & .602 & -.483 & .251 & -.071 & .091 & -.074 & -.017 & -.012 & -.225 \\
\hline$@ 23 \mathrm{t}$ & .537 & -.280 & -.072 & .149 & .250 & -.221 & -.048 & -.072 & -.325 \\
\hline$@ 23 \mathrm{v}$ & .473 & -.278 & -.099 & .101 & .380 & -.253 & -.007 & -.189 & -.253 \\
\hline$@ 23 \mathrm{w}$ & .544 & -.365 & -.260 & -.179 & .260 & -.191 & .020 & -.016 & .292 \\
\hline$@ 23 \mathrm{x}$ & .506 & -.366 & -.329 & -.180 & .239 & -.062 & -.006 & .005 & .267 \\
\hline$@ 23 \mathrm{ac}$ & .479 & -.213 & -.402 & .036 & .295 & -.343 & .172 & -.119 & .127 \\
\hline$@ 23 \mathrm{ad}$ & .563 & -.108 & -.218 & .090 & .299 & -.243 & .157 & -.238 & .044 \\
\hline$@ 31 \mathrm{a}$ & .557 & -.235 & -.384 & .069 & -.046 & .295 & .151 & .297 & -.059 \\
\hline$@ 31 \mathrm{~b}$ & .603 & -.151 & -.389 & -.011 & -.028 & .397 & .074 & .289 & -.090 \\
\hline$@ 31 \mathrm{e}$ & .616 & .048 & -.450 & .106 & .017 & .230 & .132 & .151 & -.034 \\
\hline$@ 31 \mathrm{~g}$ & .537 & -.062 & -.478 & .121 & .109 & .237 & .200 & .283 & -.098 \\
\hline$@ 21 \mathrm{~d}$ & .410 & -.154 & .446 & .077 & .289 & .144 & -.046 & .009 & -.276 \\
\hline$@ 21 \mathrm{e}$ & .258 & .243 & .066 & .550 & .397 & .138 & -.237 & .021 & -.010 \\
\hline$@ 21 \mathrm{f}$ & .203 & .387 & .137 & .595 & .287 & .173 & -.245 & -.034 & .163 \\
\hline$@ 21 \mathrm{~h}$ & .287 & .320 & .141 & .579 & .239 & .253 & -.050 & -.152 & .199 \\
\hline & & & & & & & & & \\
\hline
\end{tabular}




\begin{tabular}{|c|c|c|c|c|c|c|c|c|c|}
\hline$@ 23 c$ & .519 & -.421 & .454 & -.151 & .009 & .149 & .017 & .131 & .147 \\
\hline$@ 23 d$ & .542 & -.459 & .441 & -.072 & -.045 & .146 & -.031 & .057 & .094 \\
\hline$@ 23 \mathrm{e}$ & .566 & -.362 & .424 & -.080 & -.005 & .145 & .055 & -.024 & .059 \\
\hline$@ 23 \mathrm{~h}$ & .636 & -.217 & .175 & .055 & -.069 & .009 & -.064 & .119 & .340 \\
\hline$@ 23 i$ & .620 & -.367 & .250 & -.026 & -.014 & .020 & -.015 & .033 & .239 \\
\hline @,231 & .613 & -.382 & .102 & .083 & -.021 & -.007 & .055 & .050 & .214 \\
\hline$@ 22 b$ & .547 & -.114 & -.072 & .432 & -.443 & -.139 & -.086 & -.164 & .034 \\
\hline$@ 22 c$ & .552 & -.119 & -.117 & .470 & -.472 & -.075 & -.022 & -.134 & .023 \\
\hline$@ 22 d$ & .578 & -.265 & -.056 & .347 & -.473 & -.081 & .041 & -.116 & -.126 \\
\hline @, 22e & .659 & -.311 & -.017 & .263 & -.299 & -.086 & .016 & -.001 & -.214 \\
\hline @)32aа & .736 & .291 & -.107 & -.046 & .022 & -.119 & -.293 & .114 & -.060 \\
\hline @32ab & .718 & .171 & -.018 & -.144 & .012 & -.166 & -.338 & .168 & -.025 \\
\hline & .705 & .285 & -.067 & -.164 & -.005 & -.187 & & .221 & -.013 \\
\hline @32ad & .704 & .295 & -.038 & -.168 & -.002 & -.079 & -.360 & .219 & .030 \\
\hline @)32ag & .671 & .238 & -.023 & -.235 & .047 & .181 & .098 & -.263 & .007 \\
\hline (a)32ah & .657 & .285 & .085 & -.174 & .092 & .265 & .060 & -.309 & -.038 \\
\hline @a)32ai & .669 & .254 & -.002 & -.263 & .010 & .325 & .065 & -.256 & -.079 \\
\hline (a)32aj & .645 & .257 & -.097 & -.178 & -.034 & .250 & .122 & -.395 & -.003 \\
\hline (@)32al & .629 & .396 & -.114 & -.157 & -.136 & .029 & -.041 & -.153 & .041 \\
\hline @32am & .704 & .301 & -.090 & -.138 & -.184 & -.032 & -.078 & -.094 & .105 \\
\hline @32an & .666 & .235 & .014 & -.238 & -.203 & -.002 & -.080 & -.078 & -.022 \\
\hline @,32ao & .662 & .347 & -.023 & -.190 & -.124 & -.133 & -.115 & -.021 & -.022 \\
\hline @4a & .415 & .350 & .257 & -.080 & .121 & -.065 & .042 & .104 & -.201 \\
\hline (a) $4 \mathrm{~h}$ & .501 & .379 & .206 & .008 & .029 & -.326 & .347 & -.020 & .063 \\
\hline$@ 4 \mathrm{i}$ & .417 & .525 & .240 & .185 & -.028 & -.236 & .422 & .171 & .139 \\
\hline$@ 4 j$ & .418 & .530 & .247 & .053 & -.002 & -.104 & .362 & .292 & .065 \\
\hline a 4k & .554 & .286 & .237 & .070 & .036 & -.079 & .247 & .221 & -.244 \\
\hline \multicolumn{10}{|c|}{ Extraction Method: Principal Component Analysis. } \\
\hline & & & & & & & & & \\
\hline
\end{tabular}




\section{VITA}

\section{HAORAN ZHENG}

EDUCATION

2006-2009

2009-2010

2011-2012

2014-2018
B.S., International Economic

North China University of Technology

Beijing, China

B.S., Business Administration

Kennesaw State University

Marietta, Georgia

M.B.A.,

Florida International University

Miami, FL

Doctoral Candidate

Florida International University

Miami, FL

Student Volunteer at Conference for Production and Operations Management Society (POMS) 2016, Orlando, FL;

Peer reviewer for International Conference on Information Systems (ICIS) 2017;

Reviewer for Information Systems Management Journal;

Member of Association for Information Systems (AIS), the Institute for Operations Research and the Management Sciences (INFORMS), Production and Operations Management Society (POMS), Decision Sciences Institute (DSI)

\section{CONFERENCE PROCEEDINGS}

Kolotylo, M., Zheng, H., Dahiya, R., Parente, R., "Information technology outsourcing and knowledge transfer: Achieving strategic alignment through organizational learning". International Conference on Knowledge Management and Innovation (ICKMI 2017), New York, NY. (Abstract Submission)

Zheng, H. (2017). Affordances of Mobile Communal Referral Service, presented at Americas Conference on Information Systems (AMCIS 2017), Boston, MA. 